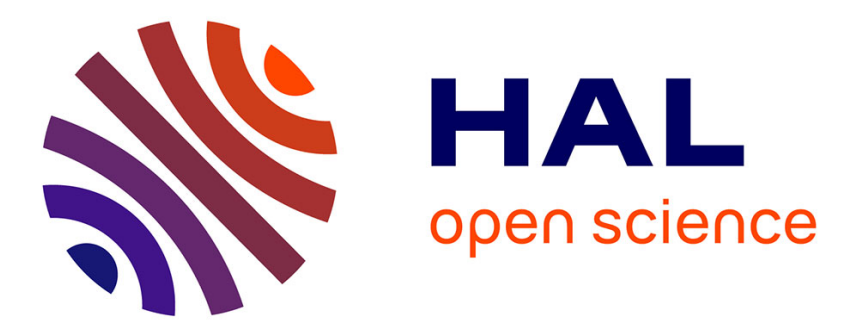

\title{
Selective Oxidation of Methane to Formaldehyde Catalyzed by Phosphates: Kinetic Description by Bond Strengths and Specific Total Acidities
}

\author{
Vasilij Gomonaj, Hervé Toulhoat
}

\section{To cite this version: \\ Vasilij Gomonaj, Hervé Toulhoat. Selective Oxidation of Methane to Formaldehyde Catalyzed by Phosphates: Kinetic Description by Bond Strengths and Specific Total Acidities. ACS Catalysis, 2018, 8 (9), pp.8263-8272. 10.1021/acscatal.8b02629 . hal-01955648}

\section{HAL Id: hal-01955648 \\ https: / hal.sorbonne-universite.fr/hal-01955648}

Submitted on 14 Dec 2018

HAL is a multi-disciplinary open access archive for the deposit and dissemination of scientific research documents, whether they are published or not. The documents may come from teaching and research institutions in France or abroad, or from public or private research centers.
L'archive ouverte pluridisciplinaire HAL, est destinée au dépôt et à la diffusion de documents scientifiques de niveau recherche, publiés ou non, émanant des établissements d'enseignement et de recherche français ou étrangers, des laboratoires publics ou privés. 


\title{
Selective Oxidation of Methane to Formaldehyde Catalyzed by
}

\section{Phosphates: Kinetic Description by Bond strengths and specific}

\section{total acidities.}

Vasilij Gomonaj' and Hervé Toulhoat ${ }^{*}$

1National University of Uzhgorod, Department of Physical and Colloid Chemistry, Pidhirna Street, 46, Uzhgorod 380,

Ukraine

2 IFP Energies nouvelles, 1 \& 4 avenue de Bois-Préau, 92852 Rueil-Malmaison, France, and Sorbonne Universités, UPMC Univ. Paris 06, UMR CNRS 7197, Laboratoire de Réactivité de Surface, Tour 43-33, 3ème étage, Case 178, 4 Place Jussieu, F-75252, Paris, France

Keywords: Heterogeneous catalysis; methane oxidation; formaldehyde; kinetic modeling; specific total acidity descriptor; metal-oxygen bond strength descriptor; DFT; Bond Order Conservation principle

\begin{abstract}
A kinetic model predicts the experimental activity and selectivity patterns obtained in oxidation of methane for divided unsupported orthophosphates $\left(\mathrm{M}_{3}{ }_{3}\left(\mathrm{PO}_{4}\right)_{2}, \mathrm{M}^{\mathrm{m}} \mathrm{PO}_{4},\right)$ and pyrophosphates $\left(\mathrm{M}_{2} \mathrm{P}_{2} \mathrm{O}_{7}, \mathrm{M}^{\mathrm{v}} \mathrm{P}_{2} \mathrm{O}_{7}\right)$ catalysts spanning extended ranges of $\mathrm{M}-\mathrm{O}$ bond strength (calculated from first principles) and specific total acidity $\mathrm{H}^{\circ}$. A volcano curve is obtained when total methane oxidation rates are plotted against $\mathrm{M}-\mathrm{O}$ bond strength. $\mathrm{M}^{\mathrm{v}} \mathrm{P}_{2} \mathrm{O}_{7}$ Pyrophosphates are the most acidic catalysts $\left(\mathrm{H}^{\circ}>10 \mu \mathrm{mol} . \mathrm{m}^{2}\right)$ and remarkably selective to formaldehyde $(>90 \%)$. For this subset of catalysts, experimental oxidation rates deviate however from predictions in correlation with their acidity, suggesting a significant deactivation phenomenon. $\mathrm{H}^{\circ}$ is shown to be described, and therefore predictable for these phosphates, by a structural parameter, the average $\mathrm{P}-\mathrm{Oa}$ bond length, $\mathrm{Oa}$ being a bridging atom between $\mathrm{M}$ and $\mathrm{P}$. Differences in acidity are interpreted as a consequence of the compression or elongation of the Oa-P bond inside the M-Oa-P bridges.
\end{abstract}




\section{Introduction}

Direct conversion of $\mathrm{CH}_{4}$ with the help of oxidants got much more attention, because it is thermodynamically much easier than under non-oxidative conditions [1].

According to the importance of process and scale of production, production of formaldehyde by direct methane oxidation is on the first places. It is connected with the constant increase in the formaldehyde needs for the processes of organic synthesis, as one important monomer for production of plastics, synthetic fibers and other materials.

In early research of methane oxidation catalysts, metallic platinum and palladium were generally preferred, while silver, gold, nickel and copper were also studied. Among simple oxides, $\mathrm{Co}_{3} \mathrm{O}_{4}, \mathrm{NiO}, \mathrm{MnO}_{2}$ showed the highest activity, $\mathrm{Cr}_{2} \mathrm{O}_{3}, \mathrm{Fe}_{2} \mathrm{O}_{3}, \mathrm{CuO}$ were moderately active, and $\mathrm{ZnO}, \mathrm{TiO}_{2}, \mathrm{~V}_{2} \mathrm{O}_{5}, \mathrm{MoO}_{3}, \mathrm{WO}_{3}$ were the less active. However, the products of methane oxidation on all oxide catalysts were $\mathrm{CO}_{2}$ and $\mathrm{H}_{2} \mathrm{O}$, while only $\mathrm{SiO}_{2}$ oxide in the form of quartz was discovered selective in methane oxidation into formaldehyde in 1963 [2].

Taking into account the high selectivity of quartz at methane oxidation, experiments were carried out to study aluminum silicates as catalysts of selective methane oxidation. For that purpose, $\mathrm{H}^{+}$ions were exchanged with various cations of valency 2 to 4 . Ions exchange from $\mathrm{H}^{+}$to $\mathrm{Na}^{+}$in aluminosilicate led to full loss of formaldehyde selectivity, indicating that sodium ions are catalytic poisons $[3,4]$.

Oxides on the basis of cations pairs Al-Si, Al-P, B-P, Al-B, turned out the most selective methane oxidation catalysts in formaldehyde [5-9].

On the majority of catalysts tested in the selective oxidation of methane under conditions of a flow reactor, the yield of formaldehyde (the amount of $\mathrm{CH}_{4}$ (in mol\%) converted into $\mathrm{CH}_{2} \mathrm{O}$ ) in a single run of the reaction mixture through the reactor was even lower than $1 \%[10]$. This parameter was $2-4 \%$ for catalytic systems recognized to be the most promising systems. In the majority of cases, the selectivity of methane conversion into formaldehyde above $50 \%$ was observed only at very low (less than $2 \%$ ) degrees of methane conversion. $\mathrm{CH}_{3} \mathrm{O}_{2}^{*}$ radicals, were 
detected by freezing free radicals from a reaction mixture of methane oxidation on $\mathrm{SiO}_{2}$ in a $\mathrm{CO}_{2}$ matrix and a correlation was found between the yield of $\mathrm{CH}_{2} \mathrm{O}$ and the concentration of $\mathrm{HO}_{2}^{*}$ and $\mathrm{CH}_{3} \mathrm{O}_{2}^{*}$ peroxide radicals, which were detected using EPR spectroscopy, in the reaction vessel volume.

Lately, a lot of publications have appeared dealing with catalysts preparations with different elements and oxides supported on $\mathrm{SiO}_{2}$, on which high selectivity of formaldehyde can be obtained. These works are examined in detail in the thesis work by H. Launay [11] and related papers $([12],[13])$

Investigations aimed at elucidating more precisely the nature of the sites responsible for the high rate of generation of formaldehyde on $\mathrm{SiO}_{2}$ and $\mathrm{V}_{2} \mathrm{O}_{5}-\mathrm{SiO}_{2}$ catalysts were made in [14]. The formation of formaldehyde as a partial oxidation product over silica was associated with high activities. The results indicated that not all silica samples are equally active, "pyrolytic" or "fumed" silicas being very much less active than "precipitated" silicas: even the bare silica shows appreciable activity. Vanadium oxide-silica catalysts can perform the partial oxidation of methane to formaldehyde with extremely high activities: the yield of formaldehyde can reach a value of 800 g.kg cat ${ }^{-1} \cdot \mathrm{h}^{-1}$; bare silica also shows appreciable values up to $300 \mathrm{~g} \cdot \mathrm{kg} \mathrm{cat}^{-1} \cdot \mathrm{h}^{-1}$.

To obtain information about the mechanism of methane oxidation over surface, experiments were carried out in which were studied the influence of different factors on selectivity [15]. The nature of intermediate compounds in the catalytic process was detected by recording the DRIFT spectra of surface species formed upon contact of $\mathrm{CH}_{4}$ with $\mathrm{Mo} / \mathrm{SnO}_{2}$. The spectra exhibit a discrete band at $1680 \mathrm{~cm}^{-1}$ together with the band at $1190 \mathrm{~cm}^{-1} \gamma(\mathrm{H}-\mathrm{CO})$. These bands are typical for $v(\mathrm{C}=\mathrm{O})$ stretching in coordinatively bonded formaldehyde on Lewis acid sites. Accordingly, this suggests that the first detectable adsorbed species is formaldehyde.

Consequently, the generation of formaldehyde upon $\mathrm{CH}_{4}$ decomposition may indicate that the $\mathrm{Mo} / \mathrm{SnO}_{2}$ has a high concentration of Lewis acid sites. However, the desorption of 
formaldehyde may be due to its low concentration and/or due to extracting lattice oxygen to form additionally $\mathrm{CO}$ and $\mathrm{CO}_{2}$.

In a recent review of "catalytic oxidation of light alkanes $(\mathrm{C} 1-\mathrm{C} 4)$ by heteropoly compounds", Sun et al. extensively address many practical as well as fundamental aspects [16]. They conclude on the difficulty to understand the variety of activities that can be obtained with heteropolyanions catalysts (HPA) in view of the complexity and multiplicity of factors involved, so that "To fully make a deep structure activity relationship in this kind of catalysis, it is necessary to decompose elementary steps and study them in a systematic way".

In that spirit we report here a systematic comparison of divided unsupported phosphates $\left(\mathrm{M}_{3}^{\mathrm{II}}\left(\mathrm{PO}_{4}\right)_{2}, \mathrm{M}^{\mathrm{III}} \mathrm{PO}_{4},\right)$ and pyrophosphates $\left(\mathrm{M}_{2}^{\mathrm{II}} \mathrm{P}_{2} \mathrm{O} 7, \mathrm{M}^{\mathrm{IV}} \mathrm{P}_{2} \mathrm{O}_{7}\right)$ catalytic properties in methane oxidation, showing large variations in oxidation activity and selectivities towards formaldhehyde, $\mathrm{CO}$ and $\mathrm{CO}_{2}$. We interpret these patterns through a microkinetic model according to which three descriptors suffice to predict the activity and selectivity of a given phosphate catalyst: the $\mathrm{M}-\mathrm{O}$ bond strength $\mathrm{E}_{\mathrm{MO}}$, where $\mathrm{M}$ is the hetero-element, the P-Oa bond strength $\mathrm{E}_{\mathrm{POa}}$, where $\mathrm{Oa}$ is a bridging oxygen between $\mathrm{M}$ and $\mathrm{P}$, and the experimental specific

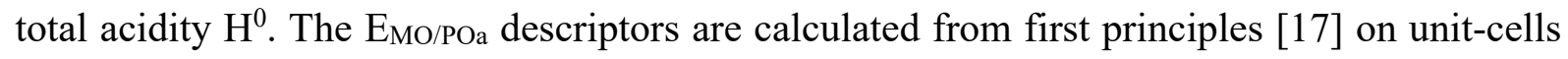
of the corresponding bulk phosphate crystal. $\mathrm{H}^{0}$ turns out to be correlated with the computed average P-Oa distances in M-Oa-P bridges. This approach allows to underline the crucial role of surface acidity in the origin of selectivity to formaldehyde.

Materials and Methods

a) Catalysts preparation and characterization 
Catalysts were prepared by precipitating hydroxides by ammonia from solutions of nitrates. Phosphates were then precipitated from hydroxides by addition of orthophosphoric or pyrophosphoric acid. Precipitated phosphates were collected on a Büchner filter, washed from ions $\mathrm{NH}_{4}{ }^{+}$and $\mathrm{NO}_{3}{ }^{-}$, and the filter cake dried at $393 \mathrm{~K}$. The dried up powdery catalysts were tableted then calcined at $973 \mathrm{~K}$. Tablets were further divided into scraps, which were finally screened to collect the 3-4 $\mathrm{mm}$ fraction. These catalysts were characterized by X-ray diffractometry, BET method, and for acidity.

Typical X-Ray diffractograms and BET areas for the various structures obtained are reported in Supporting Information SI-1 as well as the corresponding technical details. BET areas were found to vary in the range $6-90 \mathrm{~m}^{2} \cdot \mathrm{g}^{-1}$.

Acidities were determined according to a method derived from that described by Benesi ([18], [19]), namely titration by n-butylamine of weighed dried powders suspensions in dry benzene, in presence of Hammett indicators in the pKa interval -5.6 to +6.8 . We report acidities as $H^{0}$ in $\mu \mathrm{mol} . \mathrm{m}^{-2}$, the integral amount of acid sites measured in the $\mathrm{pKa}$ interval, normalized by the BET surface area.

b) Catalytic experiments

Catalytic experiments have been performed using a specifically designed batch reactor, provided with an external recycle pump and a liquid product condenser placed downstream of the reactor and maintained at $10-15^{\circ} \mathrm{C}$, which traps the oxygenated products and prevents their further oxidation. This setup is schematised in Supporting Information SI-2. The feed rate of reaction mixture is set between 3 and $15 \mathrm{Nl} \cdot \mathrm{hr}^{-1}$, while the recycle flow-rate is maintained at $150 \mathrm{~N} 1 . \mathrm{hr}^{-1}$ so as to ensure the condition of equivalence with a perfectly stirred differential reactor. In these conditions all methane, passed through catalyst, can be completely transformed into products of reaction [20]. The adequacy of this particular setup to compare selective oxidation catalysts has been independently demonstrated [10]. Reagents and products of reaction were analyzed by gas chromatography, which used TCD and FID. Analysis of $\mathrm{CH}_{4}$, 
$\mathrm{HCOOH}, \mathrm{CO}, \mathrm{CO}_{2}$ and other possible products were carried out with the help of a column filled by Porapak Q. Carbon balance was usually in the range of $1 \%$.

c) DFT calculations

The "Yin-Yang" algorithm has been described in reference [17]. In the variant used here, absolute values of total energies per unit cell are computed for:

1. the bulk compound $\mathrm{M}_{\mathrm{i}} \mathrm{X}_{\mathrm{j}}, E_{\text {Yin-Yang }}$,

2. the same unit cell as for the bulk with target atom $\mathrm{M}$ removed, $E_{Y i n}$,

3. the same unit cell as for the bulk with all atoms except $M$ removed, $E_{Y a n g}$.

With $n$ the number per unit cell of nearest neighbour atoms $\mathrm{X}$ to target atom $\mathrm{M}$, we define the bond energy descriptor $E_{M X}$ as:

$$
E_{M X}=\frac{\left[E_{Y i n-Y a n g}-\left(E_{Y i n}+E_{Y a n g}\right)\right]}{n}
$$

$E_{M X}$ can therefore be viewed as a "rebonding" energy of X to its complement in the original bulk structure $\mathrm{M}_{\mathrm{i}} \mathrm{X}_{\mathrm{j}}$.

Calculations were performed through the MedeA interface [21]. Structures of the reference phosphates were recovered from the Pearson and ICSD crystallographic databases [22] through the InfomaticA module in MedeA, which was also helpful in analyzing these structures for the determination of $n$ as well as distances and angles, and providing them as inputs of ab initio calculations. Total energy calculations were performed with the VASP version 5.3 software [23] within the density functional theory, using projected augmented wavefunctions, the PBE functional [24] in the generalized gradient approximation, Spin Orbit Coupling option, and periodic boundary conditions. The unit cell parameters and atomic positions of the bulk compounds were optimized in order to minimize the total energy $E_{\text {Yin-Yang }}$ under the approximations made in VASP, but these geometric parameters were kept unchanged to 
compute $E_{Y i n}$ and $E_{Y a n g}$. All series of calculations were submitted through the PREDIBOND® module [25] within MedeA, which implements the Yin-Yang algorithm.

Results and discussion

a) Characterization of catalysts

a-1) Experimental structural properties

Twelve catalysts are compared in the present study, including 7 divided unsupported orthophosphates $\left(\mathrm{Ni}_{3}{ }_{3}\left(\mathrm{PO}_{4}\right)_{2}, \mathrm{Co}_{3}{ }_{3}\left(\mathrm{PO}_{4}\right)_{2}, \mathrm{Mg}_{3}{ }_{3}\left(\mathrm{PO}_{4}\right)_{2}, \mathrm{Fe}^{\mathrm{III}} \mathrm{PO}_{4}, \mathrm{Cr}^{\mathrm{III}} \mathrm{PO}_{4}, \mathrm{Al}^{\mathrm{III}} \mathrm{PO}_{4}, \mathrm{~B}^{\mathrm{III}} \mathrm{PO}_{4}\right)$ and 5 pyrophosphates $\left(\mathrm{Mn}_{2}{ }_{2} \mathrm{P}_{2} \mathrm{O}_{7}, \mathrm{Ti}^{\mathrm{IV}} \mathrm{P}_{2} \mathrm{O}_{7}, \mathrm{Si}^{\mathrm{IV}} \mathrm{P}_{2} \mathrm{O}_{7}, \mathrm{Ge}^{\mathrm{IV}} \mathrm{P}_{2} \mathrm{O}_{7}, \mathrm{Sn}^{\mathrm{IV}} \mathrm{P}_{2} \mathrm{O}_{7}\right)$. Table 1 reports the space groups and a choice of geometric features obtained by inspection in real space of the unitcells of reference materials matching the observed powder X-ray diffraction spectra of our catalysts as presented in Supporting Information. In the case of orthophosphates, all $\mathrm{O}$ atoms are bridging $\mathrm{P}$ and $\mathrm{M}$ ions: in what follows we call them $\mathrm{Oa}$, although these sites are in some cases cristallographically different. Each $\mathrm{P}$ ion is coordinated to $4 \mathrm{Oa}$, forming a $\mathrm{PO}_{4}{ }^{3-}$ structural unit, while $\mathrm{M}$ ions are coordinated to 6 or 4 Oa. In the case of pyrophosphates, besides Oa types bridges, there are $\mathrm{Ob}$ atoms bridging two $\mathrm{P}$ ions, forming the $\mathrm{Oa}_{3} \mathrm{PObPOa}_{3}^{4-}\left(\right.$ i.e. $\mathrm{P}_{2} \mathrm{O}_{7}^{4-}$ ) structural unit. From a chemical standpoint, we recognize here the essential difference between phosphates and pyrophosphates. In Table 1, the structures are sorted by order of decreasing average P-Oa bond length d1a.

Table 1: Experimental (E) and computed (C) structural properties of reference structures for phosphate catalysts. SG: space Group. Average distance P-Oa: d1aE/C; Average distance MOa: d2aE/C; Average angle P-Oa-M: $\theta \mathrm{aE} / \mathrm{C}$; Average angle P-Ob-P: $\theta \mathrm{bE}$; Number of P atoms

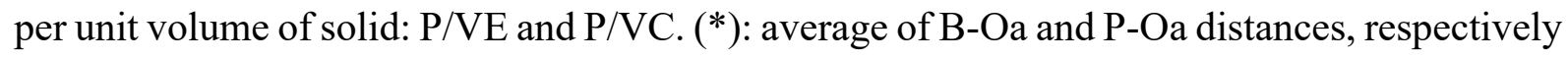
1.469 and $1.513 \AA$ (see text). 


\begin{tabular}{llllllll}
\hline Solid & SG & Ref & diaE & d2aE & $\theta a E$ & $\theta b E$ & $10^{2} . \mathrm{P} / \mathrm{VE}$ \\
\hline & & & $\AA$ & $\AA$ & 0 & 0 & $\AA^{-3}$ \\
\hline $\mathrm{Mn}_{2} \mathrm{P}_{2} \mathrm{O}_{7}$ & $\mathrm{C} 2 / \mathrm{m}$ & {$[26]$} & 1.611 & 2.15 & 125.8 & 180 & 1.59 \\
$\mathrm{CrPO}_{4}$ & $\mathrm{Cmcm}$ & {$[27]$} & 1.571 & 1.99 & 127.6 & & 1.63 \\
$\mathrm{Co}_{3}\left(\mathrm{PO}_{4}\right)_{2}$ & $\mathrm{P}-1$ & {$[28]$} & 1.563 & 2.09 & 130.4 & & 1.25 \\
$\mathrm{Ni}_{3}\left(\mathrm{PO}_{4}\right)_{2}$ & $\mathrm{P} 1$ & {$[29]$} & 1.549 & 2.08 & 126.7 & & 1.45 \\
$\mathrm{FePO}_{4}$ & $\mathrm{P} 3121$ & {$[30]$} & 1.533 & 1.80 & 145.1 & & 1.18 \\
$\mathrm{Mg}_{3}\left(\mathrm{PO}_{4}\right)_{2}$ & $\mathrm{P} 2 \_1 / \mathrm{c}$ & {$[31]$} & 1.526 & 2.12 & 148.6 & & 1.26 \\
$\mathrm{AlPO}_{4}$ & $\mathrm{P} 3221$ & {$[32]$} & 1.507 & 1.73 & 150.2 & & 1.27 \\
$\mathrm{BPO}_{4}$ & $\mathrm{I}-4$ & {$[33]$} & $1.491(*)$ & 1.47 & 134.2 & & 1.57 \\
$\mathrm{TiP}_{2} \mathrm{O}_{7}$ & $\mathrm{~Pa}-3$ & {$[34]$} & 1.466 & 1.91 & 168.3 & 180 & 1.69 \\
$\mathrm{SiP}_{2} \mathrm{O}_{7}$ & $\mathrm{~Pa}-3$ & {$[35]$} & 1.434 & 1.72 & 163.7 & 180 & 1.92 \\
$\mathrm{GeP}_{2} \mathrm{O}_{7}$ & $\mathrm{~Pa}-3$ & {$[36]$} & 1.390 & 1.85 & 153.6 & 180 & 1.88 \\
$\mathrm{SnP}_{2} \mathrm{O}_{7}$ & $\mathrm{~Pa}-3$ & {$[34]$} & 1.402 & 1.94 & 171.0 & 180 & 1.63 \\
\hline
\end{tabular}


Table 1: (continued)

\begin{tabular}{lllllll}
\hline Solid & SG & Ref & $\mathrm{d} 1 \mathrm{aC}$ & $\mathrm{d} 2 \mathrm{aC}$ & $\theta \mathrm{aC}$ & $1^{2} . \mathrm{P} / \mathrm{VC}$ \\
\hline & & & $\AA$ & $\AA$ & 0 & $\AA^{-3}$ \\
\hline $\mathrm{Mn}_{2} \mathrm{P}_{2} \mathrm{O}_{7}$ & $\mathrm{C} 2 / \mathrm{m}$ & {$[26]$} & 1.552 & 2.20 & 128.5 & 1.54 \\
$\mathrm{CrPO}_{4}$ & $\mathrm{Cmcm}$ & {$[27]$} & 1.557 & 2.02 & 128.3 & 1.56 \\
$\mathrm{Co}_{3}\left(\mathrm{PO}_{4}\right)_{2}$ & $\mathrm{P}-1$ & {$[28]$} & 1.557 & 2.09 & 124.5 & 1.23 \\
$\mathrm{Ni}_{3}\left(\mathrm{PO}_{4}\right)_{2}$ & $\mathrm{P} 1$ & {$[29]$} & 1.566 & 2.13 & 123.1 & 1.41 \\
$\mathrm{FePO}_{4}$ & $\mathrm{P} 3121$ & {$[30]$} & 1.548 & 1.88 & 141.8 & 1.12 \\
$\mathrm{Mg}_{3}\left(\mathrm{PO}_{4}\right)_{2}$ & $\mathrm{P} 2 \_1 / \mathrm{c}$ & {$[31]$} & 1.553 & 2.00 & 146.0 & 1.22 \\
$\mathrm{AlPO}_{4}$ & $\mathrm{P} 3221$ & {$[32]$} & 1.540 & 1.75 & 145.8 & 1.22 \\
$\mathrm{BPO}_{4}$ & $\mathrm{I}-4$ & {$[33]$} & 1.543 & 1.47 & 134.5 & 1.52 \\
$\mathrm{TiP}_{2} \mathrm{O}_{7}$ & $\mathrm{~Pa}-3$ & {$[34]$} & 1.520 & 1.94 & 167.1 & 1.45 \\
$\mathrm{SiP}_{2} \mathrm{O}_{7}$ & $\mathrm{~Pa}-3$ & {$[35]$} & 1.511 & 1.76 & 158.7 & 1.73 \\
$\mathrm{GeP}_{2} \mathrm{O}_{7}$ & $\mathrm{~Pa}-3$ & {$[36]$} & 1.514 & 1.87 & 157.3 & 1.60 \\
$\mathrm{SnP}_{2} \mathrm{O}_{7}$ & $\mathrm{~Pa}-3$ & {$[37]$} & 1.514 & 2.03 & 161.1 & 1.38 \\
\hline
\end{tabular}

a-2) Computed geometries and bond strengths

Starting from reference structures unit-cells, computed geometries were obtained from firstprinciples according to the method described previously. Experimental and computed minimum energy unit-cells differ slightly, as expected from the level of approximation involved in our DFT calculations. Computed values are also reported in Table 1, so as to allow easier comparisons with experimental values.

Combining densities and stoichiometries of unit-cells, we report also the number of $\mathrm{P}$ atoms per unit volume of bulk material, which is revealed to be almost constant at $1.5 \times 10^{-5} \mathrm{P}_{\mathrm{nm}} \mathrm{nm}^{-3}$ in average, with a mere $13 \%$ standard deviation. From this result, we expect superficial densities of $\mathrm{P}$ atoms, and therefore of P-Oa bridges, to be of the same order for all the divided unsupported phosphates in our set of catalysts. Assuming that exposed catalytic surfaces have unit-cells scaling like VUC ${ }^{2 / 3}$ where VUC is the unit-cell volume of the bulk material, we estimate this average site density to be of the order of $1.26 \times 10^{19}$ sites.m ${ }^{-2}$ 
M-Oa, P-Oa, and P-Ob bond strengths were computed according to the Yin-Yang method as described above, starting from the computed minimum energy unit-cells. The values are reported in Table 2, where structures are listed in the same order as for Table 1. Table SI-3-1 in Supporting Information reports computed charges on atoms resulting from a Bader analysis of the electronic structures of optimized unit-cells. There appear neither correlation of charges with computed bond strengths, nor with bond lengths. 
Table 2: Computed bond energies in $\mathrm{kJ} \mathrm{mol}^{-1}$ for DFT optimized reference structures of phosphate catalysts. $E_{M O a}$ : M-Oa bond energy; $E_{P O}$ : Average P-O bond energy; $E_{P O b}$ : P-Ob bond energy; $E_{P O a}:$ P-Oa bond energy $\left(E_{P O a}=\left(4 E_{P O}-E_{P o b}\right) / 3\right)$

\begin{tabular}{lllll}
\hline Solid & Емоа & Еро & Eроь & Ероа \\
\hline $\mathrm{Mn}_{2} \mathrm{P}_{2} \mathrm{O}_{7}$ & 151.7 & 426.8 & 397.4 & 436.6 \\
$\mathrm{CrPO}_{4}$ & 201.6 & 373.9 & & 373.9 \\
$\mathrm{Co}_{3}\left(\mathrm{PO}_{4}\right)_{2}$ & 132.5 & 376.4 & & 376.4 \\
$\mathrm{Ni}_{3}\left(\mathrm{PO}_{4}\right)_{2}$ & 122.2 & 372.7 & & 372.7 \\
$\mathrm{FePO}_{4}$ & 283.2 & 402.3 & & 402.3 \\
$\mathrm{Mg}_{3}\left(\mathrm{PO}_{4}\right)_{2}$ & 318.7 & 470.0 & & 470.0 \\
$\mathrm{AlPO}_{4}$ & 355.2 & 487.3 & & 487.3 \\
$\mathrm{BPO}_{4}$ & 402.4 & 428.8 & & 428.8 \\
$\mathrm{TiP}_{2} \mathrm{O}_{7}$ & 337.7 & 429.9 & 400.3 & 439.8 \\
$\mathrm{SiP}_{2} \mathrm{O}_{7}$ & 302.4 & 409.0 & 408.0 & 409.3 \\
$\mathrm{GeP}_{2} \mathrm{O}_{7}$ & 228.7 & 412.9 & 404.2 & 415.8 \\
$\mathrm{SnP}_{2} \mathrm{O}_{7}$ & 221.4 & 431.4 & 404.6 & 440.3 \\
\hline
\end{tabular}


a-3) Experimental acidic properties

As shown in Table SI-3-2 in Supporting Information, specific total acidities vary over more than two orders of magnitudes for this set of divided unsupported phosphate catalysts. $\mathrm{M}^{\mathrm{IV}} \mathrm{P}_{2} \mathrm{O}_{7}$ pyrophosphates are clearly the most acidic solids, while $\mathrm{Mn}_{2} \mathrm{P}_{2} \mathrm{O}_{7}$ is the least. $H^{0}$ is nicely anticorrelated to the experimental P-Oa bond length, as shown on Figure 1. In the case of $\mathrm{BPO}_{4}$, the average of B-Oa and P-Oa distances is taken into account, considering the closeness of these elements. This correlation is however not linear. It may appear surprising to obtain such a relationship between an extensive quantity like $H^{0}$ and an intensive structural quantity. However, as mentioned above, from a structural argument we expect superficial densities of POa-M bridges to be almost identical for the whole set of divided unsupported phosphates considered here. We expect these superficial bridges to react in presence of traces of water (e.g. product of the total oxidation of $\mathrm{CH}_{4}$ ), the weakest M-Oa bond being hydrolyzed preferentially according to $* \mathrm{P}-\mathrm{Oa}-\mathrm{M} *+\mathrm{H}_{2} \mathrm{O}=* \mathrm{P}-\mathrm{OaH}+* \mathrm{M}-\mathrm{OH}$ where $*$ denotes a superficial atom. Therefore, it can be deduced that $H^{0}$ actually compares acid strengths for similar acid sites densities, and essentially reduces itself in this context to an intensive quantity.

Computed P-Oa bond lengths are similarly anticorrelated to $H^{0}$, although with less regularity, and might as well be used as a predictive descriptor of $H^{0}$ for phosphates.

Ramis, Busca et al. have already reported very strong Brönsted acidities for very similar materials, layered pyrophosphates of $\mathrm{Ti}, \mathrm{Zr}, \mathrm{Ge}$ and $\mathrm{Sn}$ [41], revealed by IR spectra and butene1 isomerization catalytic tests. They state that "in all four cases a sharp $v(\mathrm{OH})$ band centred between 3665 and $3650 \mathrm{~cm}^{-1}$ is predominant and looks similar to the bands detected under similar conditions for samples of other phosphate compounds such as $\mathrm{AlPO}_{4}$ (refs. given) $\mathrm{BPO}_{4}$ (refs given) $(\mathrm{VO})_{2} \mathrm{P}_{2} \mathrm{O}_{7}$ (refs given) as well as phosphorus-treated Silica, (refs given). In all such cases this sharp band is surface-sensitive, being perturbed upon adsorption, and has been assigned to the OH stretching of free surface POH groups". 
Although we cannot provide IR spectra for the whole set of our phosphate catalysts, we present in Supporting Information the data we have for $\mathrm{CrPO}_{4}, \mathrm{Ni}_{3}\left(\mathrm{PO}_{4}\right)_{2}, \mathrm{Co}_{3}\left(\mathrm{PO}_{4}\right)_{2}, \mathrm{FePO}_{4}$, $\mathrm{AlPO}_{4}$ and $\mathrm{BPO}_{4}$ : They systematically exhibit similar bands in the vicinity of $3600 \mathrm{~cm}^{-1}$ revealing the existence of surface $\mathrm{OH}$ groups on these solids.

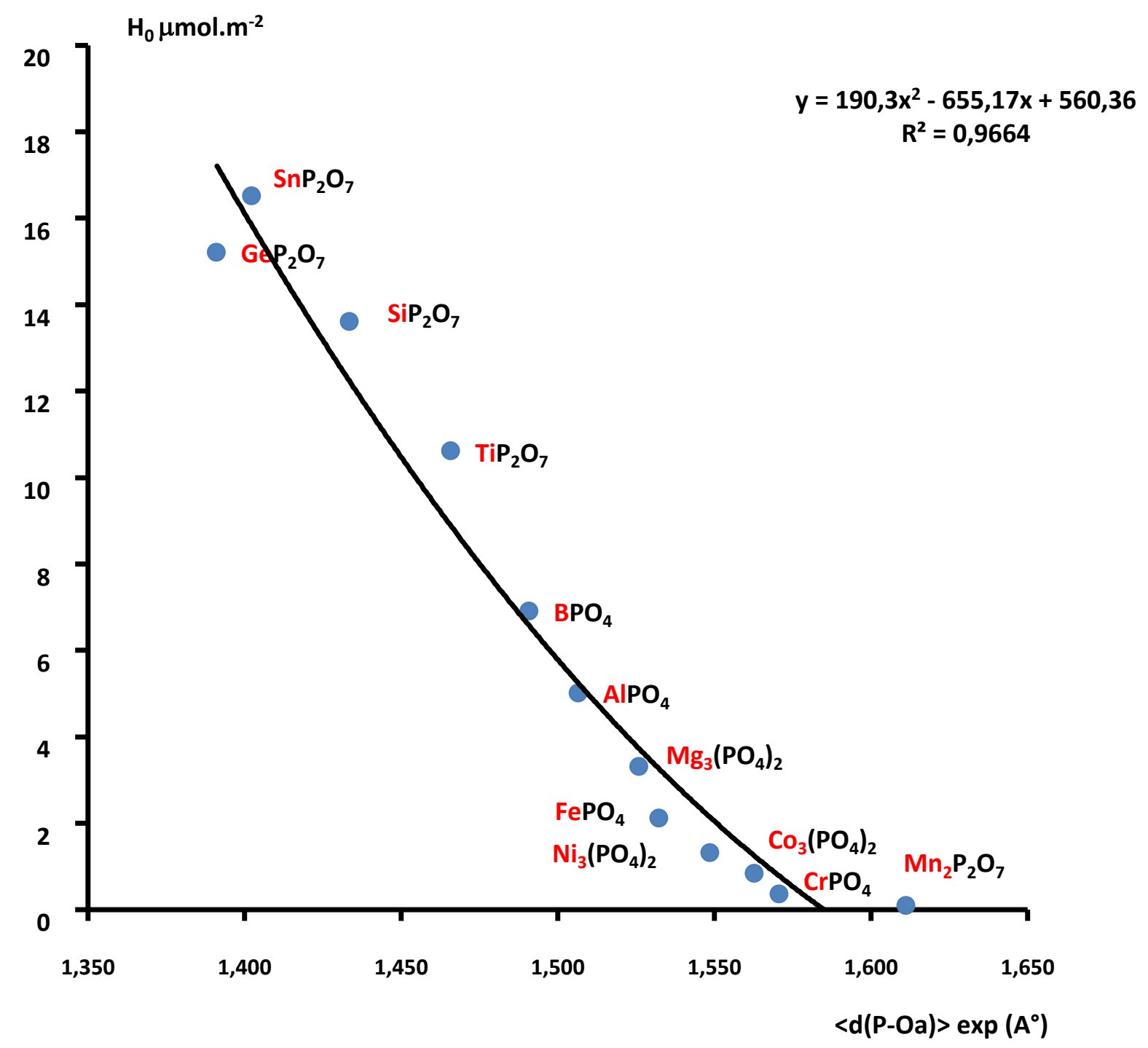

Figure 1: Correlation between the specific total acidity of phosphate catalysts and the average P-Oa distance. The polynomial equation in inset is that of a mere tendency curve (black line) without particular physical meaning. 
b) Catalytic properties in selective oxidation of methane

Table SI-3-3 in Supporting Information displays specific methane oxidation rates and selectivities in partial and total oxidation products, formaldehyde $\mathrm{CH}_{2} \mathrm{O}, \mathrm{CO}$ and $\mathrm{CO}_{2}$, obtained for the set of divided unsupported phosphate catalysts considered. While the selectivity in $\mathrm{CH}_{2} \mathrm{O}$ appears strongly correlated to acidity $H^{0}$, and anticorrelated to the rate $w$, the other patterns are more complex, and strongly non-linear. In the following section we present the essential features of a kinetic model enabling a consistent interpretation of these patterns. Details of the derivation are provided in Supporting Information section SI-4.

b-1) Kinetic model of selective methane oxidation

To carry out the catalytic process of methane oxidation, conditions were chosen under which homogeneous stages of formaldehyde decomposition and oxidation are practically excluded (the usage of hardening, filling of free volumes of reactor with matter and other), so in these conditions a heterogeneous mechanism dominates. Table 3 presents the assumed nine steps of such a mechanism, as proposed in [37]. We consider these steps a priori reversible. 
Table 3: Catalytic elementary steps of methane selective oxidation: Z: free Lewis acidic sites on the catalyst's surface (either $\mathrm{M}$ or $\mathrm{P}$ cations exposed in surface and coordinatively unsaturated); $\mathrm{ZO}, \mathrm{ZOHCH}_{3}, \mathrm{ZOHCH}_{2}, \mathrm{ZOHCH}_{2} \mathrm{O}$... sites occupied by adsorbed species, respectively $-\mathrm{O},-\mathrm{OHCH}_{3},-\mathrm{OHCH}_{2},-\mathrm{OHCH}_{2} \mathrm{O}$...

$\begin{array}{ll}\text { Step № } & \text { Reaction equation } \\ 1 & \mathrm{O}_{2}(\mathrm{~g})+2 \mathrm{Z} \Leftrightarrow 2 \mathrm{ZO} \\ 2 & \mathrm{CH}_{4}(\mathrm{~g})+\mathrm{ZO} \Leftrightarrow \mathrm{ZOHCH}_{3} \\ 3 & \mathrm{ZOHCH}_{3}+\mathrm{ZO} \Leftrightarrow \mathrm{ZOHCH}_{2}+\mathrm{ZOH} \\ 4 & \mathrm{ZOHCH}_{2}+\mathrm{ZO} \Leftrightarrow \mathrm{ZOHCH}_{2} \mathrm{O}+\mathrm{Z} \\ 5 & \mathrm{ZOHCH}_{2} \mathrm{O} \Leftrightarrow \mathrm{CH}_{2} \mathrm{O}+\mathrm{ZOH} \\ 6 & \mathrm{ZOHCH}+\mathrm{OH} \Leftrightarrow \mathrm{ZHCOOH}+\mathrm{ZOH} \\ 7 & \mathrm{ZHCOOH} \Leftrightarrow \mathrm{CO}(\mathrm{g})+\mathrm{H}_{2} \mathrm{O}(\mathrm{g})+\mathrm{Z} \\ 8 & \mathrm{ZHCOOH}+\mathrm{ZO} \Leftrightarrow \mathrm{CO}_{2}(\mathrm{~g})+\mathrm{H}_{2} \mathrm{O}(\mathrm{g})+2 \mathrm{Z} \\ 9 & 2 \mathrm{ZOH} \Leftrightarrow \mathrm{H}_{2} \mathrm{O}(\mathrm{g})+\mathrm{ZO}+\mathrm{Z}\end{array}$

Step 1 is the dissociative chemisorption of dioxygen occurring on a superficial cationic site exhibiting a Lewis acidic character. Since all phosphate catalysts may express both $\mathrm{M}$ and $\mathrm{P}$ cations in their outer surface, our notation describes formally two simultaneous networks of surface reactions contributing in parallel to the gaseous products with different energetic descriptors, but following the same mechanisms. Competing steps 5 and 6 are crucial since the latter is the entrance to oxidative degradation steps 7 and 8 . Activation of step 5, i.e. formaldehyde desorption, relative to step 6 , will therefore orient the selectivity towards mild oxidation into formaldehyde instead of total oxidation.

We have reported in Supporting Information the detailed analysis of our kinetic model, leaving in this section only the key results. Our main assumptions involve i) a LangmuirHinshelwood mechanism for both types of $\mathrm{Z}$ sites, determining the surface coverages of competing species; ii) entrance channel of carbon at the catalyst's surface by a carbidic insertion of methane into a $\mathrm{ZO}$ bond yielding $\mathrm{HO}-\mathrm{Z}-\mathrm{CH}_{3}$ surface species; iii) neglecting coverages of species of order equal or greater than two in coverage by ZO; iv) neglecting the rates of reverse 
elementary surface reactions before those of the corresponding direct reactions since experiments were conducted in a mode simulating a differential reactor with continuous removal of products and therefore surface intermediates must be far from equilibrium.

For a given catalytic surface denoted by subscript $j$, we obtain the following equations for the total rate of methane oxidation $w_{C_{4}, j}$ and selectivities $S_{C_{2} O, j}, S_{C O, j}$ and $S_{C_{2}, j}$ towards carbonaceous products $\mathrm{CH}_{2} \mathrm{O}, \mathrm{CO}$ and $\mathrm{CO}_{2}$ :

$$
w_{C H_{4}, j}=k_{2, j} \theta_{\text {ZOHCH3,j }}
$$

With:

$$
\begin{aligned}
& \theta_{Z O H C H 3, j}=\left(P_{O_{2}} K_{1, j}\right)^{1 / 2} P_{C H_{4}} K_{2, j}\left(1+\left(P_{O_{2}} K_{1}, j\right)^{1 / 2}\left(1+P_{C H_{4}} K_{2, j}\right)\right)^{-2} \\
& S_{C H_{2} O, j}=\frac{k_{5, j}}{\left(k_{5, j}+k_{6, j} \theta_{Z O, j}\right)} \\
& S_{C O, j}=\frac{k_{7, j} k_{6, j} \theta_{Z O, j}}{\left(k_{5}, j+k_{6, j} \theta_{Z O, j}\right)\left(k_{7, j}+k_{8, j} \theta_{Z O, j}\right)} \\
& S_{C O_{2}, j}=\frac{k_{6, j} k_{8, j} \theta_{Z O, j}{ }^{2}}{\left(k_{5}, j+k_{6, j} \theta_{Z O, j}\right)\left(k_{7, j}+k_{8, j} \theta_{Z O, j}\right)}
\end{aligned}
$$

and:

$$
\theta_{Z O, j}=\left(P_{O_{2}} K_{1, j}\right)^{1 / 2}\left(1+\left(P_{O_{2}} K_{1, j}\right)^{1 / 2}\left(1+P_{C H_{4}} K_{2, j}\right)\right)^{-1}
$$

where $K_{1, j}$ and $K_{2, j}$ denote equilibrium adsorption constants of $\mathrm{O}_{2}$ and $\mathrm{CH}_{4}$ from gas phase on catalyst surface $j$, and $k_{l, j}$ denote forward rate constants with subscript $l=2,5,6,7,8$ relating to the step number, and subscript $j$ to the catalyst.

Equilibrium adsorption constants can be expressed as function of adsorption enthalpies and entropies with:

$$
K_{i, j}=\frac{1}{P_{i}^{0}} \exp \left(-\Delta H_{i, j}^{0}+T \Delta S_{i, j}^{0}\right) / R T
$$

and rate constants $k_{l, j}$ can be expressed according to Eyring [38]: 
$k_{l, j}=\frac{k_{B} h}{T} \exp ^{\left(-\Delta H_{l, j}^{ \pm}(T)+\mathrm{T} \Delta S_{l, j}^{ \pm}(T)\right) / R T}$

where $k_{B}$ and $h$ are the Boltzmann and Planck constants respectively, and $\Delta H_{l, j}^{ \pm}(T)$ and $\Delta S_{l, j}^{ \pm}(T)$ are respectively the free enthalpies and entropies of activation of step $l$ for catalyst $j$.

As explained in Supporting Information, we postulate linear continuous relationships between enthalpies and bond energies for $i=1,2$ and $1=2,6,7,8$ :

$$
\begin{aligned}
& \Delta H_{i}^{0}=E_{i}^{0}-\beta_{i} E_{X O} \\
& \Delta H_{l}^{ \pm}=E_{l}^{ \pm}-\alpha_{l} E_{X O}
\end{aligned}
$$

while for forward step 5 we use by analogy the descriptor of catalyst acidity $H^{0}$ :

$$
\Delta H_{5}^{ \pm}=E_{5}^{ \pm}-\alpha_{5} H^{0}
$$

Where $\alpha_{5}$ is positive and has the appropriate dimension $\mathrm{kJ} . \mathrm{m}^{2} . \mu \mathrm{mol}^{-2}$.

We justify this approach as follows: forward step 5 is the desorption of $\mathrm{CH}_{2} \mathrm{O}$ from the $\mathrm{Z}$ center of a ZOH site, as pictured by Fig. SI-5-3, therefore breaking a Z-C bond. $\mathrm{CH}_{2} \mathrm{O}$ is a very polar molecule, and in the adsorbed state its carbonyl group will undergo an electrophilic attack of the terminal oxygen by any vicinal acidic proton $\left(\mathrm{e} . \mathrm{g} . \mathrm{H}^{\delta+} \ldots . \mathrm{O}^{\delta-}=\mathrm{P}\right)$ and a nucleophilic attack of the carbon by the conjugated base (e.g. $\mathrm{O}^{-}=\mathrm{P}$ ), thus weakening the $\mathrm{Z}-\mathrm{CH}_{2} \mathrm{O}$ bond. Therefore, the more acidic the catalyst, the easier the desorption of formaldehyde and this explains why the total acidity $H^{0}$ can be taken as a proximal descriptor of $\mathrm{Z}-\mathrm{CH}_{2} \mathrm{O}$ bonds weaknesses.

Combining equations (2) to (12), we note that the oxidation rate $w_{\mathrm{CH}_{4}}$ and selectivities in the three gaseous carbonaceous products are completely determined by parameters $\Delta S_{i, j}^{0}, \Delta S_{l, j}^{ \pm}, E_{i}^{0}$ , $E_{l}^{ \pm}, \beta_{i}, \alpha_{l}$, for $i=1,2$ and $l=2,5,6,7,8$ as long as catalysts can be described by $E_{X O}$, for $X=P, M$, and $H^{0}$. We further assume:

$$
\begin{aligned}
& \Delta S_{i, j}^{0}=\Delta S_{i}^{0} \\
& \Delta S_{l, j}^{ \pm}=\Delta S^{ \pm}
\end{aligned}
$$


and in order to express the expected increasing affinity of $\mathrm{O}_{2}$ for $\mathrm{Z}$ sites and decreased affinity of $\mathrm{CH}_{4}$ for $\mathrm{ZO}$ sites as $E_{X O}$ increases, we set $\beta_{1}=-1$ and $\beta_{2}=1$.

Therefore 15 parameters remain to be determined through a fitting procedure: $\Delta S_{1}^{0}, \Delta S_{2}^{0}$, $E_{1}^{0}, E_{2}^{0}, \Delta S^{ \pm}, E_{l}^{ \pm}$and $\alpha_{l}$ for $l=2,5,6,7,8$.

Since we consider $\mathrm{X}=\mathrm{M}$ and $\mathrm{X}=\mathrm{P}$ separately, we sum up predicted rates for both kinds of sites and add moreover a catalyst independent thermal rate:

$$
w_{\mathrm{CH}_{4}}=W_{\mathrm{CH}_{4}}^{M}+W_{\mathrm{CH}_{4}}^{P}+W_{C H_{4}}^{T h}=k_{2}^{M} \theta_{M O H C H 3}+k_{2}^{P} \theta_{P O H C H 3}+W_{C H_{4}}^{T h}
$$

where the superscripts $M$ and $P$ refer to the choice of descriptors $E_{M O}$ or $E_{P O}$ in equations SI(10) and (11). The thermal rate, a $16^{\text {th }}$ free parameter, sets a lower limit to the rate in absence of catalyst, and imparts more physical realism by allowing a smooth convergence of the predicted residual rate for vanishing or very high values of the descriptors $E_{M O}$ or $E_{P O}$. Accordingly, predicted selectivities become:

$$
S_{A}=\frac{w_{C H_{4}}^{M}}{W_{C H_{4}}} S_{A}^{M}+\frac{w_{C H_{4}}^{P}}{W_{C H_{4}}} S_{A}^{P}
$$

$$
\text { For } \mathrm{A}=\mathrm{CH}_{2} \mathrm{O}, \mathrm{CO}, \mathrm{CO}_{2}
$$

We describe our two steps fitting procedure in Supporting Information, and report the best fitting 15 parameters in Table SI-4-1.

Resulting from this optimization, best fitted forward rates constants $k_{l, j}^{M}$ for $l=2,5,6,7,8$ and the twelve phosphate catalysts considered are plotted against $E_{M O}$ in Figure 2: while forward step 2 appears limiting, forward steps 5, 6, 7 and 8 exhibit higher rate constants by 4 to 13 orders of magnitude. This is consistent with one of the key assumptions underlying our derivation of the kinetic model.

$k_{5, j}$ is according to our model independent of $E_{M O}$ but linearly dependent of $H^{0}$, overcomes $k_{6, j}$ for the 4 most acidic catalysts, while both constants are very close in the case of $\mathrm{BPO}_{4}$. 
Plotting rates versus $E_{X O}$, we clearly obtain a volcano curve, as displayed in Figure 3. Except for the four pyrophosphates, for which predicted rates appear well below experimental rates. By contrast, predicted selectivities match experiments very well for the complete set of 12 divided unsupported phosphate catalysts, as shown in Figures 4 and 5.

Coming back to the outlying data in Figure 3 corresponding to the four pyrophosphates $\mathrm{M}^{\mathrm{IV}} \mathrm{P}_{2} \mathrm{O}_{7}$, the nice linear relationship obtained when plotting in a log scale for these catalysts the ratios of predicted over measured oxidation rates versus total acidity function $H^{0}$ (see Figure 6), suggests that for this set of highly acidic catalysts a significant deactivation has occurred along the catalytic test, for instance due to the deposition of carbonaceous species as expected when acidic catalysts are exposed to hydrocarbons at high temperatures. This important point must be further investigated, since if such a deactivation could be avoided or limited, it might provide a way to develop $\mathrm{CH}_{2} \mathrm{O}$ selective catalysts with greatly improved productivities. For instance, we find here a productivity in $\mathrm{CH}_{2} \mathrm{O}$ of $10.3 \mathrm{~g} \cdot \mathrm{kg}^{-1} \cdot \mathrm{h}^{-1}$ for the catalyst $\mathrm{SnP}_{2} \mathrm{O}_{7}$ which would amount to $262 \mathrm{~g} \cdot \mathrm{kg}^{-1} \cdot \mathrm{h}^{-1}$ if the theoretical activity was recovered, not so far from the state of the art. 


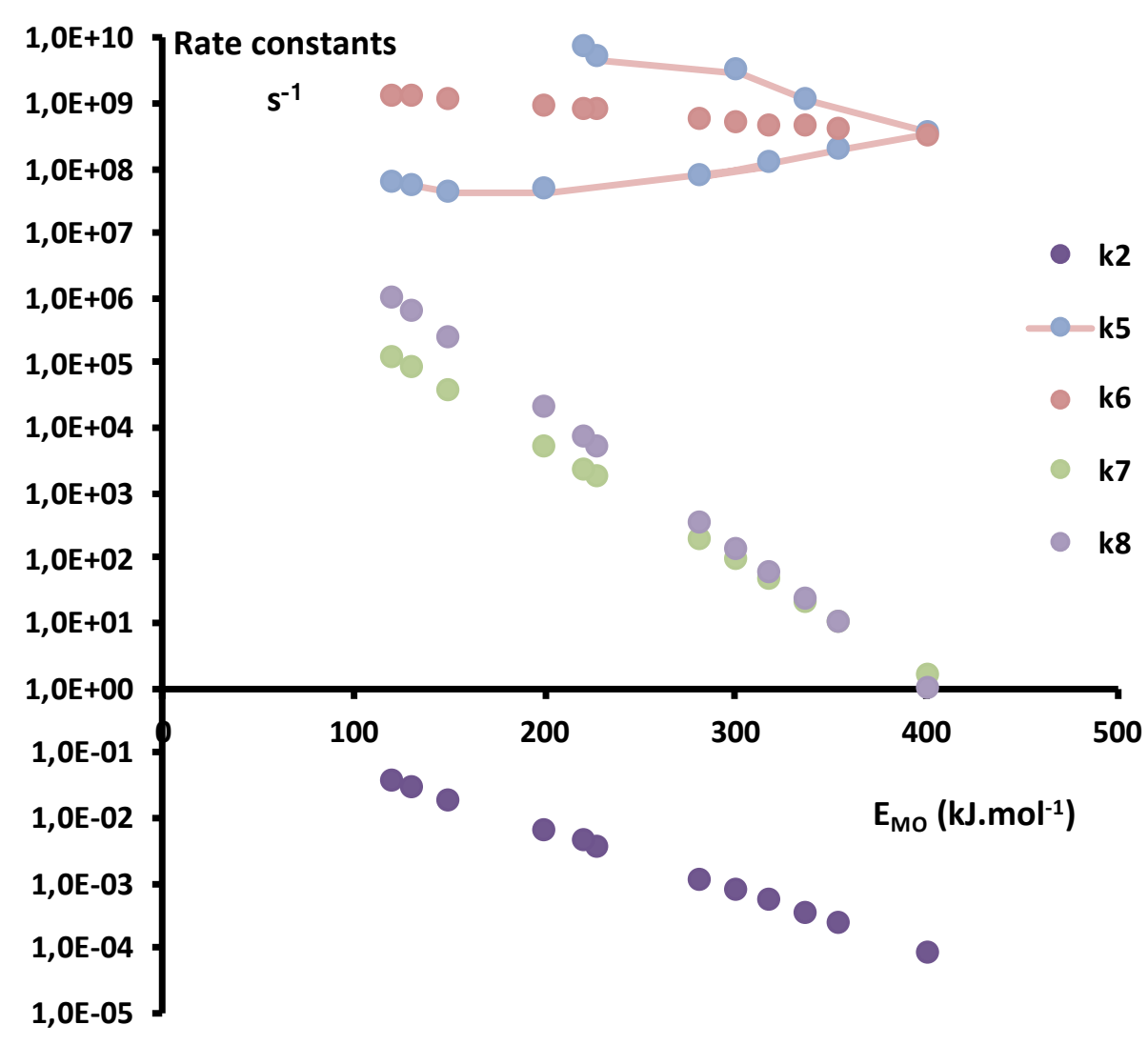

Figure 2: Plot against $E_{M O}$ of the best fitted forward rates constants $k_{l, j}^{M}$ for $l=2,5,6,7,8$ and the twelve phosphate catalysts considered. 


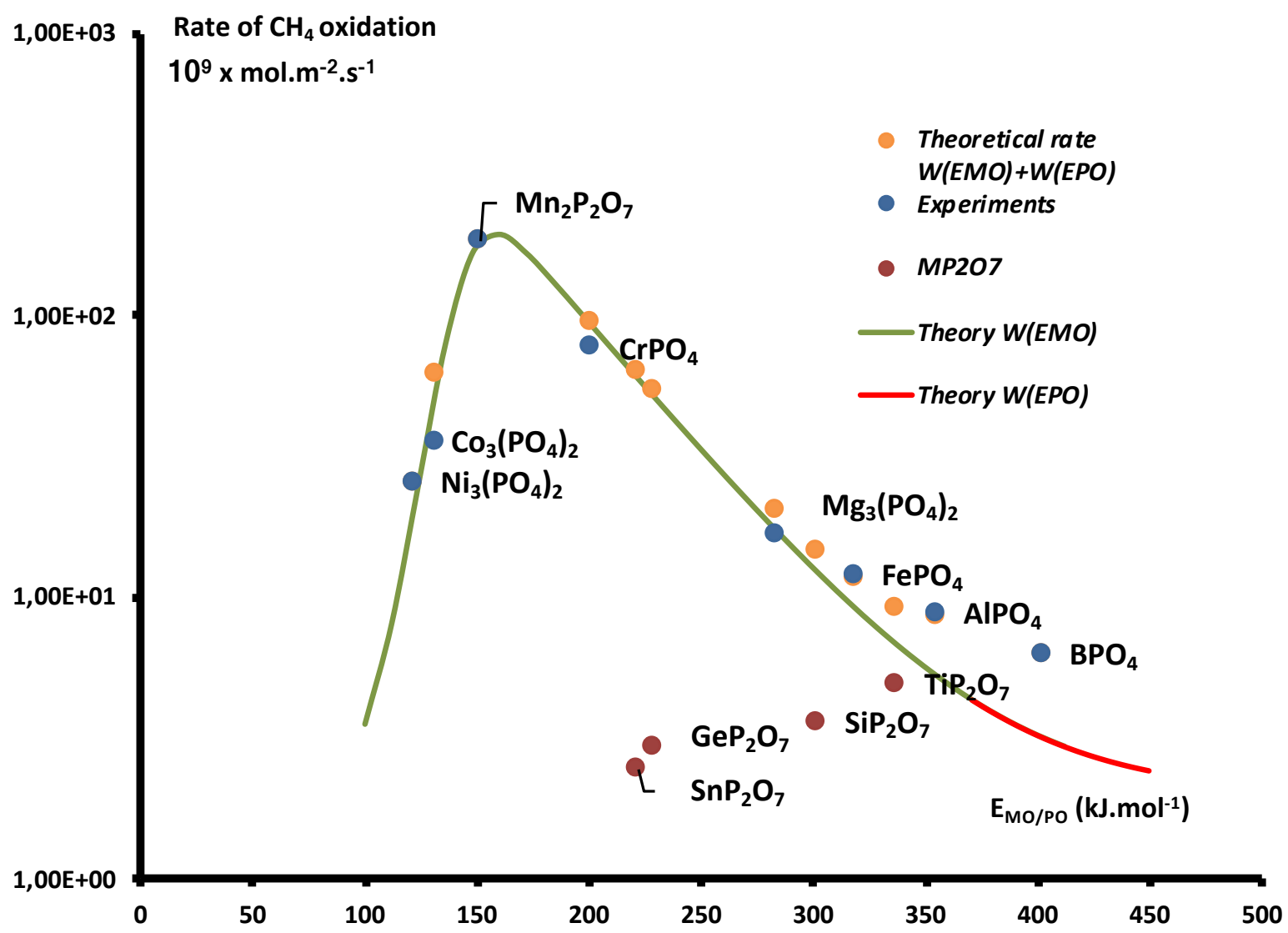

Figure 3: Volcano plot of methane oxidation rates versus metal oxygen bond strengths ( $E_{X O}$ computed at the DFT level). Deviations of the experimental rates from predicted rates for strongly acidic pyrophosphates $\mathrm{MP}_{2} \mathrm{O}_{7}$ (brown symbols) are the larger the higher the acidity. 


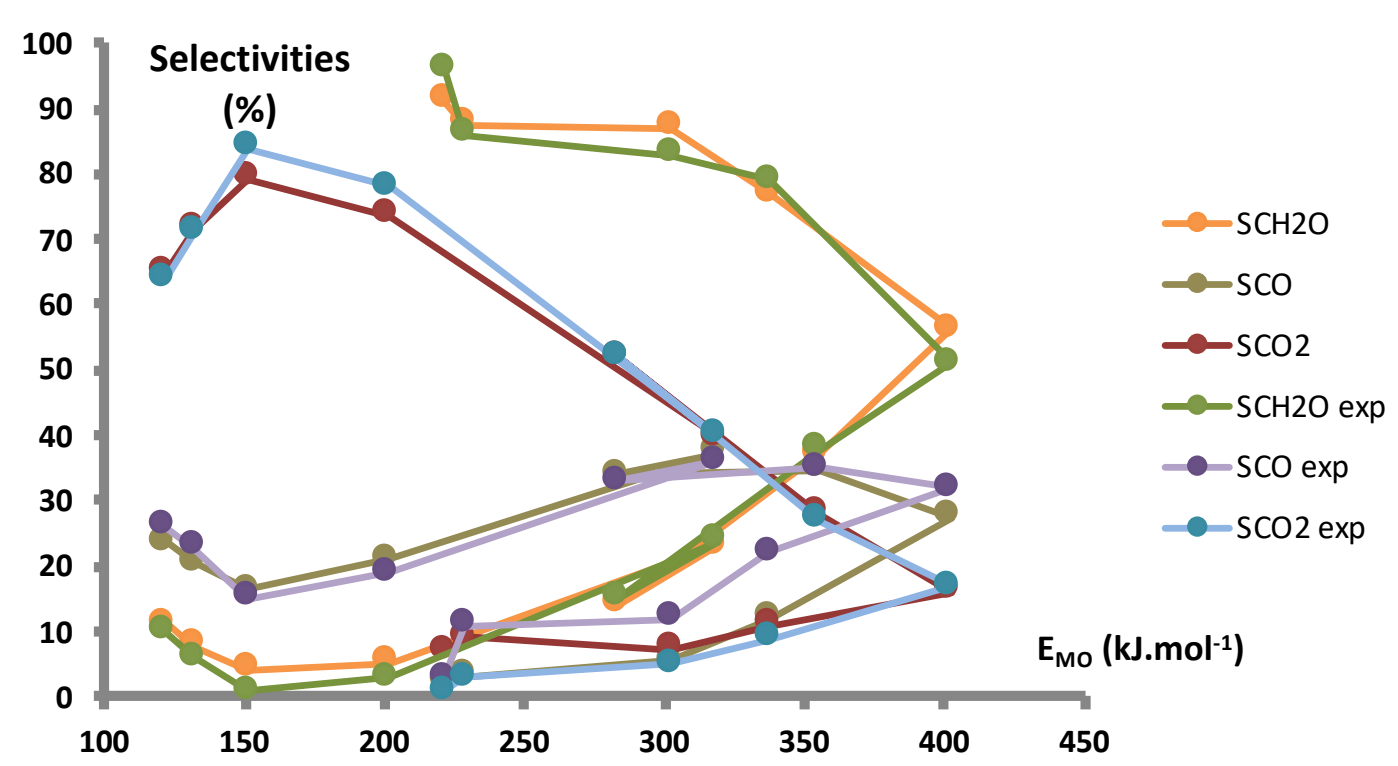

Figure 4: Comparison of predicted and experimental selectivities for the complete set of 12 divided unsupported phosphate catalysts, plotted against $E_{M O a}$ 


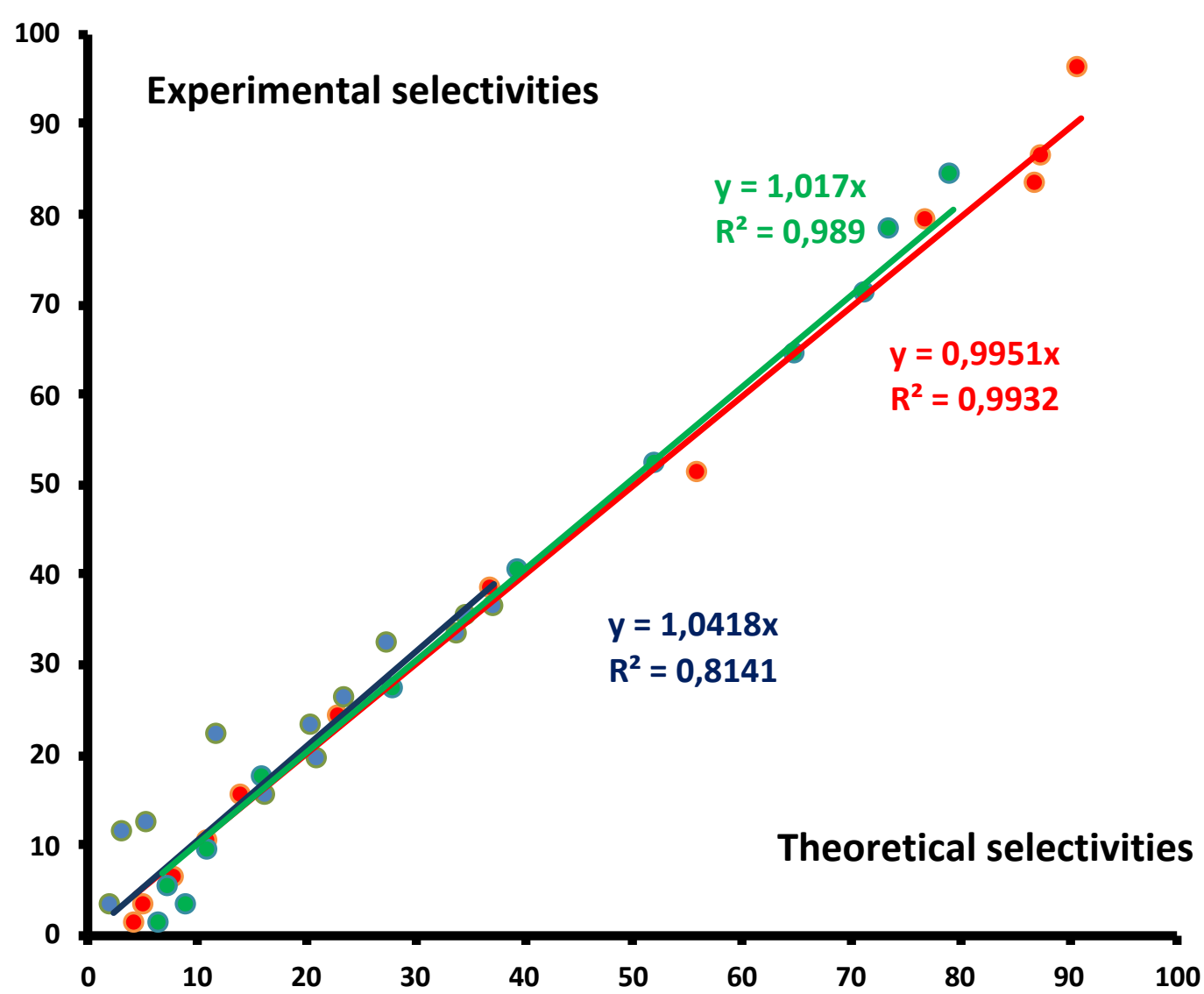

Figure 5: Parity diagram comparing experimental to predicted selectivities: red dots: $\mathrm{S}_{\mathrm{CH} 2 \mathrm{O}}$; blue dots: $\mathrm{S}_{\mathrm{CO}}$; green dots: $\mathrm{S}_{\mathrm{CO} 2}$. The equations of the corresponding linear regression plots and associated squared coefficients of correlation are shown in insets 


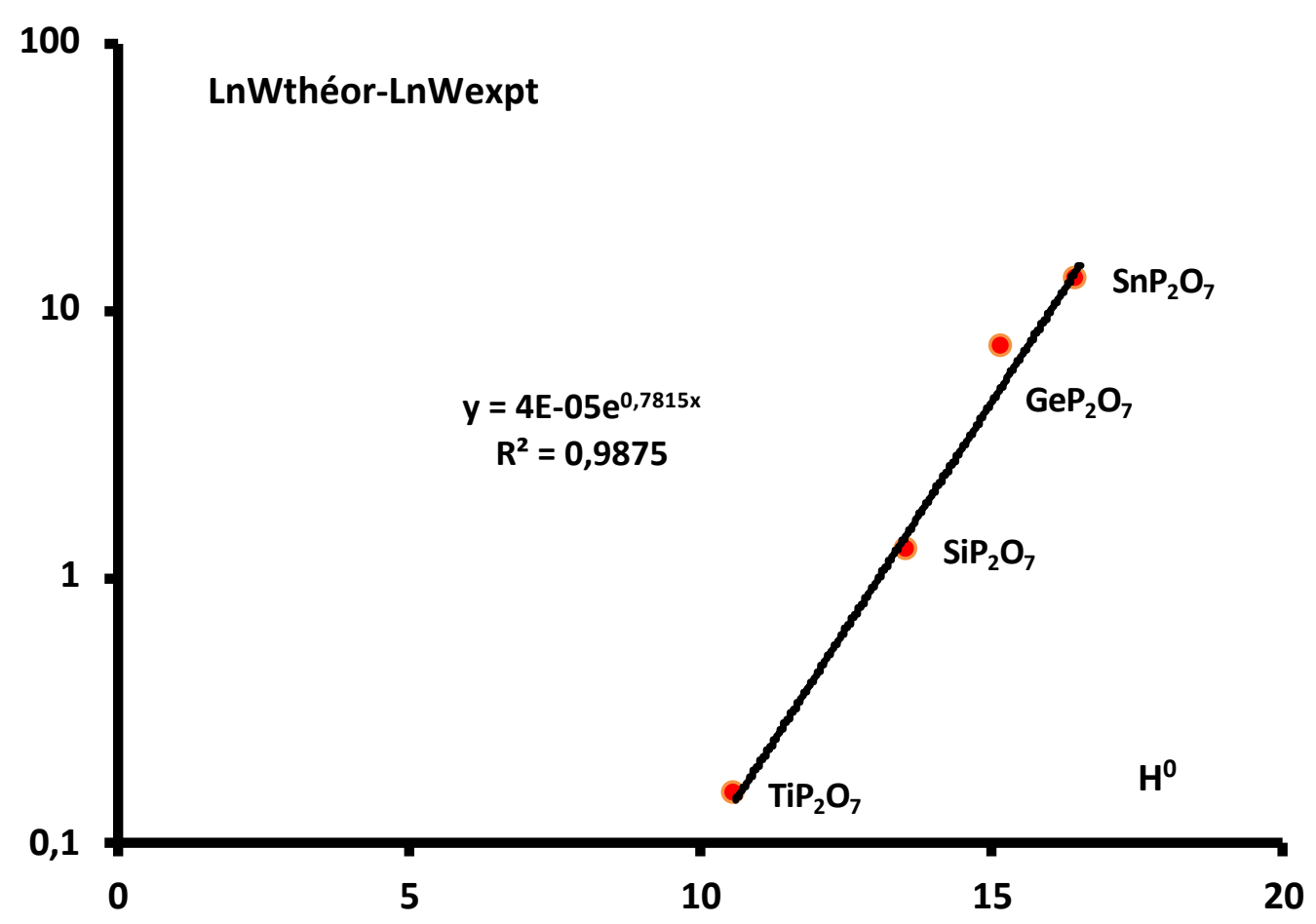

Figure 6: Plot of the deviation of experimental from predicted oxidation rates versus experimental total acidity function, for the highly acidic pyrophosphate catalysts $\mathrm{M}^{\mathrm{IV}} \mathrm{P}_{2} \mathrm{O}_{7}$. The simple correlation obtained suggests a significant deactivation maybe related to coke forming side reactions catalyzed by initial acid sites.

c) Structural and energetic description of acidity

One can conclude from Tables 2 and SI-3-2 that there is no obvious relation between acidity $H^{0}$ and computed bond strengths, in contrast with the clear description by average P-Oa bond lengths illustrated on Figure 1. With increasing $E_{M O a}$, we notice however different trends for the 8 less acidic phosphates and the 4 highly acidic pyrophosphates: increasing acidity for the former group, decreasing for the latter. Bond lengths are in general not necessarily correlated with bond strengths in a set of homologous compounds, but rather reflect bond orders, shorter bonds being associated with higher orders. The obvious example is the hierarchy of single, 
double and triple $\mathrm{C}-\mathrm{C}$ bond lengths in hydrocarbons, although in that case bond strengths and orders are correlated.

However, we expect a non-linear relationship to hold between bond energies and bond lengths for a homologous family of compounds like phosphates: such a potential energy function can be represented by the well-known Morse potential:

$$
E(r)=D_{e}\left(\left[1-e^{\alpha\left(\mathrm{r}-r_{0}\right)}\right]^{2}-1\right)
$$

On Figure 7, we have plotted $E_{P O a}($ Table 2) against d1aC (Table 1) together with a Morse potential best fitting the data. We compare DFT computed values of bond energies and bond lengths in order to ensure consistency. We evaluate the relative error on $E_{P O a}$ to $5 \%$, and to 0.5 $\%$ on $\mathrm{d} 1 \mathrm{aC}$. The $2 \mathrm{xstandard}$ deviation from the best fitting Morse potential is $4 \%$. This potential has a minimum for $\mathrm{d} 1 \mathrm{aC}=1,53 \AA$, very close to the value of $1,535 \AA$ reported for the P-Oa bond distance in $\mathrm{H}_{3} \mathrm{PO}_{4}$, which can be considered as representative for the unconstrained phosphate ion.

In this way, we understand that in pyrophosphates $\mathrm{M}^{\mathrm{IV}} \mathrm{P}_{2} \mathrm{O}_{7}$ the $\mathrm{P}-\mathrm{Oa}$ bonds are compressed, while they are elongated in $\mathrm{Mn}_{2} \mathrm{P}_{2} \mathrm{O}_{7}$ and orthophosphates, relative to the unconstrained $\mathrm{PO}_{4}{ }^{3-}$ ion. Constraints acting on P-Oa bonds are the resultant of several factors brought in by heteroions $\mathrm{M}$, like their oxidation state, ionic radii, electronic configuration, which contribute to determine the free energy minimum corresponding to the actual crystal structures. In a compressed bond, where electrons are more confined, the bonding electronic density at the critical mid-point must increase, therefore the bond order, so as to compensate for the increase repulsion of the closer nuclei. It is the reverse in an elongated bond, relative to the unconstrained same bond. 


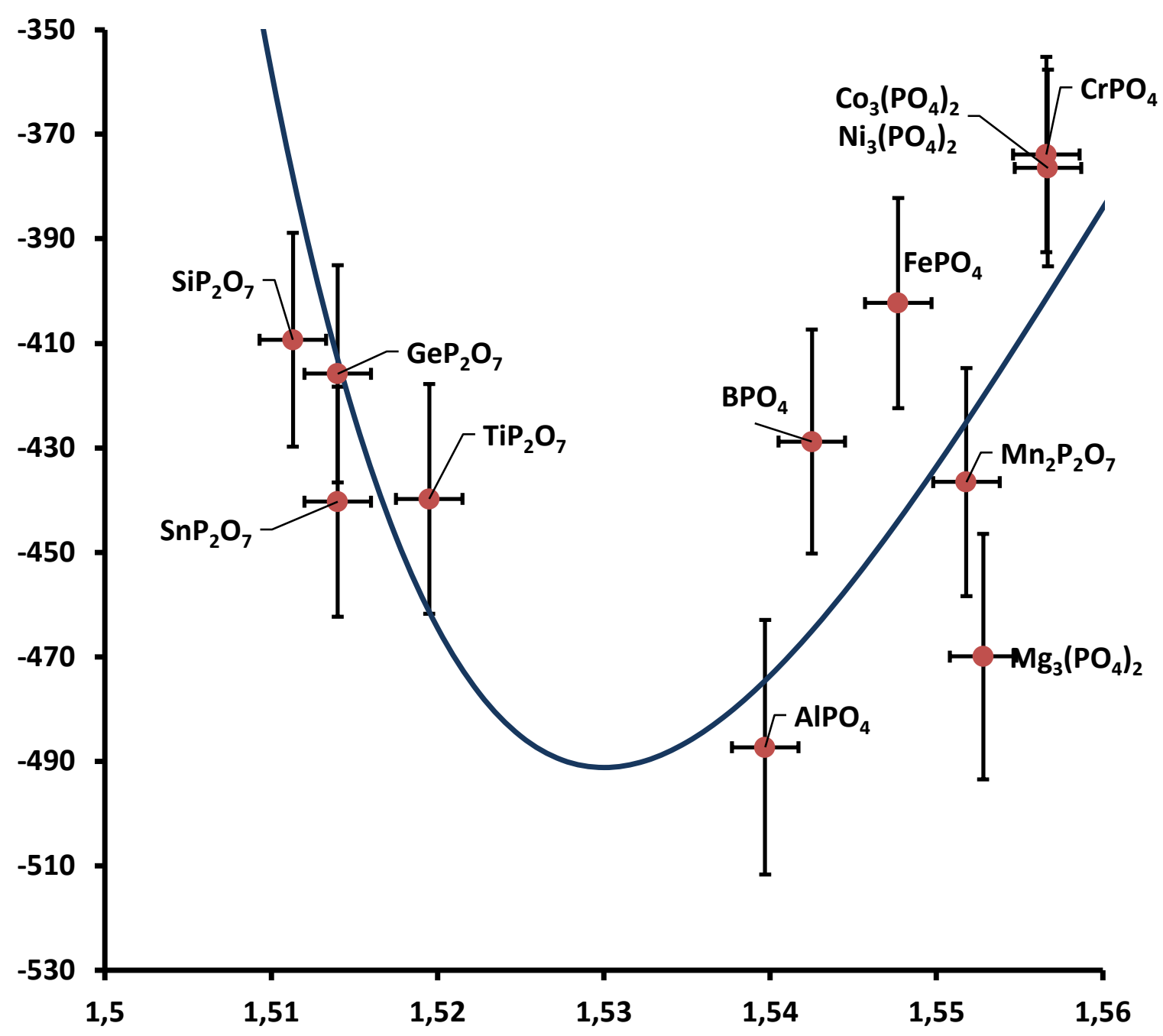

Figure 7: Plot of computed P-Oa bonds strengths (Table2) versus the corresponding computed P-Oa distances (Table 1). Error bars indicate estimated relative errors. The blue line is the Morse potential (equation 17) with parameters $r_{0}=1,53 \AA, \alpha=20,97 \AA^{-1}$ and $D e=491,2 \mathrm{~kJ} \cdot \mathrm{mol}^{-1}$. 
Table 4: bond orders of P-Oa bonds estimated according to equations (1) ( $B O A$, parameter $a$ fitted to 0,0474$)$ and (2) $(B O B)$ of reference [40], using bond lengths computed by DFT, and the optimal Morse potential shown on Figure 5.

\begin{tabular}{lll}
\hline Solid & BO A & BO B \\
\hline $\mathrm{Mn}_{2} \mathrm{P}_{2} \mathrm{O}_{7}$ & 0,631 & 0,633 \\
$\mathrm{CrPO}_{4}$ & 0,571 & 0,572 \\
$\mathrm{Co}_{3}\left(\mathrm{PO}_{4}\right)_{2}$ & 0,569 & 0,571 \\
$\mathrm{Ni}_{3}\left(\mathrm{PO}_{4}\right)_{2}$ & 0,472 & 0,474 \\
$\mathrm{FePO}_{4}$ & 0,688 & 0,690 \\
$\mathrm{Mg}_{3}\left(\mathrm{PO}_{4}\right)_{2}$ & 0,618 & 0,620 \\
$\mathrm{AlPO}_{4}$ & 0,815 & 0,816 \\
$\mathrm{BPO}_{4}$ & 0,768 & 0,769 \\
$\mathrm{TiP}_{2} \mathrm{O}_{7}$ & 1,248 & 1,246 \\
$\mathrm{SiP}_{2} \mathrm{O}_{7}$ & 1,484 & 1,480 \\
$\mathrm{GeP}_{2} \mathrm{O}_{7}$ & 1,401 & 1,399 \\
$\mathrm{SnP}_{2} \mathrm{O}_{7}$ & 1,401 & 1,399 \\
\hline
\end{tabular}

Finally, in order to understand the connection shown on Figure 1 between $H^{0}$ and the P-Oa bond length, we invoke the Bond Order Conservation (BOC) principle [39], [40]: indeed, Brönsted acid hydroxyls will be necessarily expressed on the phosphate catalysts surfaces at Oa* surface atoms inherited from bulk bridging Oa atoms, and will result as discussed above from the dissociative chemisorption of water, implying hydrolysis of the weakest bonds, which are always the M-Oa bonds. From that, we expect that the more compressed, or higher order the Oa-P bond in the bulk, the weakest and lowest order the corresponding $\mathrm{H}-\mathrm{Oa}$ * bond at the surface. Bond orders of Oa-P bonds estimated according to equations (1) and (2) given by van Santen in [40] are reported in Table 4 . The total acidity $H^{0}$ and bond orders A or B are indeed fairly correlated, as shown on figure 8 .

Ramis, Busca et al. [41] also raised the important question of the origin of variations in acid strength of surface P-OH groups in metal phosphates, and tentatively addressed this question in terms of nature of the chemical bonds involved, as it should make sense: "It then seems reasonable to propose that the Brönsted-acid strength of the surface POH groups increases 
with increasing covalency of the (PO)-M bond, which may cause an increase in the ionic character of the POH bonds. However, increased covalency of the metal-phosphate bonds decreases the cationic character of the bonded metal atoms, so decreasing their Lewis-acid strength when they are exposed on the external crystal surface." Their statement implicitly relates surface and bulk bonding properties. The latter are reflected in the bulk structures. We had independently tested a possible correlation between the Pauling electronegativity of elements $\mathrm{M}$ and the measured (surface) acidity of our metal phosphates but found it rather unconvincing $\left(\mathrm{R}^{2}=0,17\right)$. Our approach based on a DFT evaluation of bond strengths and from that on bond orders provides an alternative interpretation.

A confirmation of this ansatz will however necessitate a further study, out of scope of the present report, involving for instance DFT simulations of realistic models of phosphate catalysts surfaces. 


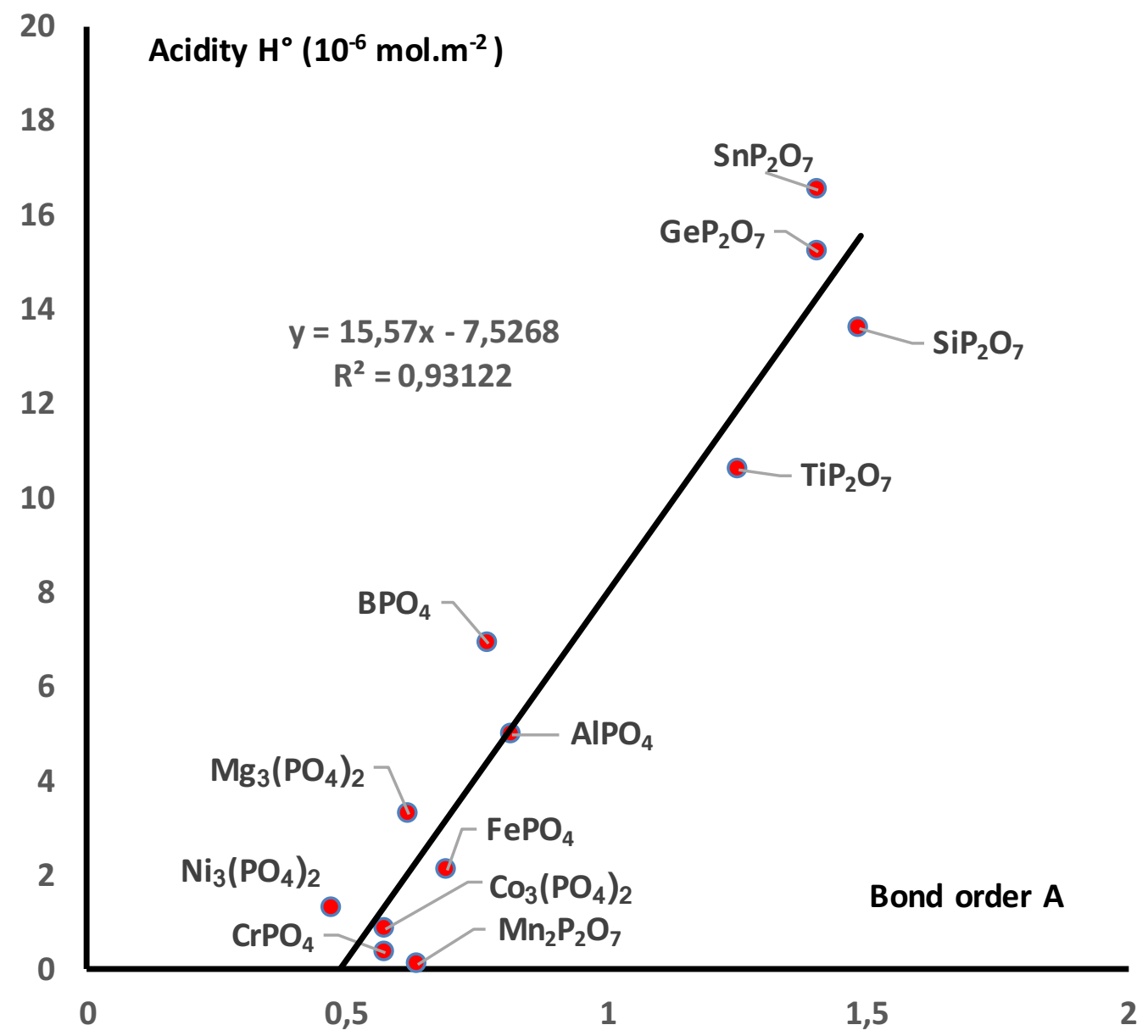

Figure 8: Plot showing the correlation obtained between experimental total acidity $H^{0}$ and calculated bond order A 


\section{Conclusions}

We have reported the catalytic properties towards oxidation of methane at $873 \mathrm{~K}$ of an ensemble of twelve unsupported phosphate catalysts of general formulae $\mathrm{M}_{3}^{\mathrm{II}}\left(\mathrm{PO}_{4}\right)_{2}, \mathrm{M}^{\mathrm{III}} \mathrm{PO}_{4}$, $\mathrm{M}_{2}^{\mathrm{II}} \mathrm{P}_{2} \mathrm{O}_{7}$, and $\mathrm{M}^{\mathrm{IV}} \mathrm{P}_{2} \mathrm{O}_{7}$, exhibiting a wide range of acidity.

Oxidation products collected from a simulated continuous stirred tank reactor based on a high recycle flow differential reactor, were formaldehyde $\mathrm{CH}_{2} \mathrm{O}, \mathrm{H}_{2} \mathrm{O}$, and the carbon oxides $\mathrm{CO}$ and $\mathrm{CO}_{2}$.

Selectivity towards $\mathrm{CH}_{2} \mathrm{O}$ is strongly correlated to the specific total acidity $H^{0}$, measured using Hammett indicators according to the Benesi method. The activity and selectivity patterns are shown to be accurately predicted thanks to a microkinetic model involving three descriptors to represent the catalysts: $H^{0}$, and the $\mathrm{M}-\mathrm{Oa}$ and P-Oa bond strengths $E_{M O a}$ and $E_{P O a}$, as computed by DFT according to the "Yin-Yang" method, where Oa is a bridging O atom between ions $\mathrm{M}$ and $\mathrm{P}$ in the perfect crystal unit-cell.

The activity of catalysts, except that of the four highly acidic $\mathrm{M}^{\mathrm{IV}} \mathrm{P}_{2} \mathrm{O}_{7}$ pyrophosphates, follow a volcano curve when plotted against the descriptors $E_{M O a}$ or $E_{P O a}$. Outlying pyrophosphates experimental activities however deviate from the model prediction by amounts strictly correlated to the corresponding $H^{0}$ values, suggesting they were affected by a deactivation phenomenon linked to their high acidities, e.g. irreversible coverage of surface $O$ vacancies $(Z$ sites) by unsaturated hydrocarbons products of acid-catalyzed side reactions.

Acidities $H^{0}$ are shown to be closely anticorrelated to P-Oa bond lengths, as measured in the bulk unit-cells of the corresponding cristallized phosphates. We interpret this finding in terms of Brönsted acid sites exclusively associated to surface P-Oa bonds, the surface density of the latter reflecting the nearly constant volumic density of $\mathrm{P}$ atoms across the set of phosphates considered. The extensive quantity $H^{0}$ can hence coincide with an intensive structural quantity. 
Being able to fit the plot of computed P-Oa bond energies versus P-Oa bond lengths with a Morse potential, we analyze the observed variation of P-Oa bond lengths in the set of phosphates studied in terms of compression or elongations relative to that in the free orthophosphate ion, the latter being characterized by a bond length close to the Morse potential minimum.

Further, we propose that the observed anticorrelation (Figure 1) is a manifestation of the Bond Order Conservation principle, since protons are expected to interact all the less with surface Oa atoms, as the latter are engaged in a P-Oa bond of higher order, more confining to their valence electrons.

We expect our findings will be useful in the quest of new catalysts allowing high productivities in valuable mild oxidation products of methane, providing computational and experimental descriptors in the broad family of phosphates.

Analogous concepts might apply for other families of catalysts like sulfates, nitrates, borates, aluminates and silicates. 


\section{ASSOCIATED CONTENT}

Supporting Information. One pdf file including four sections: SI-1: Catalysts characterization (X-Ray diffraction, BET areas, IR spectra of phosphate catalysts); SI-2 : Bench-Scale Catalysts testing equipment; SI-3 : Supplementary Tables; SI-4 : Kinetic Model; SI-5 : Molecular models of key surface intermediates along the catalytic pathways.

\section{Author Information}

\section{Corresponding Author:}

Hervé Toulhoat

Email: herve.toulhoat@orange.fr 


\section{References}

1. Otsuka, K; Wang, Y; Sunada, E.; Yamanaka, I. Direct Partial Oxidation of Methane to Synthesis Gas by Cerium Oxide. J. Catal., 1998, 175, 152-160.

2. Gomonaj, V.I.; Stadnik, P.M. The Role of the Vessel Surface in the Methane Oxidation reaction. Kinet. Catal., 1963, 4, 348-352 (in Russ.)

3. Gomonaj, V.I.; Jershow, B.M.; Stadnik, P.M. Heterogeneously Homogeneous Oxidation of Methane on Aluminosilicates. Catalysis and Catalysts, 1967, 3, 111 (in Russ.)

4. Gomonaj, V.I.; Kovach, I.J.; Vorozhilchak, O.I. Investigation of the Catalytic Properties of Aluminosilicates in the Methane Oxidation Reaction. Catalysis and Catalysts, 1974, 11, 56 (in Russ.)

5. Gomonaj, V.I.; Borko, V.A. Self-oscillations in the Heterogeneous Catalytic Reaction of Oxidation of Methane with Oxygen. Kinet. Catal., 1991, 32, 998 (in Russ.)

6. Gomonaj, V.I.; Kovach, I.J. Method for Obtaining Formaldehyde, 1974, Russ. Patent 438635

7. Gomonaj, V.I. Regularities in the Selection of Catalysts for the Selective Oxidation of Normal Alkanes, Catalysis and Catalysts, 1989, 26, 52 (in Russ.)

8. Borko, V.A.; Gomonaj, V.I.; Szekeresh, K. J. Relationship between Catalytic Properties and Surface Reducibility of Catalysts in the Partial Oxidation of Methane by Molecular Oxygen. React. Kinet. Catal. Lett., 1980, 14, 439 (in Russ.).

9. Gomonaj, V.I.; Borko, V.A.; Szekeresh, K.J.; Fogel, E. J. Regularities in the Formation of Oxygen-Containing Products and C2-Hydrocarbons from Methane on Acidic and Basic Catalysts. Solid Fuel Chem., 1993, 2, 57 (in Russ.) 
10. Bobrova, I.I.; Bobrov, N.N.; Simonova, L.G.; Parmon, V.N. Direct Catalytic Oxidation of Methane to Formaldehyde: New Investigation Opportunities Provided by an Improved Flow Circulation Method. Kinet. Catal., 2007, 48, 676-692.

11. Launay, H. Développement de Catalyseurs à Base d'Oxyde de Molybdène ou de Vanadium Supporté sur Silice pour l'Oxydation Ménagée du Méthane en Formaldéhyde. Thèse de Doctorat en Catalyse, Université Claude Bernard - Lyon I, 2005, HAL Id: tel00011544 ( In French.)

12. Nguyen, L.D.; Loridant, S.; Launay, H.; Pigamo, A.; J.L. Dubois, J.L.; Millet, J.M.M. Study of new catalysts based on vanadium oxide supported on mesoporous silica for the partial oxidation of methane to formaldehyde: Catalytic properties and reaction mechanism. J. Catal., 2006, 237, 38-48.

13. Launay, H.; Loridant, S.; Pigamo, A.; Dubois, J.L.; Millet, J.M.M. Vanadium species in new catalysts for the selective oxidation of methane to formaldehyde: Specificity and molecular structure dynamics with water. J. Catal., 2007, 246, 390-398.

14. Parmaliana, A.; Frusteri, F.; Mezzapica, A.; Scurrell, M.S.; Giordano, N. Novel High Activity Catalysts for Partial Oxidation of Methane to Formaldehyde. J. Chem. Soc., Chem. Commun., 1993, 751-753.

15. Nasser, H.; Rédey, Á.; Yuzhakova, T.; Kovács, J. In situ DRIFT study of nonoxidative methane reaction on $\mathrm{Mo} / \mathrm{SnO}_{2}$ catalyst. React. Kinet. Catal. Lett., 2008, 94, 165-173.

16. Sun, M.; Zhang, J.; Putaj, P.; Caps, V.; Lefebvre, F.; Pelletier, J.; Basset, J.M. Catalytic Oxidation of Light Alkanes (C1-C4) by Heteropoly Compounds. Chem. Rev., 2014, 114, 981-1019.

17. Toulhoat, H.; P. Raybaud, P. Kinetic interpretation of catalytic activity patterns based on theoretical chemical descriptors. J. Catal. 2003, 216, 63-72.

18. Benesi, H.A. Acidity of Catalyst Surfaces .I. Acid Strength From Colors of Adsorbed Indicators. J. Am. Chem. Soc. 1956, 78, 5490-5494. 
19. Benesi, H.A. Acidity of catalyst surfaces. II. Amine titration using Hammett indicators. $J$. Phys. Chem. 1957, 61, 970-973.

20. Gomonaj, V.I.; Golub, N.P.; Barenblat, K.J.; Chernjavska, T.V. Physicochemical and catalytic properties of the phosphate system Co-Ni. Catalysis and Petrochemistry, 2008, 16, 65 (in Russ.)

21. MedeA: Materials Exploration and Design Analysis software from Materials Design Inc. (http://www.materialsdesign.com/)

22. Pearson's Crystal Structure Database is maintained an published by the American society of Metals http://www.asminternational.org/), and implemented uder license by Materials Design Inc. to be searchable through the InfoMaticA module of the MedeA software. Similarly, the Inorganic Crystal Structure Database ICSD is maintained by the Fachinformtionzentrum Karlsruhe (FIZ) (http://fiz-karlsruhe.de/) and available through InfoMaticA

23. Kresse, G.; Furthmüller, Efficient iterative schemes for ab initio total-energy calculations using a plane-wave basis set. Phys. Rev. B 1996, 54, 11169-11186.

24. Perdew, J.P.; Burke, K.; Ernzerhof, M. Generalized Gradient Approximation Made Simple. Phys. Rev. Lett. 1996, 77, 3865-3868.

25. Predibond 1.0 module, inside MedeA, H. Toulhoat, French Patent Application 00/07473, June 9, 2000.

26. Durand, B.; Paris, J.M.; Poix, P. Elaboration du pyrophosphate de manganèse par réaction de double décomposition. C. R. Seances Acad. Sci., Ser. C 1975, 1966, 1007-1009 (in French).

27. Attfield, J.P.; Battle, P.D.; Cheetham, A.K. The spiral magnetic structure of $\beta$ chromium(III) orthophosphate ( $\left.\beta-\mathrm{CrPO}_{4}\right)$. J. Solid State Chem., 1985, 57, 357-361. 
28. Nord, A.G.; Stefanidis, T. The cation distribution in two $(\mathrm{Co}, \mathrm{Mg})_{3}\left(\mathrm{PO}_{4}\right)_{2}$ solid solutions. Z. Kristallogr. 1980, 153, 141-149.

29. Escobal, J.; Pizarro, J.L.; Mesa, J.L.; Rojo, J.M.; Bazan, B.; Arriortua, M.I.; Rojo T., Neutron diffraction, specific heat and magnetic susceptibility of $\mathrm{Ni}_{3}\left(\mathrm{PO}_{4}\right)_{2}$. J. Solid State Chem. 2005, 178, 2626-2634.

30. Haines, J.; Cambon, O.; Hull, S. A neutron diffraction study of quartz-type $\mathrm{FePO}_{4}$ : hightemperature behavior and $\alpha-\beta$ phase transition. Z. Kristallogr. 2003, 218, 193-200.

31. Nord, A.G.; Kierkegaard, P. The crystal structure of $\mathrm{Mg}_{3}\left(\mathrm{PO}_{4}\right)_{2}$. Acta Chem. Scand. 1968, $22,1466-1474$.

32. Ng, H.N.; C. Calvo, C. X-ray study of the $\alpha-\beta$ transformation of berlinite $\left(\mathrm{AlPO}_{4}\right)$. Can. J. Phys. 1976, 54, 638-647.

33. Achary, S.N.; Tyagi, A.K. Strong anisotropic thermal expansion in cristobalite-type BPO4. J. Solid State Chem. 2004, 177, 3918-3926.

34. Levi, G.R.; Peyronel, G. Struttura Cristallographica del Gruppo Isomorpho (Si,Ti,Zr,Sn,Hf) $\mathrm{P}_{2} \mathrm{O}_{7}$. Z. Kristallogr., Kristallgeom., Kristallphys., Kristallchem. 1935, 92, 190-209.

35. Tillmanns, E.; Gebert, W.; Baur, W.H. Computer simulation of crystal structures applied to the solution of the superstructure of cubic silicondiphosphate. J. Solid State Chem. $1973,7,69-84$.

36. R. W. G. Wyckoff, The Structure of Crystals, Interscience Publishers 1951; Vol 3, p 429.

37. Gomonaj, V.I.; Golub, N.P.; Barenblat, I.A.; Sekeresh, K.J. Aluminosilicates - selective catalysts for the oxidation of n-alkanes. Ukrainian Chemical Magazine, 2008, 72, 47 (in Russ.)

38. Eyring, H. The Activated Complex in Chemical Reactions. J. Chem. Phys., 1935, 3, 107115.

39. Shustorovich, E.M. Chemisorption phenomena: Analytic modeling based on perturbation theory and bond-order conservation. Surf. Sci. Rep. 1986, 6, 1-63. 
40. van Santen, R.A. On Shustorovich's Bond-Order conservation method as applied to chemisorption. Recl. Trav. Chim. Pays-Bas 1990, 109, 59-63.

41. Ramis, G.; Busca, G.; Lorenzelli, V.; La Ginestra, A.; Galli, P.; Massucci, M.A. Surface Acidity of the Layered Pyrophosphates of Quadrivalent Ti, Zr, Ge, and Sn and Their Activity in Some Acid-catalysed Reactions. J. Chem. Soc., Dalton Trans. 1988, 0, 881886. 
Table of Contents Graphic

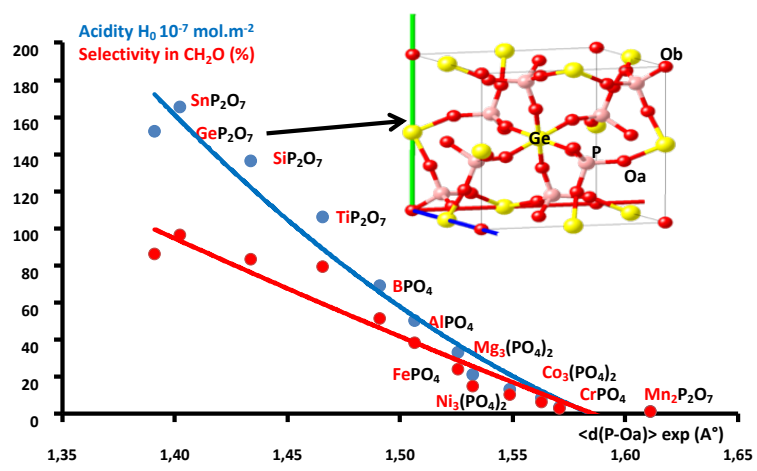




\section{Supporting Information}

\section{Selective Oxidation of Methane to Formaldehyde Catalyzed}

\section{by Phosphates: Kinetic Description by Bond strengths and}

\section{Specific Total Acidities.}

Vasilij Gomonaj' and Hervé Toulhoat ${ }^{*}$ *

${ }^{1}$ National University of Uzhgorod, Department of Physical and Colloid Chemistry, Pidhirna Street, 46, Uzhgorod 380, Ukraine

${ }^{2}$ IFP Energies nouvelles, 1 \& 4 avenue de Bois-Préau, 92852 Rueil-Malmaison, France, and Sorbonne Universités, UPMC Univ Paris 06, UMR CNRS 7197, Laboratoire de Réactivité de Surface, Tour 43-33, 3ème étage, Case 178, 4 Place Jussieu, F-75252, Paris, France

Corresponding Author:

Hervé Toulhoat

Tel. +33672766554

Email: herve.toulhoat@orange.fr 


\section{SI-1 - Catalysts characterization}

\section{$\underline{\text { X-Ray diffraction }}$}

For catalysts $\mathrm{Mn}_{2} \mathrm{P}_{2} \mathrm{O}_{7}, \mathrm{CrPO}_{4}, \mathrm{Co}_{3}\left(\mathrm{PO}_{4}\right)_{2}, \mathrm{Ni}_{3}\left(\mathrm{PO}_{4}\right)_{2}, \mathrm{FePO}_{4}, \mathrm{AlPO}_{4}, \mathrm{BPO}_{4}, \mathrm{SiP}_{2} \mathrm{O}_{7}, \mathrm{Powder}$ diffraction spectra were recorded in the $2 \theta=20-50^{\circ}$ Bragg angle interval thanks to an automated DRON-UM1 diffractometer equipped with a Cobalt anticathode and an iron filter. Inter-reticular distances $d_{i}$ were computed according to the Wulff-Bragg formula $n \lambda=$ $2 d_{i} \sin \theta_{i}$ with $\lambda m=1,7909 \AA$ the $\mathrm{Co} \mathrm{K \alpha}$ incident radiation wavelength. For catalysts $\mathrm{TiP}_{2} \mathrm{O}_{7}$, $\mathrm{GeP}_{2} \mathrm{O}_{7}, \mathrm{SnP}_{2} \mathrm{O}_{7}$, and $\mathrm{Mg}_{3}\left(\mathrm{PO}_{4}\right)_{2}$ powder diffraction spectra were recorded in the $2 \theta=10-60^{\circ}$ Bragg angle interval using a more recent diffractometer equipped with a Copper anticathode $(\lambda m=1,5418 \AA)$. The diffraction peaks intensities were normalized between 0 and 100 arbitrary units.

The powder diffraction spectra were recorded on all phosphate samples firstly after drying the freshly prepared precipitates at $393 \mathrm{~K}$, and secondly after calcination at $973 \mathrm{~K}$. Dried samples exhibited very diffuse diffraction lines, indicative of poorly crystallized or amorphous solids, while calcined phosphates exhibited thin lines with well-defined peak positions, indicative of well crystallized solids. The corresponding crystal structures were determined by comparison with tabulated reference spectra and moreover with simulated spectra as presented below. Simulations were performed thanks to the VESTA program (1) on the basis of the published reference structures as cited in the main text.

Importantly, all used catalysts were again characterized, showing no change with respect to the freshly calcined solids.

We present hereafter for each phosphate catalyst representative of a particular structure (i.e. space group): 1) experimental X Ray diffraction patterns; 2) simulated diffractions patterns for the matching reference structure; 3 ) a list of experimental and calculated reticular distances and the corresponding relative intensities for the main diffraction peaks; 4) the corresponding correlation diagrams between distances, with the regression line (dotted line, with equation and squared coefficient of correlation in inset). 
$\mathrm{Mn}_{2} \mathrm{P}_{2} \mathrm{O}_{7} \mathrm{C} 2 / \mathrm{m}$
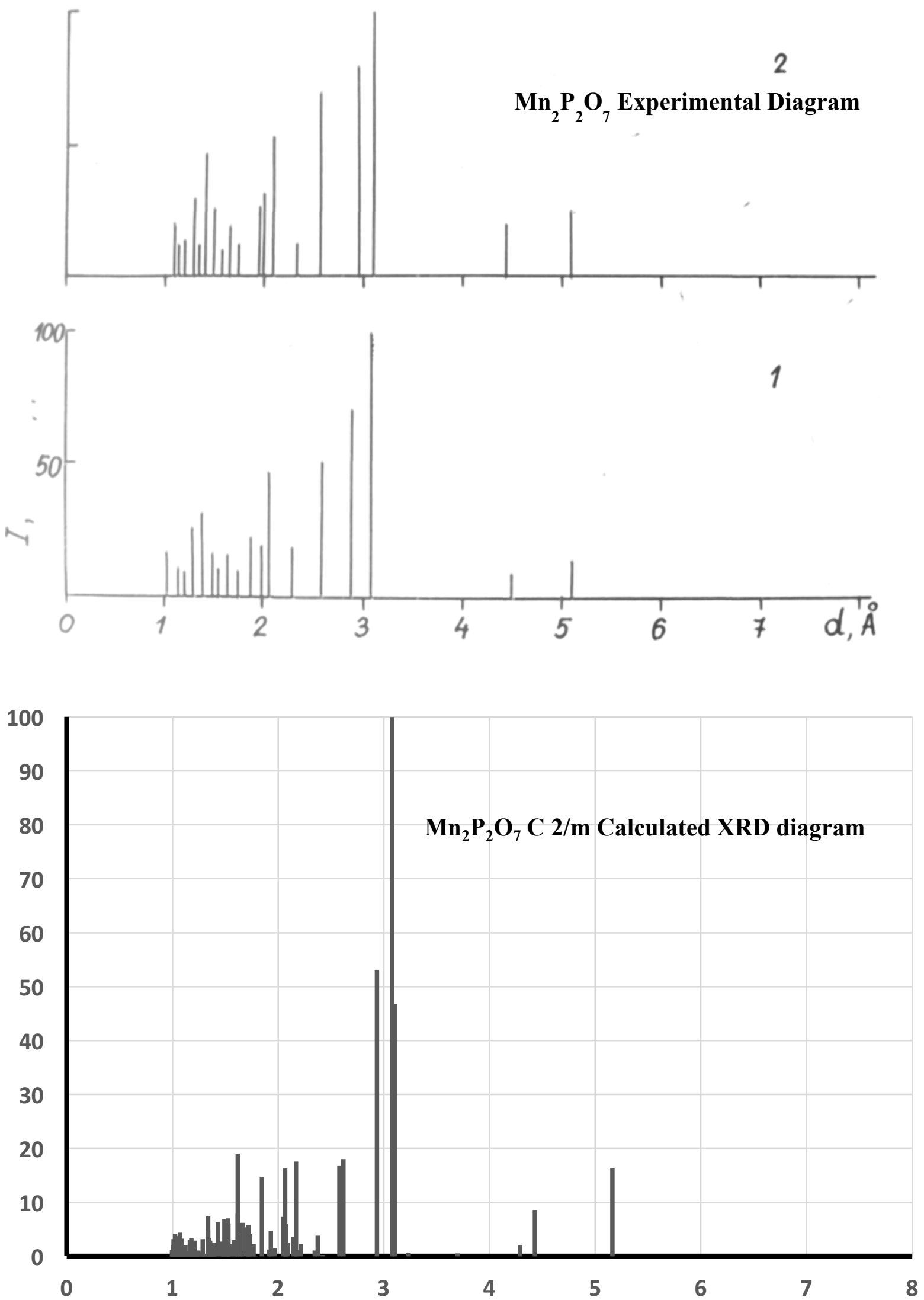

$\mathrm{Mn}_{2} \mathrm{P}_{2} \mathrm{O}_{7}$

Main lines 


\begin{tabular}{ccrr}
$\operatorname{Exp} d\left(A^{\circ}\right)$ & $\operatorname{exp~I}$ & Calc d $\left(A^{\circ}\right)$ & Calc I \\
\hline 5,2 & 8 & 5,16 & 16 \\
4,45 & 6 & 4,43 & 9 \\
3,1 & 100 & 3,08 & 100 \\
2,95 & 50 & 2,94 & 53 \\
2,6 & 20 & 2,62 & 18 \\
2,37 & 1 & 2,37 & 4 \\
2,17 & 18 & 2,17 & 18 \\
2,07 & 18 & 2,07 & 16 \\
1,85 & 10 & 1,85 & 15
\end{tabular}

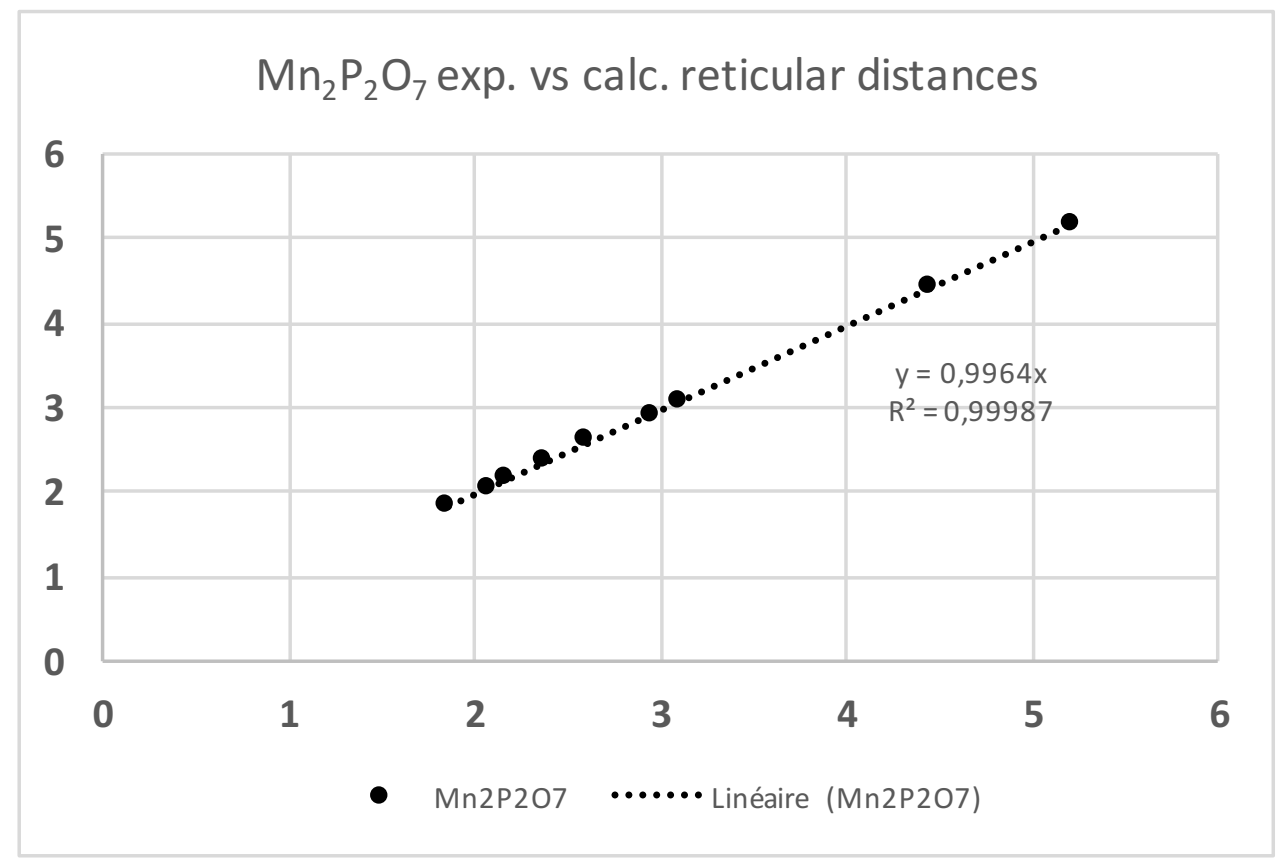




\section{$\mathrm{CrPO}_{4} \mathrm{Cmcm}$ Experimental XRD diagram}
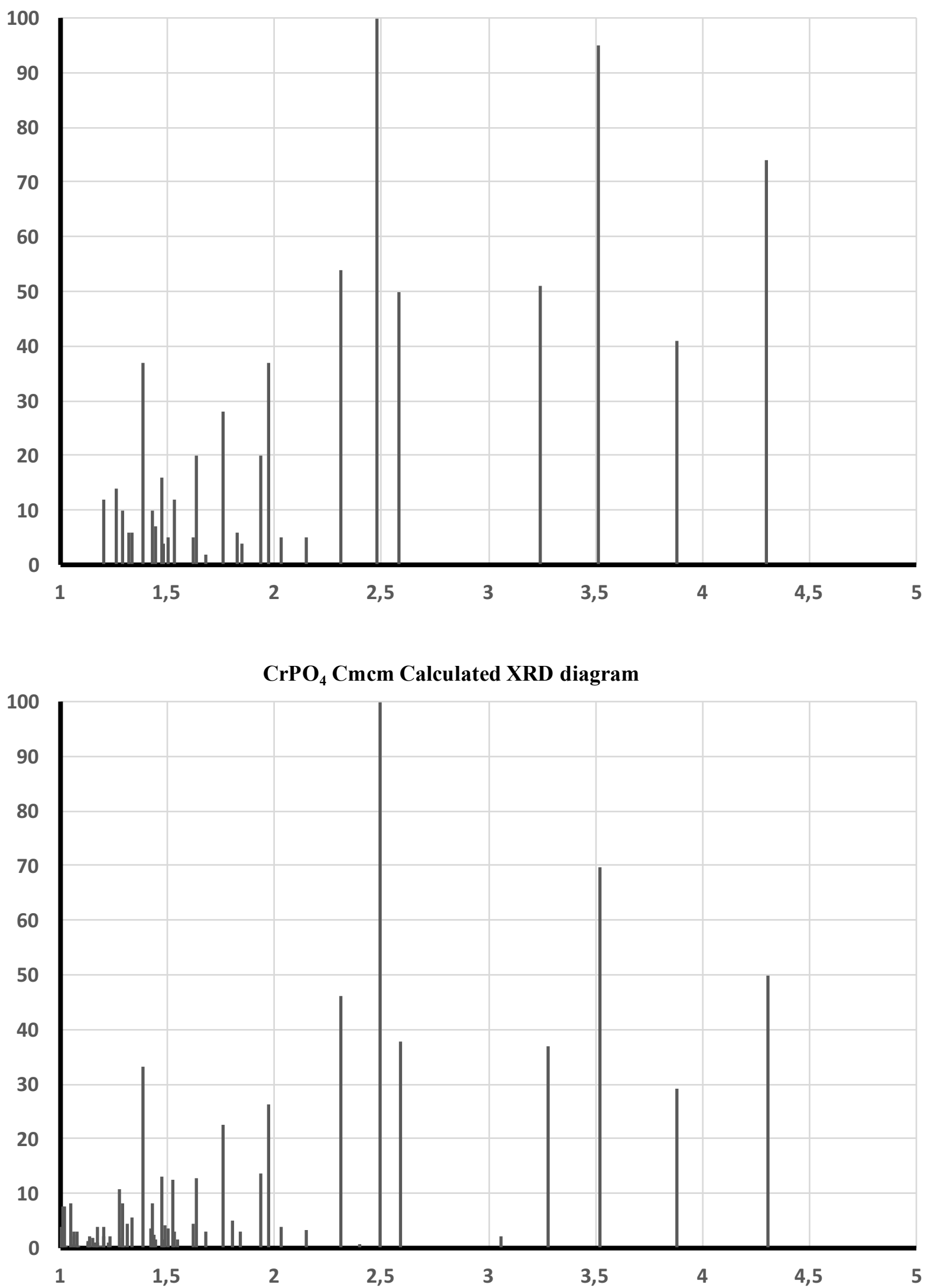
$\mathrm{CrPO}_{4}$ Main lines

\begin{tabular}{|c|c|c|c|}
\hline $\operatorname{Exp} d\left(A^{\circ}\right)$ & exp. I & Calc. d $\left(A^{\circ}\right)$ & Calc. I \\
\hline 4,30 & 74 & 4,30 & 50 \\
\hline 3,88 & 41 & 3,88 & 29 \\
\hline 3,51 & 95 & 3,52 & 70 \\
\hline 3,24 & 51 & 3,28 & 37 \\
\hline 2,58 & 50 & 2,59 & 38 \\
\hline 2,48 & 100 & 2,49 & 100 \\
\hline 2,31 & 54 & 2,31 & 46 \\
\hline 2,15 & 5 & 2,15 & 3 \\
\hline 2,03 & 5 & 2,03 & 4 \\
\hline 1,975 & 37 & 1,97 & 26 \\
\hline 1,938 & 20 & 1,94 & 14 \\
\hline 1,845 & 4 & 1,85 & 0 \\
\hline 1,828 & 6 & 1,84 & 3 \\
\hline 1,76 & 28 & 1,76 & 23 \\
\hline 1,681 & 2 & 1,68 & 3 \\
\hline 1,637 & 20 & 1,64 & 13 \\
\hline 1,621 & 5 & 1,62 & 5 \\
\hline 1,531 & 12 & 1,53 & 13 \\
\hline 1,502 & 5 & 1,50 & 4 \\
\hline 1,484 & 4 & 1,49 & 4 \\
\hline 1,473 & 16 & 1,47 & 13 \\
\hline 1,443 & 7 & 1,44 & 3 \\
\hline 1,433 & 10 & 1,43 & 8 \\
\hline 1,383 & 37 & 1,38 & 33 \\
\hline 1,337 & 6 & 1,34 & 6 \\
\hline 1,319 & 6 & 1,32 & 4 \\
\hline 1,29 & 10 & 1,29 & 8 \\
\hline 1,26 & 14 & 1,28 & 11 \\
\hline 1,202 & 12 & 1,20 & 4 \\
\hline
\end{tabular}




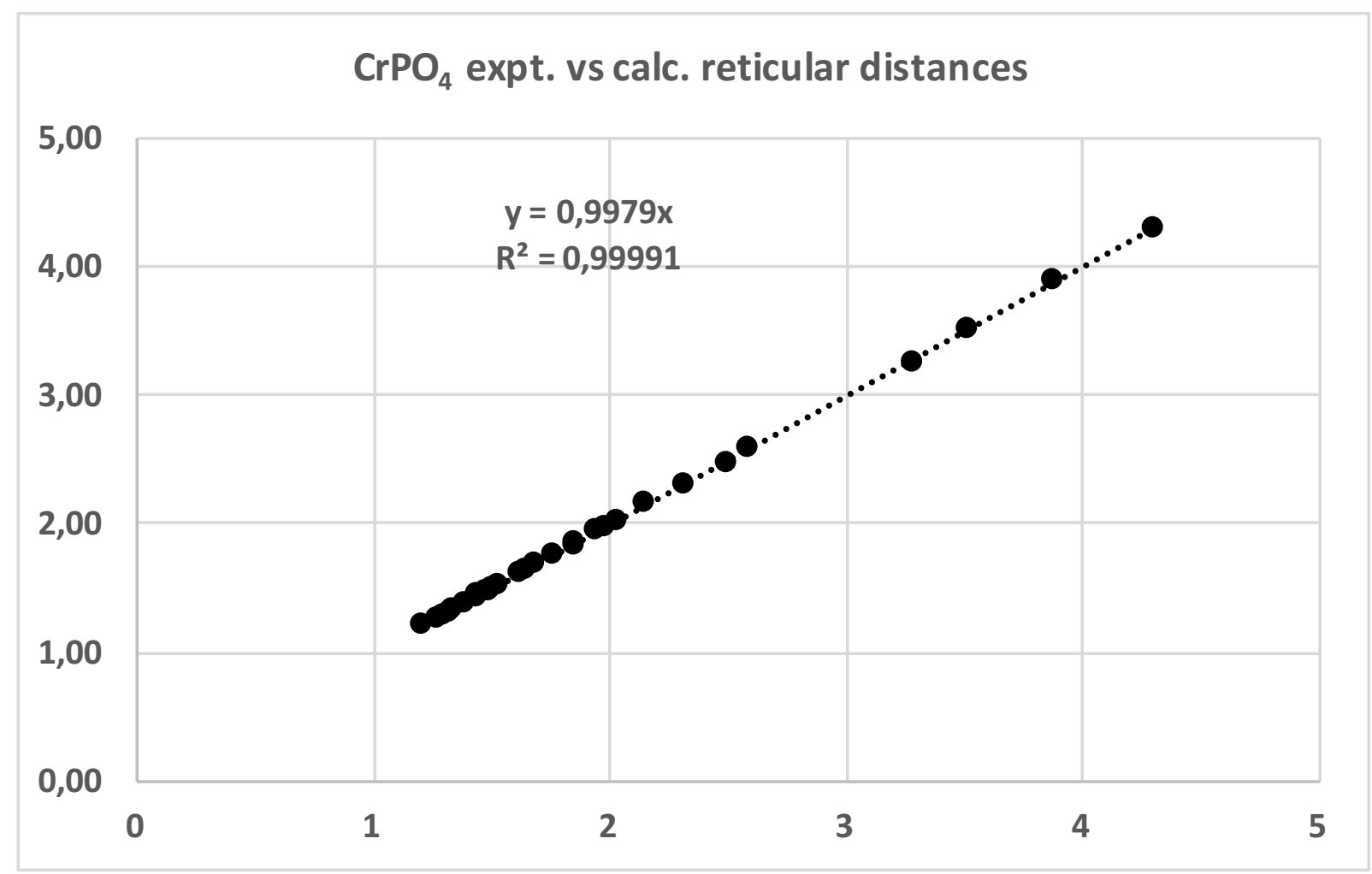


$\mathrm{Co}_{3}\left(\mathrm{PO}_{4}\right)_{2} \mathrm{P}-1$
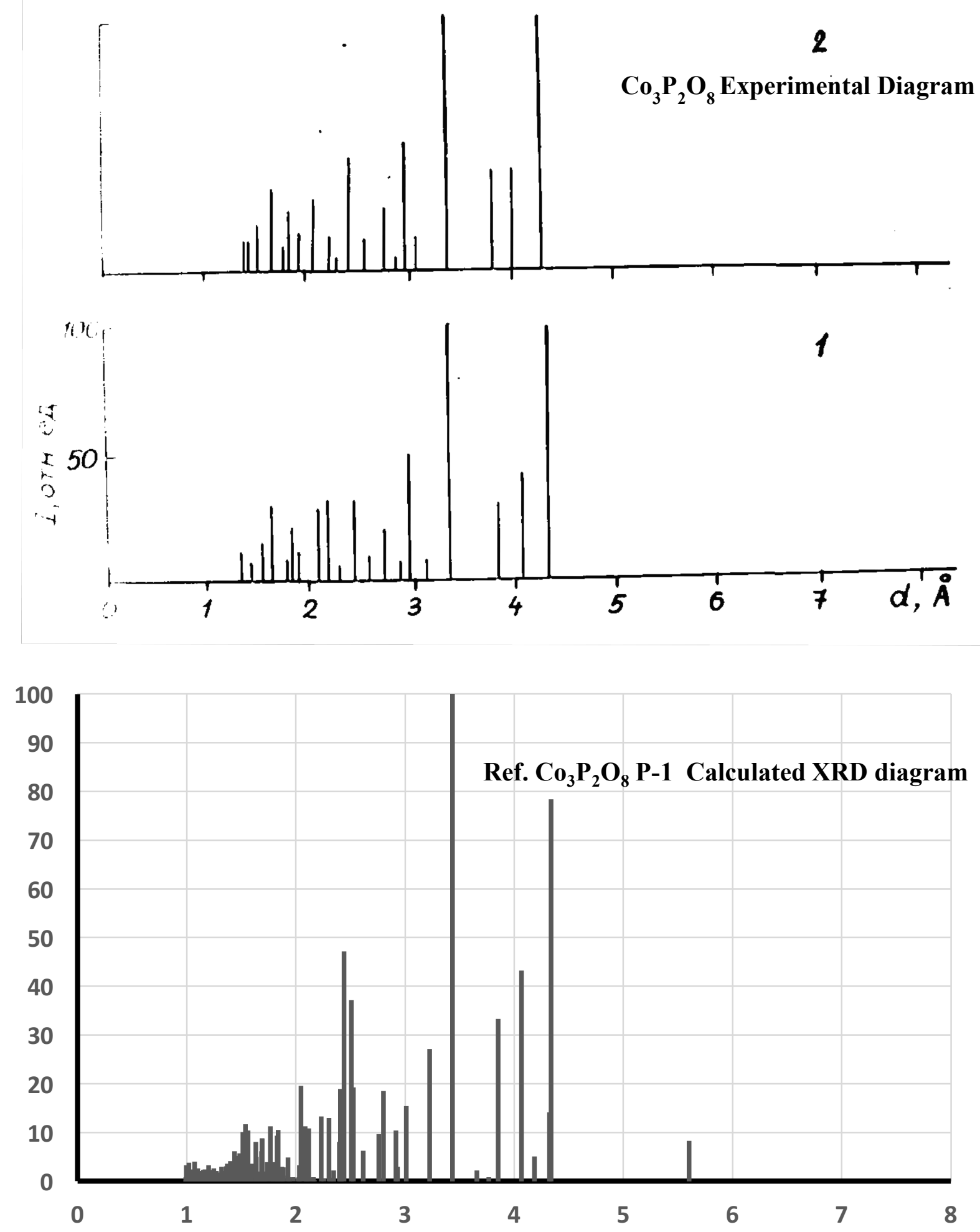
$\mathrm{CO}_{3}\left(\mathrm{PO}_{4}\right)_{2}$ Main Lines

\begin{tabular}{|c|c|c|c|}
\hline $\operatorname{Exp} d\left(A^{\circ}\right)$ & $\exp 1$ & Calc d $\left(\mathrm{A}^{\circ}\right)$ & Calc I \\
\hline 4,33 & 100 & 4,34 & 78 \\
\hline 4,09 & 30 & 4,07 & 43 \\
\hline 3,85 & 30 & 3,85 & 33 \\
\hline 3,44 & 100 & 3,44 & 100 \\
\hline 3,21 & 23 & 3,22 & 27 \\
\hline 3 & 13 & 3,01 & 15 \\
\hline 2,9 & 3 & 2,93 & 3 \\
\hline 2,78 & 20 & 2,80 & 18 \\
\hline 2,6 & 7 & 2,62 & 6 \\
\hline 2,51 & 33 & 2,51 & 37 \\
\hline 2,48 & 50 & 2,44 & 47 \\
\hline 2,3 & 3 & 2,30 & 13 \\
\hline 2,23 & 7 & 2,23 & 13 \\
\hline 2,1 & 2 & 2,10 & 2 \\
\hline 2,03 & 10 & 2,05 & 20 \\
\hline 1,93 & 7 & 1,93 & 5 \\
\hline 1,87 & 3 & 1,87 & 3 \\
\hline 1,83 & 13 & 1,84 & 11 \\
\hline 1,74 & 7 & 1,77 & 11 \\
\hline 1,69 & 17 & 1,69 & 24 \\
\hline 1,63 & 10 & 1,63 & 13 \\
\hline 1,59 & 3 & 1,59 & 2 \\
\hline 1,56 & 10 & 1,56 & 10 \\
\hline 1,54 & 10 & 1,54 & 12 \\
\hline 1,51 & 7 & 1,51 & 10 \\
\hline 1,48 & 7 & 1,48 & 6 \\
\hline 1,45 & 10 & 1,45 & 10 \\
\hline 1,39 & 7 & 1,39 & 7 \\
\hline 1,37 & 7 & 1,37 & 7 \\
\hline
\end{tabular}




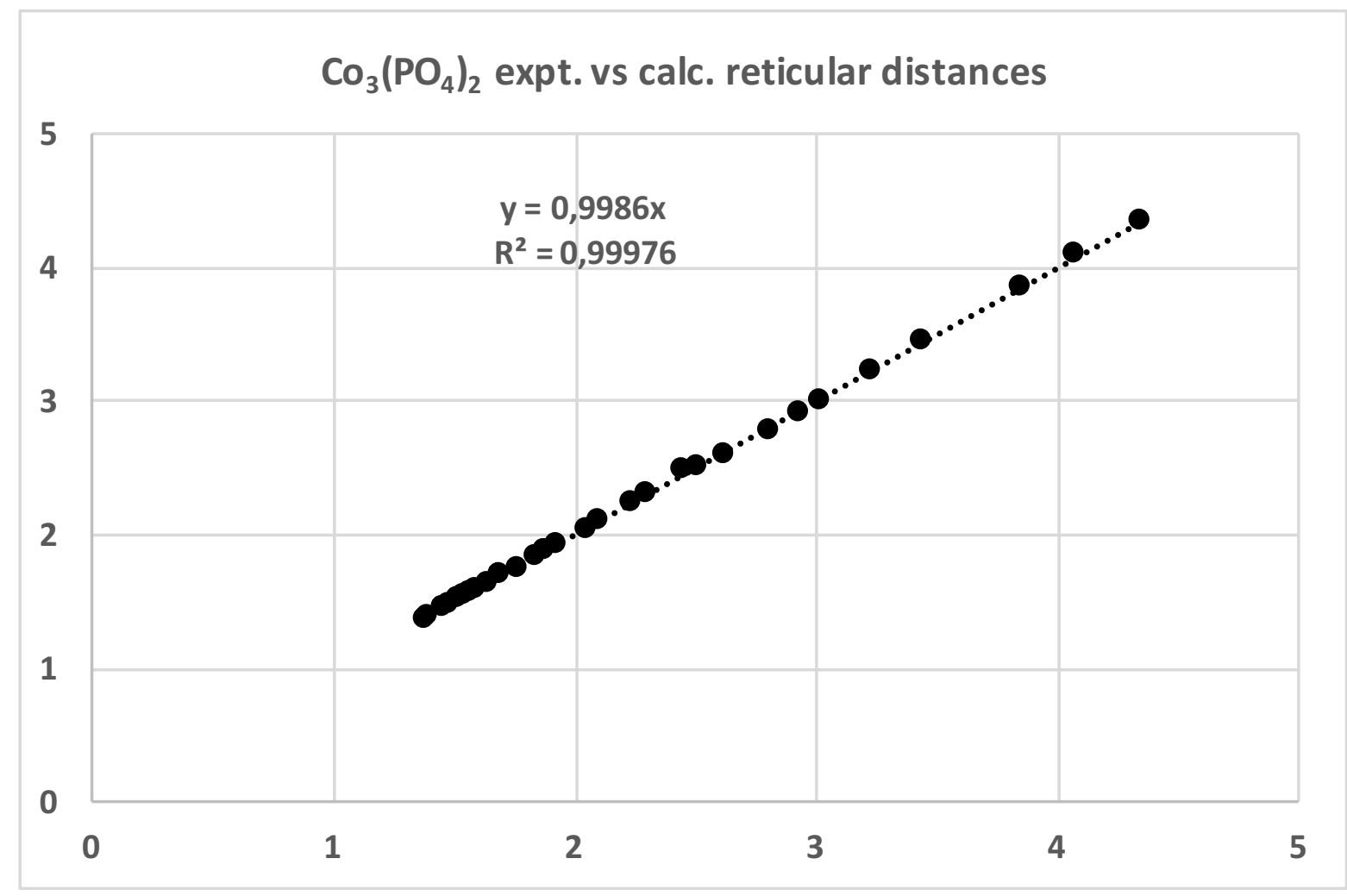



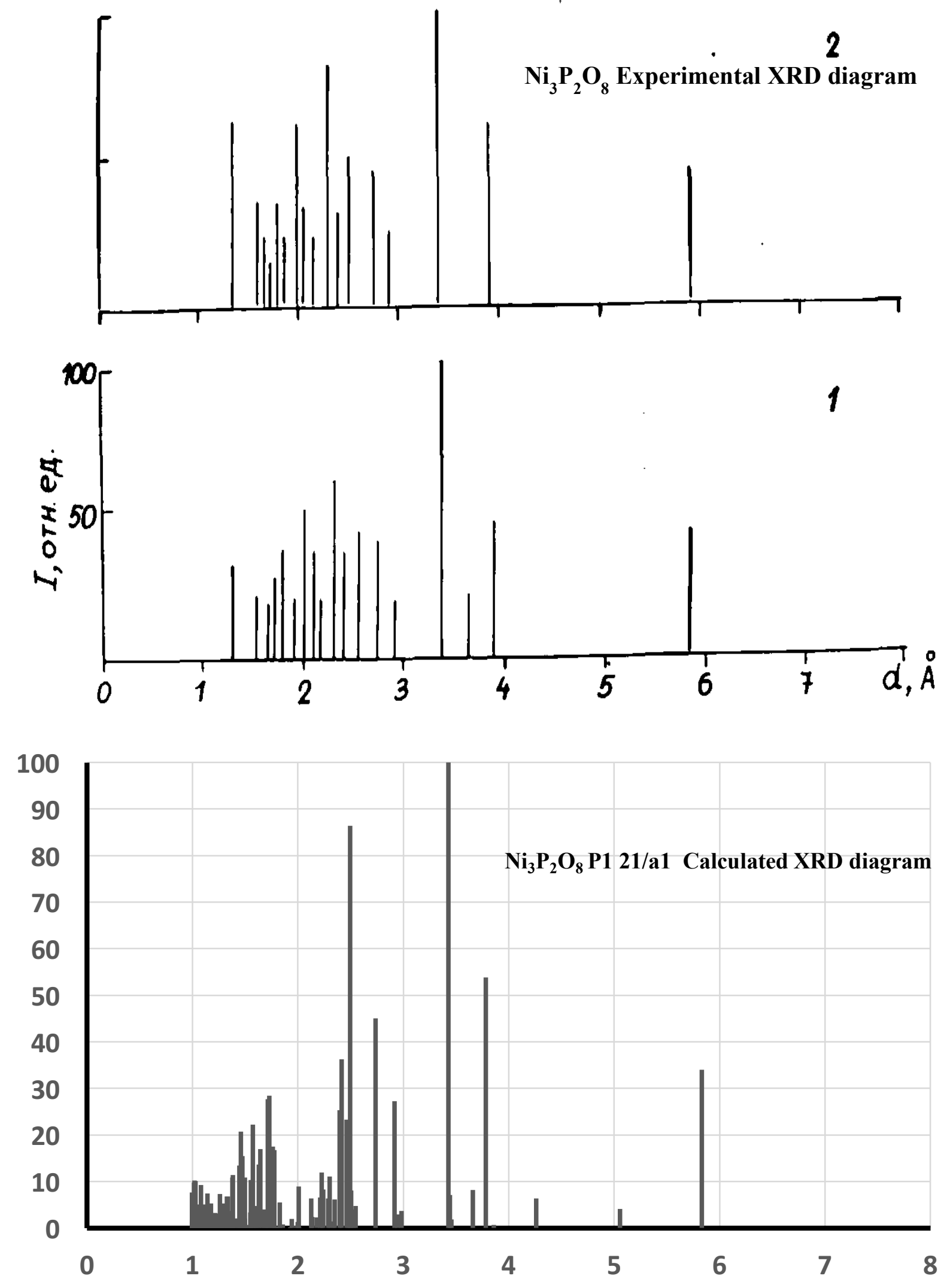
$\mathrm{Ni}_{3} \mathrm{P}_{2} \mathrm{O}_{8}$ Main lines

$\operatorname{Exp} d\left(A^{\circ}\right)$ $\begin{array}{rrrr}\exp 1 & \text { Calc d }\left(A^{\circ}\right) & \text { Calc I } & \\ 45 & 5,83 & 34\end{array}$

$\begin{array}{rrrr}5,82 & 45 & 5,83 & 34 \\ 3,81 & 63 & 3,78 & 54 \\ 3,56 & 22 & 3,66 & 8 \\ 3,34 & 100 & 3,43 & 100 \\ 2,82 & 24 & 2,91 & 27 \\ 2,68 & 46 & 2,74 & 45 \\ 2,45 & 51 & 2,49 & 86 \\ 2,30 & 33 & 2,30 & 11 \\ 2,24 & 83 & 2,23 & 12\end{array}$

$\mathrm{Ni}_{3} \mathrm{P}_{2} \mathrm{O}_{8}$ expt. vs calc. reticular distances

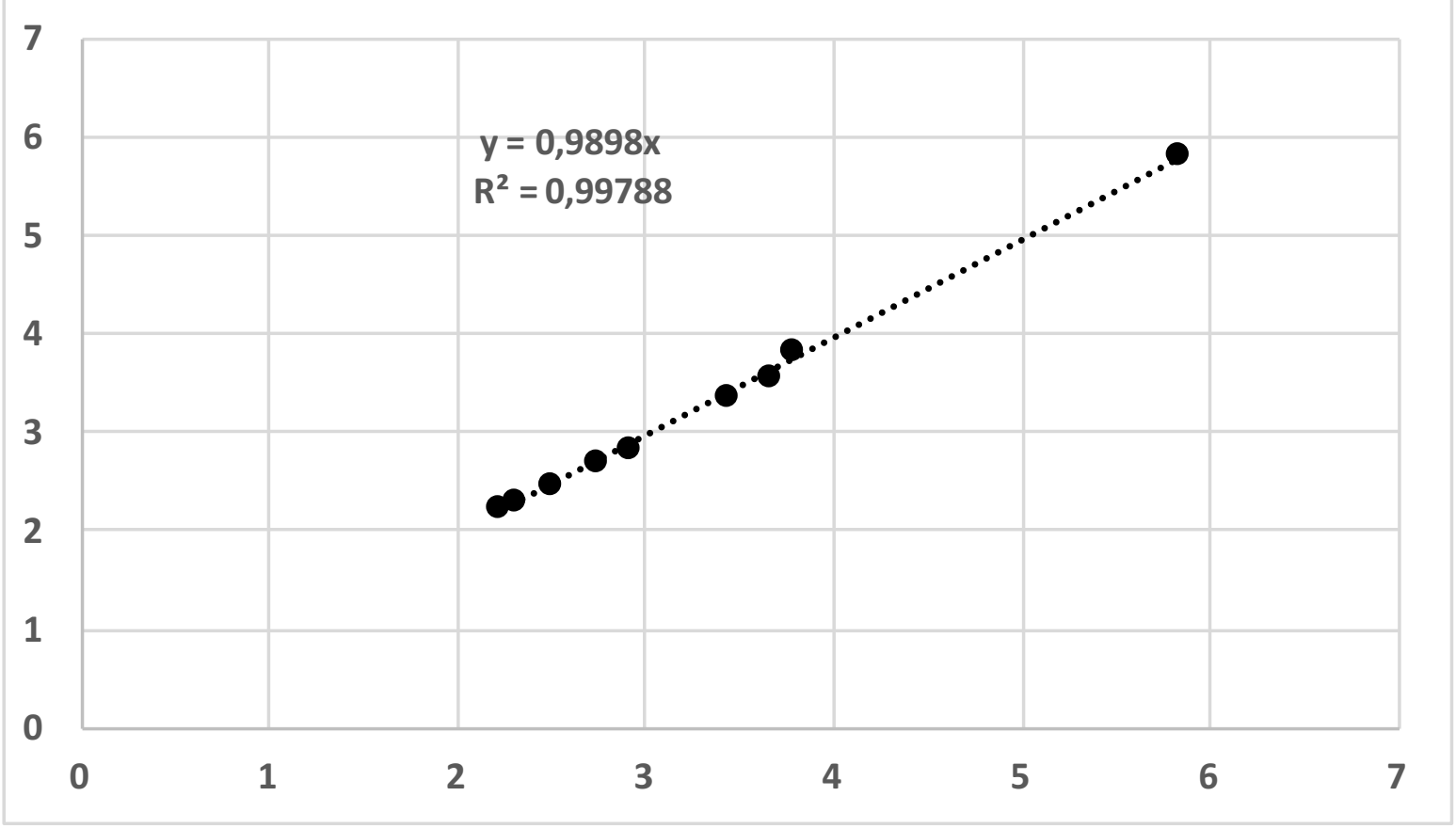


$\mathrm{FePO}_{4} \mathrm{P}_{3121}$
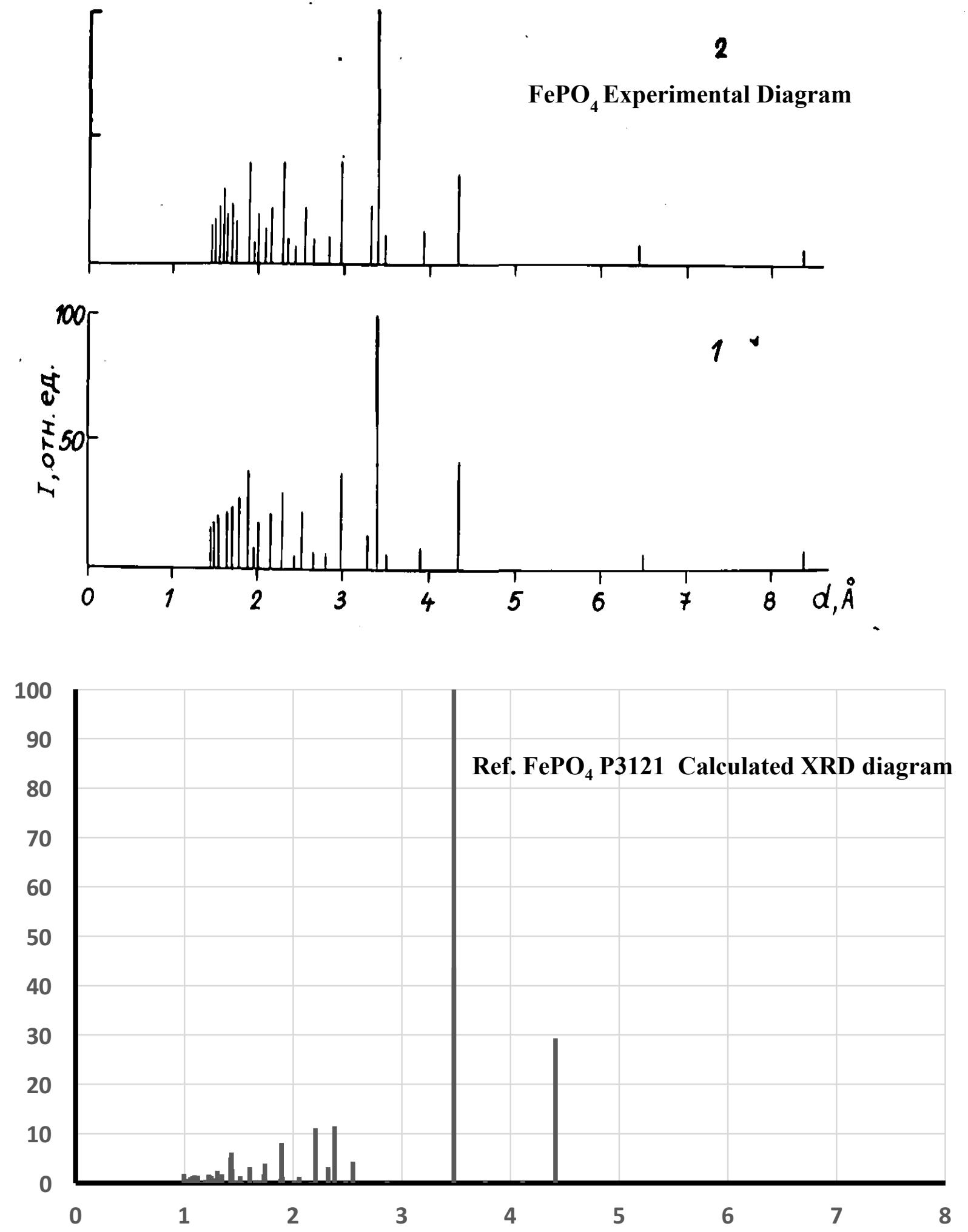
$\mathrm{FePO}_{4}$ Main lines

\begin{tabular}{rrrrr}
$\operatorname{Exp} d\left(A^{\circ}\right)$ & & $\exp I$ & Calc d $\left(A^{\circ}\right)$ & Calc I \\
\hline 4,31 & 45 & 4,42 & 29,3 \\
3,85 & 9,6 & 3,77 & 0,6 \\
3,49 & 6,2 & 3,48 & 43,6 \\
3,35 & 100 & 3,48 & 100,0 \\
2,95 & 41,4 & 2,87 & 0,5 \\
1,905 & 36 & 1,89 & 16,0
\end{tabular}

$\mathrm{FePO}_{4}$ expt. vs calc. reticular distances

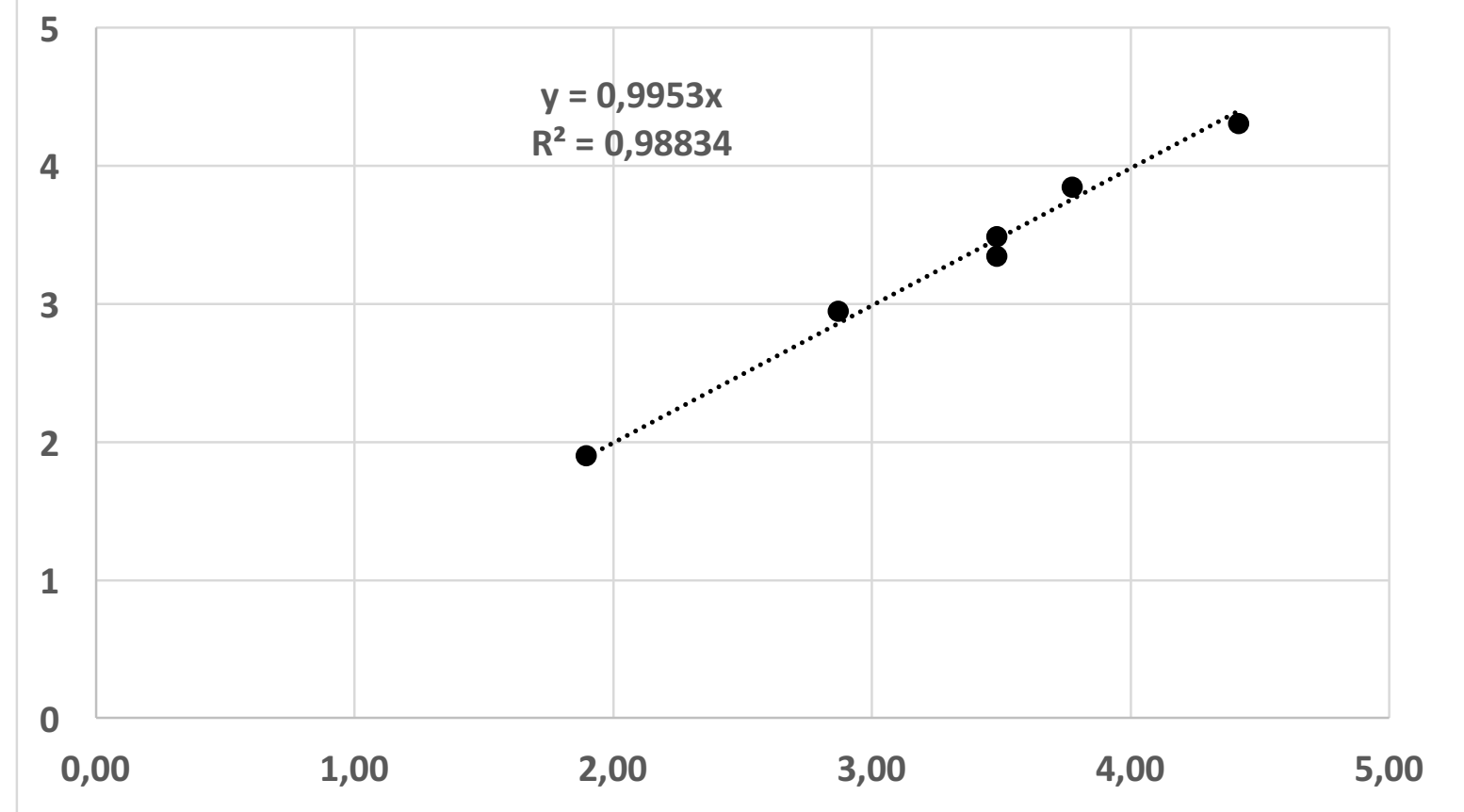


$\mathrm{Mg}_{3}\left(\mathrm{PO}_{4}\right)_{2} \quad \mathrm{P2} \_1 / \mathrm{c}$
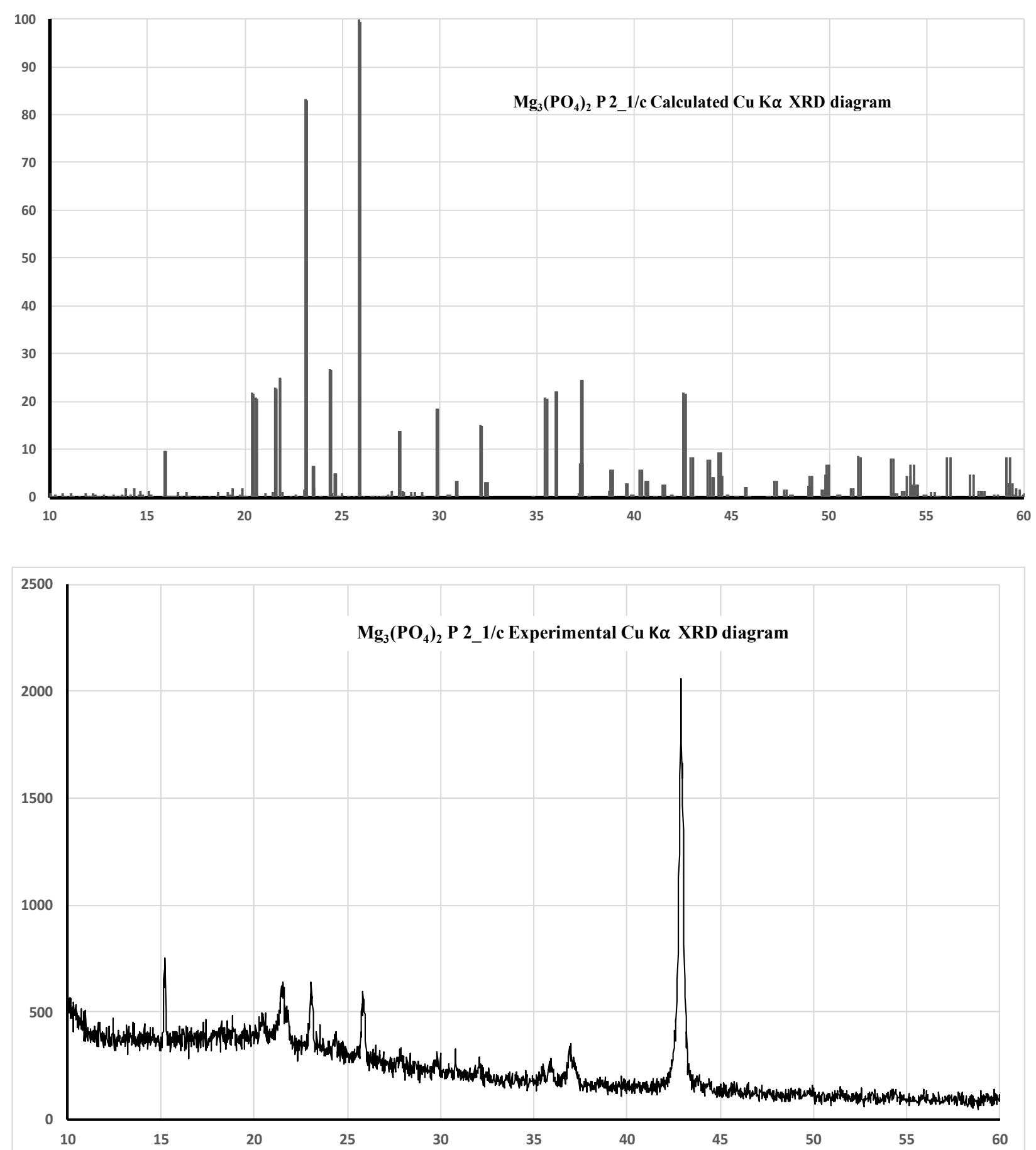
$\mathrm{Mg}_{3}\left(\mathrm{PO}_{4}\right)_{2}$ Main lines

\begin{tabular}{rrrrr}
$\operatorname{Exp} d\left(A^{\circ}\right)$ & & exp. I & Calc. d $\left(A^{\circ}\right)$ & Calc. I \\
\hline 5,82 & 20 & 5,58 & 10 \\
4,37 & 5 & 4,36 & 22 \\
4,14 & 12 & 4,12 & 23 \\
4,10 & 8 & 4,08 & 25 \\
3,86 & 17 & 3,84 & 83 \\
3,45 & 17 & 3,44 & 100 \\
2,43 & 10 & 2,42 & 25 \\
2,11 & 100 & 2,13 & 22
\end{tabular}

$\mathrm{Mg}_{3}\left(\mathrm{PO}_{4}\right)_{2}$ expt. vs calc. reticular distances

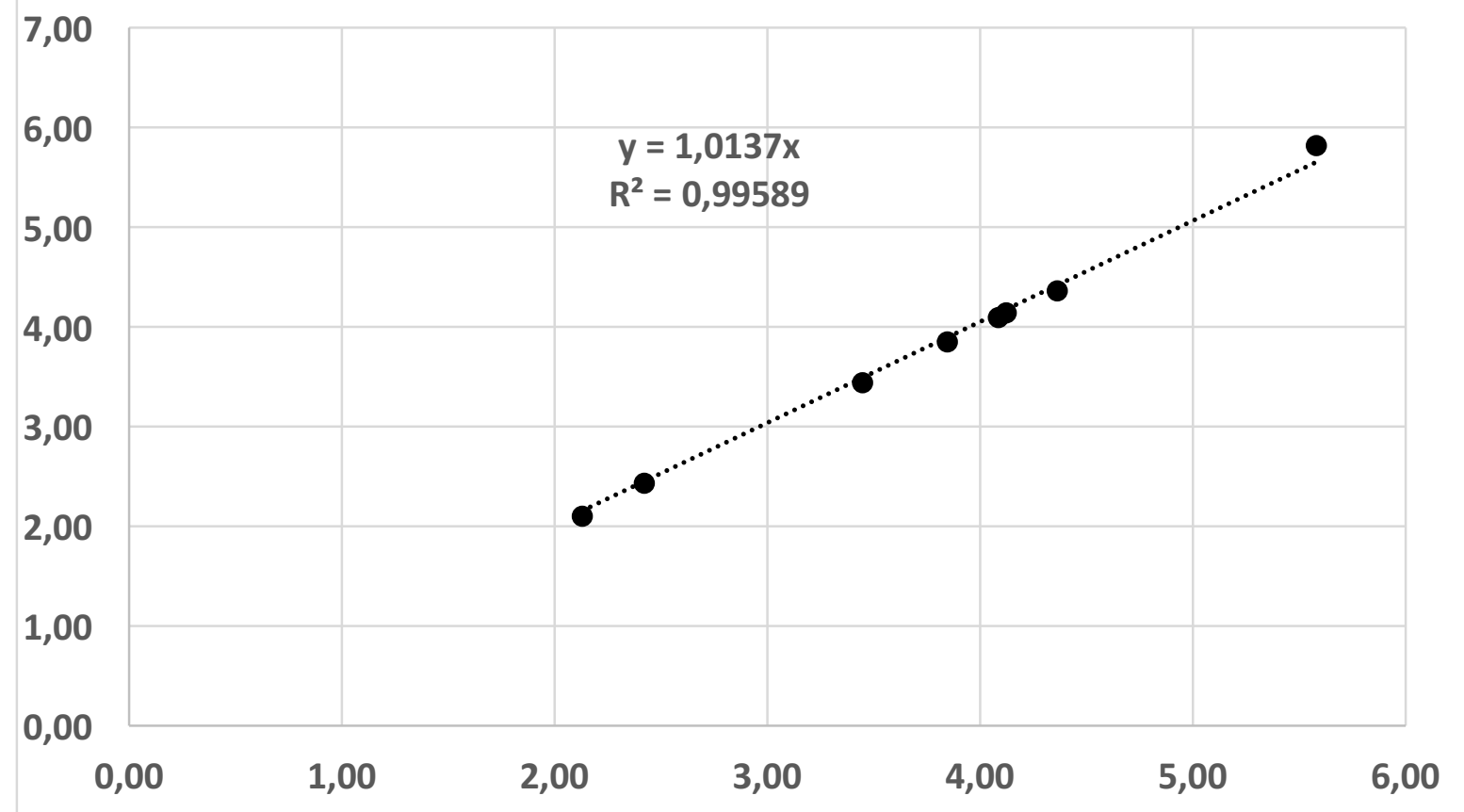


$\mathrm{AlPO}_{4} \mathrm{P} 3221$
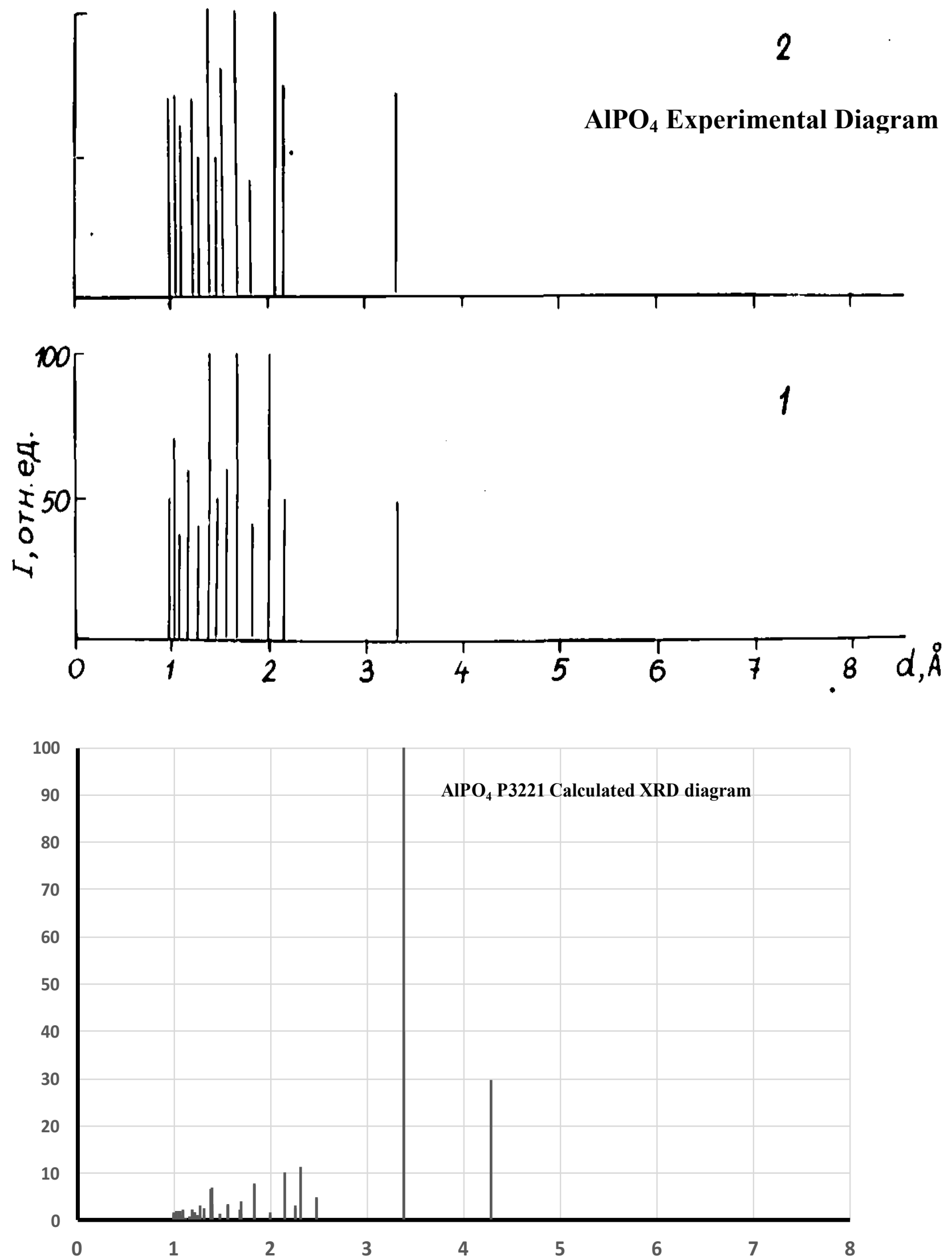
$\mathrm{AlPO}_{4}$ Main lines

\begin{tabular}{rrrrr}
$\operatorname{Exp} d\left(A^{\circ}\right)$ & & exp. I & Calc. d $\left(A^{\circ}\right)$ & Calc. I \\
\hline 3,34 & 72 & 3,37 & 100 \\
2,15 & 76 & 2,14 & 10 \\
2,09 & 100 & 2,10 & 1,5 \\
1,82 & 41 & 1,83 & 15 \\
1,64 & 100 & 1,64 & 0,5 \\
1,35 & 100 & 1,38 & 16
\end{tabular}

$\mathrm{AlPO}_{4}$ expt. vs calc. reticular distances

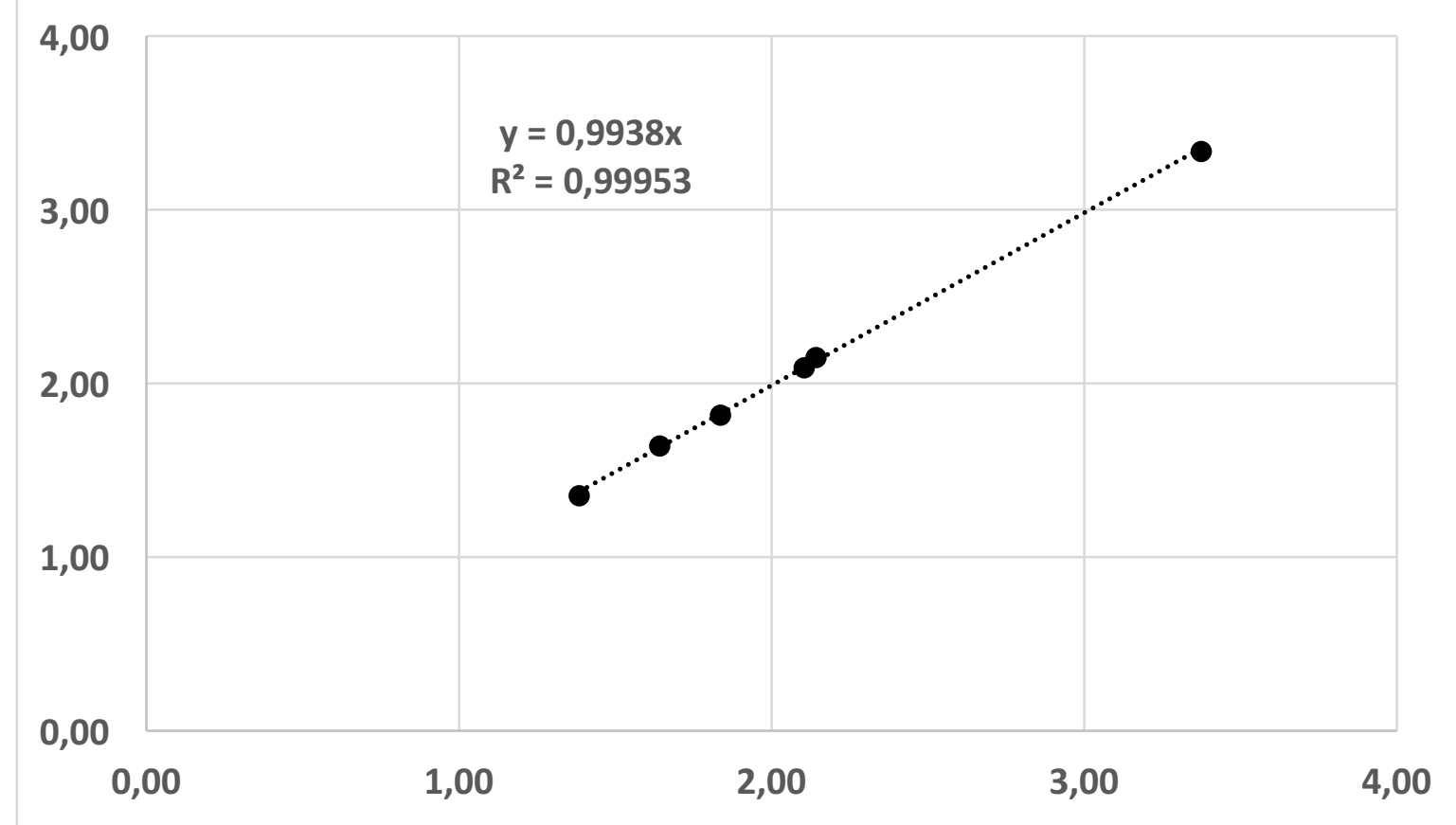


$\mathrm{BPO}_{4} \mathrm{I}-4$
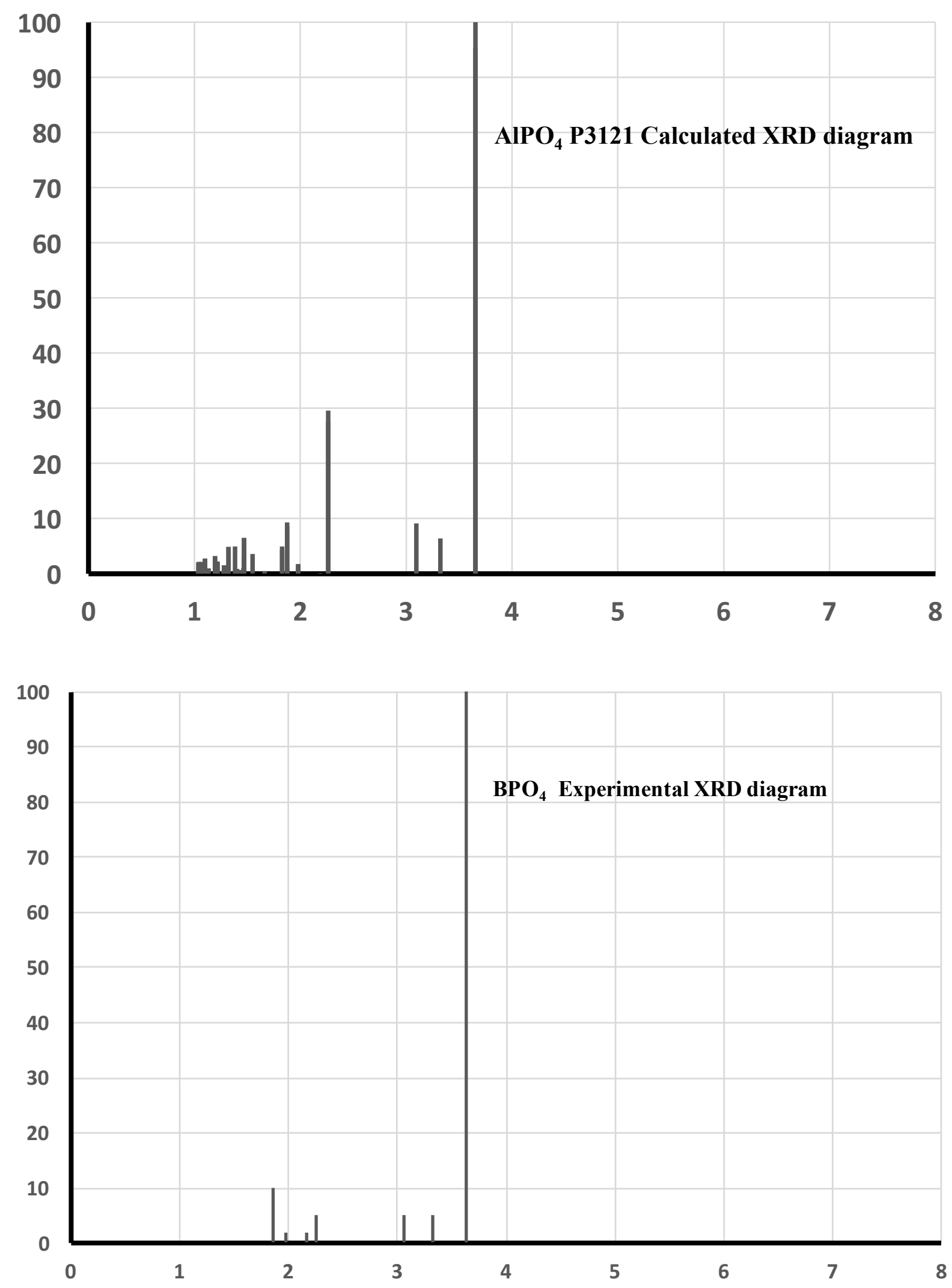


\begin{tabular}{|c|c|c|c|}
\hline \multicolumn{4}{|l|}{$\mathrm{BPO}_{4}$ Main lines } \\
\hline $\operatorname{Exp} d\left(A^{\circ}\right)$ & exp. I & Calc. d $\left(A^{\circ}\right)$ & Calc. I \\
\hline 3,63 & 100 & 3,65 & 100 \\
\hline 3,32 & 5 & 3,33 & 6 \\
\hline 3,06 & 5 & 3,09 & 10 \\
\hline 2,25 & 5 & 2,26 & 30 \\
\hline 2,17 & 2 & 2,19 & 1 \\
\hline 1,97 & 2 & 1,98 & 3 \\
\hline 1,86 & 10 & 1,88 & 10 \\
\hline
\end{tabular}

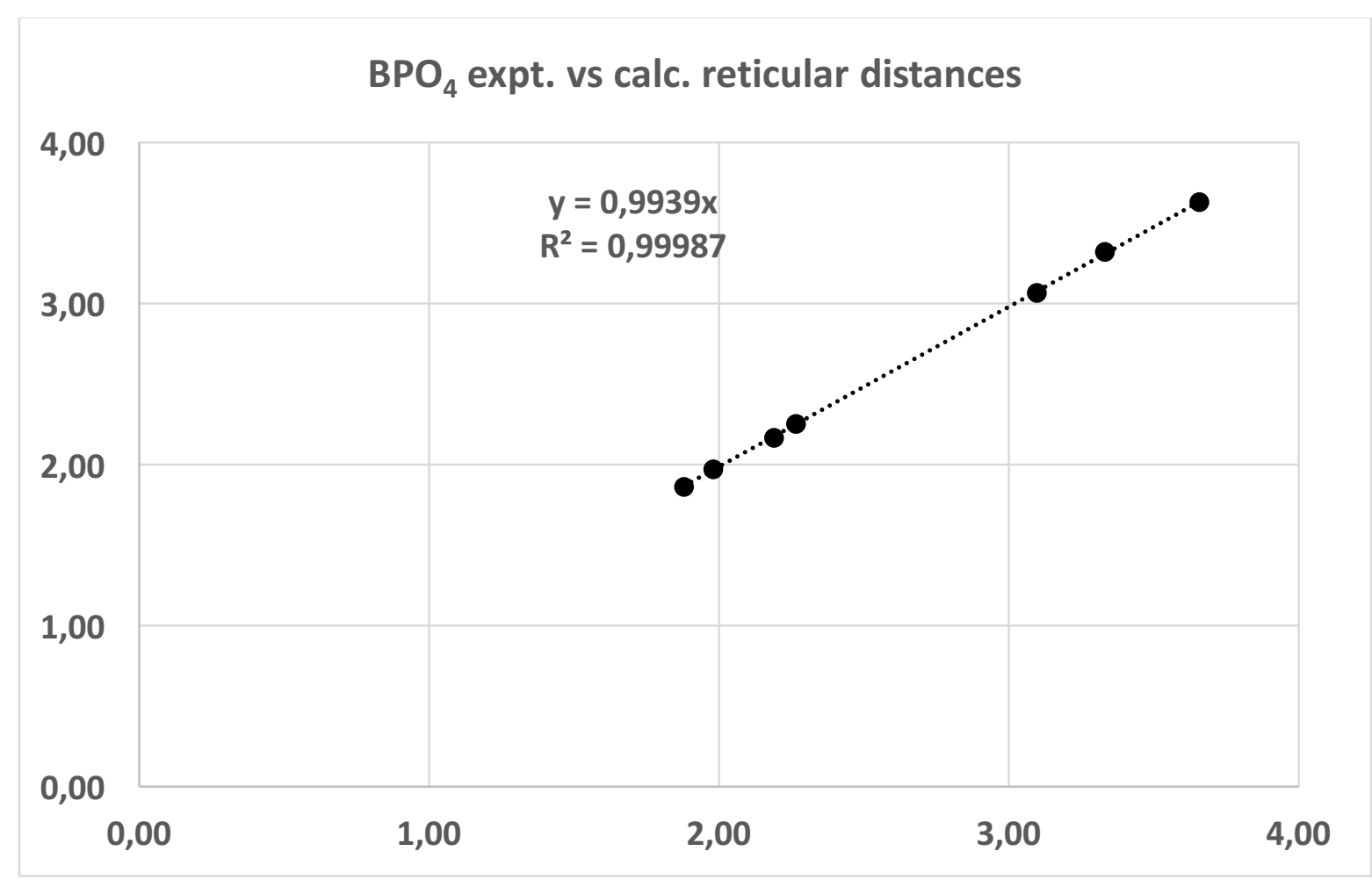


$\mathrm{TiP}_{2} \mathrm{O}_{7} \mathrm{~Pa}-3$
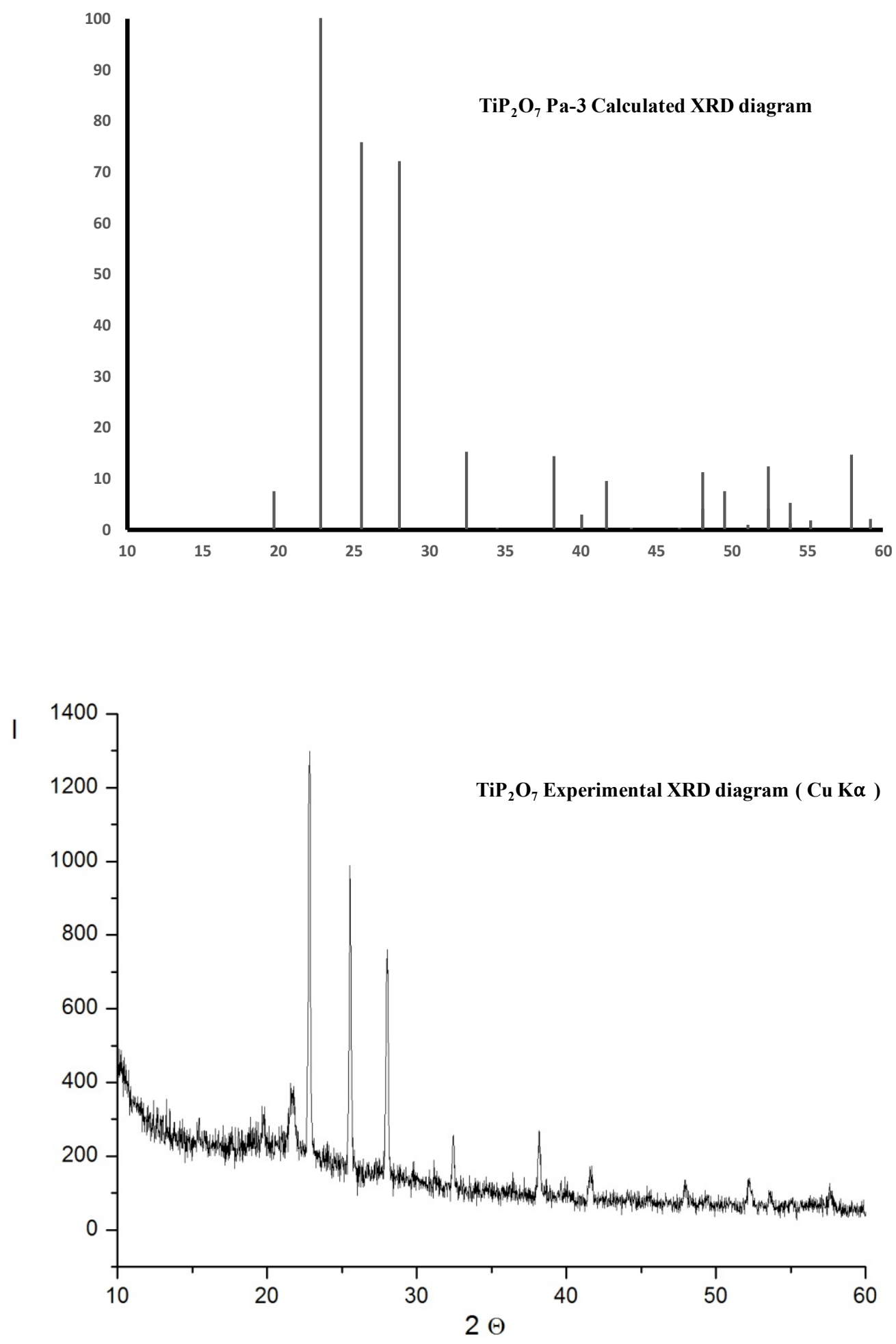
$\mathrm{TiP}_{2} \mathrm{O}_{7}$ Main lines

\begin{tabular}{rrrr}
$\operatorname{Exp} d\left(A^{\circ}\right)$ & exp. I & Calc. $d\left(A^{\circ}\right)$ & Calc. I \\
\hline 4,52 & 11 & 4,50 & 8 \\
3,91 & 100 & 3,90 & 100 \\
3,50 & 79 & 3,49 & 76 \\
3,20 & 57 & 3,18 & 72 \\
2,76 & 12 & 2,76 & 15 \\
2,36 & 18 & 2,35 & 14 \\
2,18 & 8 & 2,16 & 9 \\
1,92 & 6 & 1,89 & 11 \\
1,76 & 8 & 1,74 & 12
\end{tabular}

$\mathrm{TiP}_{2} \mathrm{O}_{7}$ expt. vs calc. reticular distances

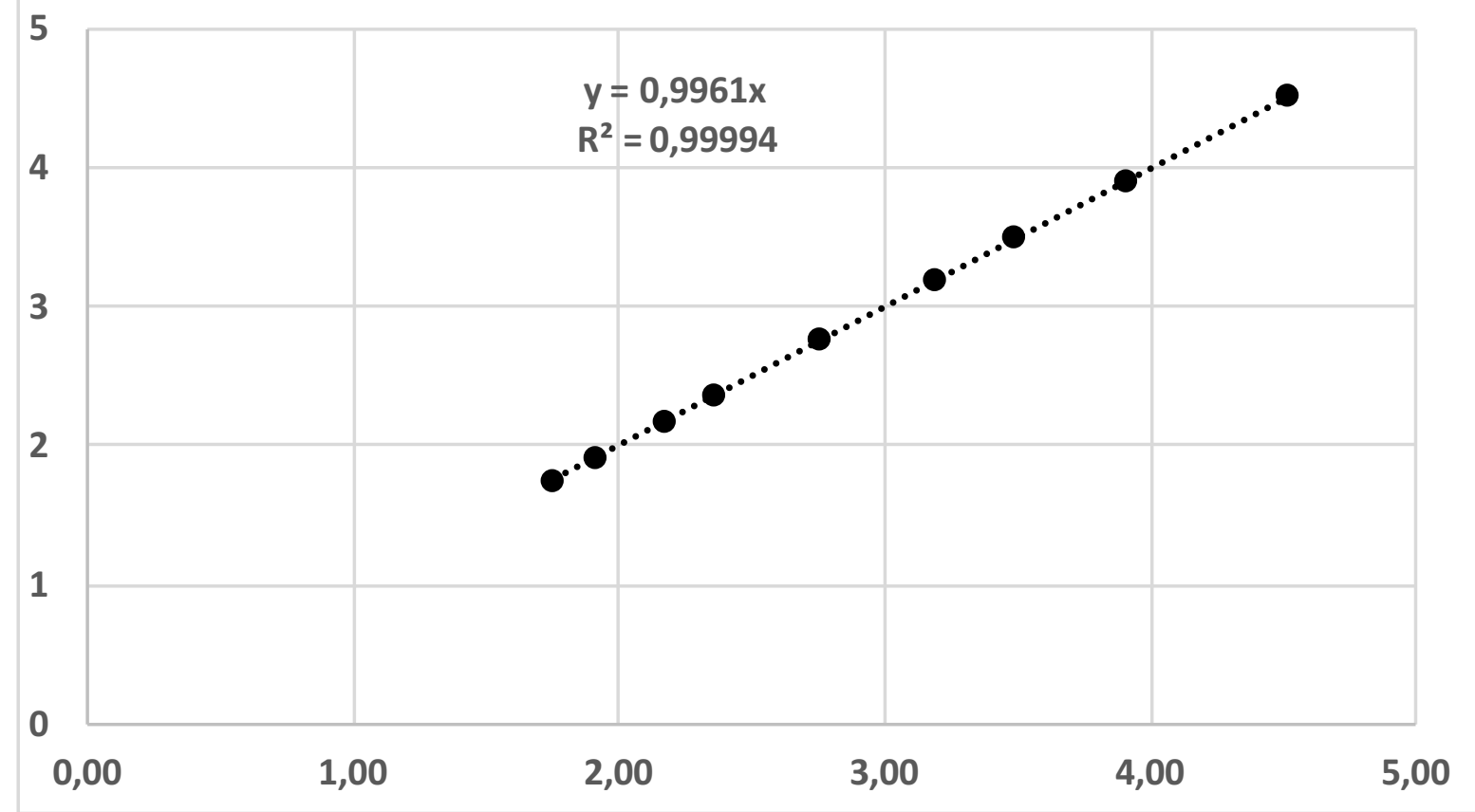


$\mathrm{SiP}_{2} \mathrm{O}_{7} \mathrm{~Pa}-3$
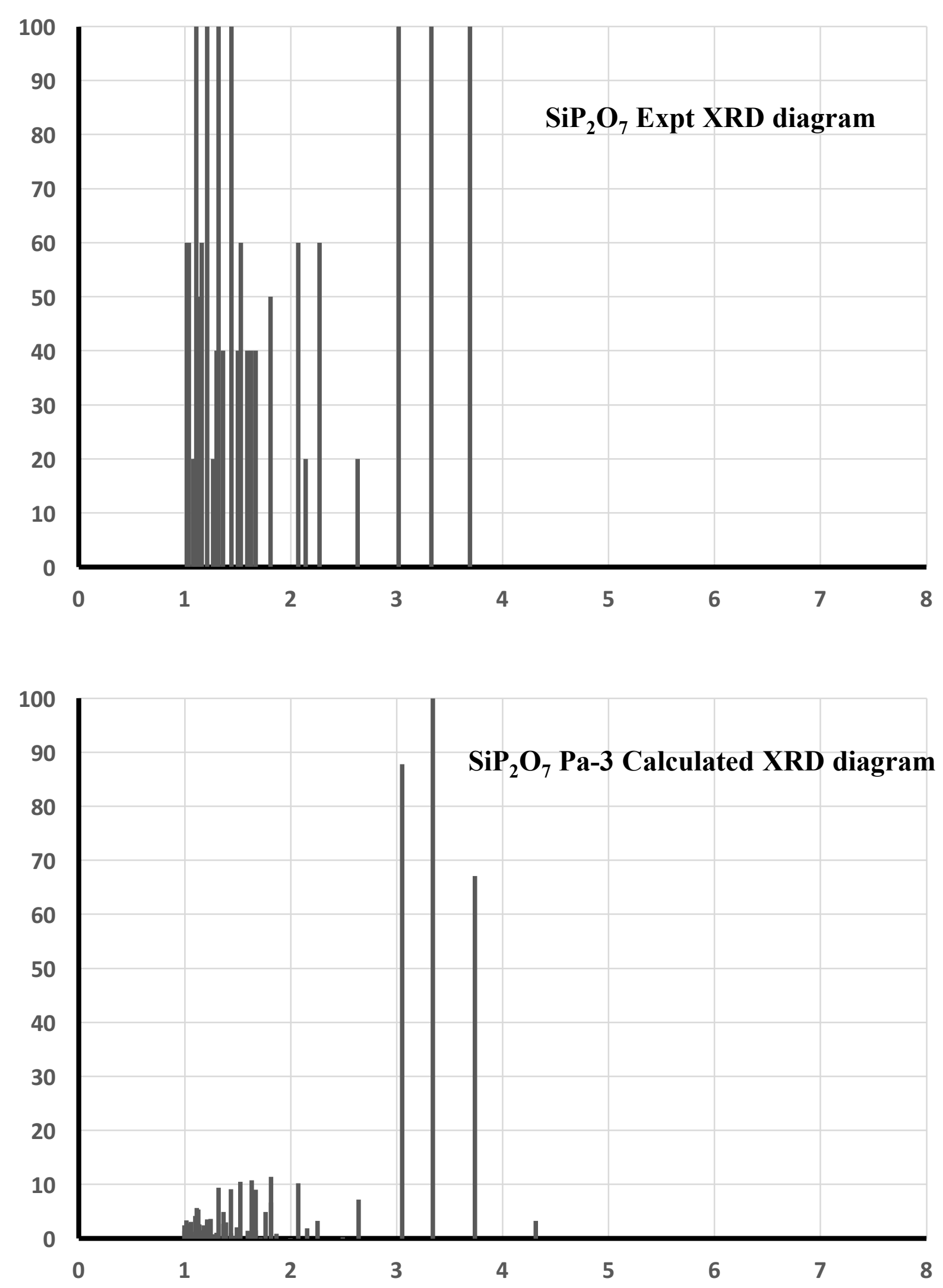
$\mathrm{SiP}_{2} \mathrm{O}_{7}$ Main lines

\begin{tabular}{|c|c|c|c|}
\hline $\operatorname{Exp} d\left(A^{\circ}\right)$ & exp. I & Calc. d $\left(A^{\circ}\right)$ & Calc. I \\
\hline 3,69 & 100 & 3,74 & 67 \\
\hline 3,33 & 100 & 3,34 & 100 \\
\hline 3,02 & 100 & 3,05 & 88 \\
\hline 2,63 & 20 & 2,64 & 7 \\
\hline 2,27 & 60 & 2,25 & 3 \\
\hline 2,14 & 20 & 2,16 & 2 \\
\hline 2,07 & 60 & 2,07 & 10 \\
\hline 1,81 & 50 & 1,81 & 18 \\
\hline 1,67 & 40 & 1,67 & 11 \\
\hline
\end{tabular}

$\mathrm{SiP}_{2} \mathrm{O}_{7}$ expt. vs calc. reticular distances

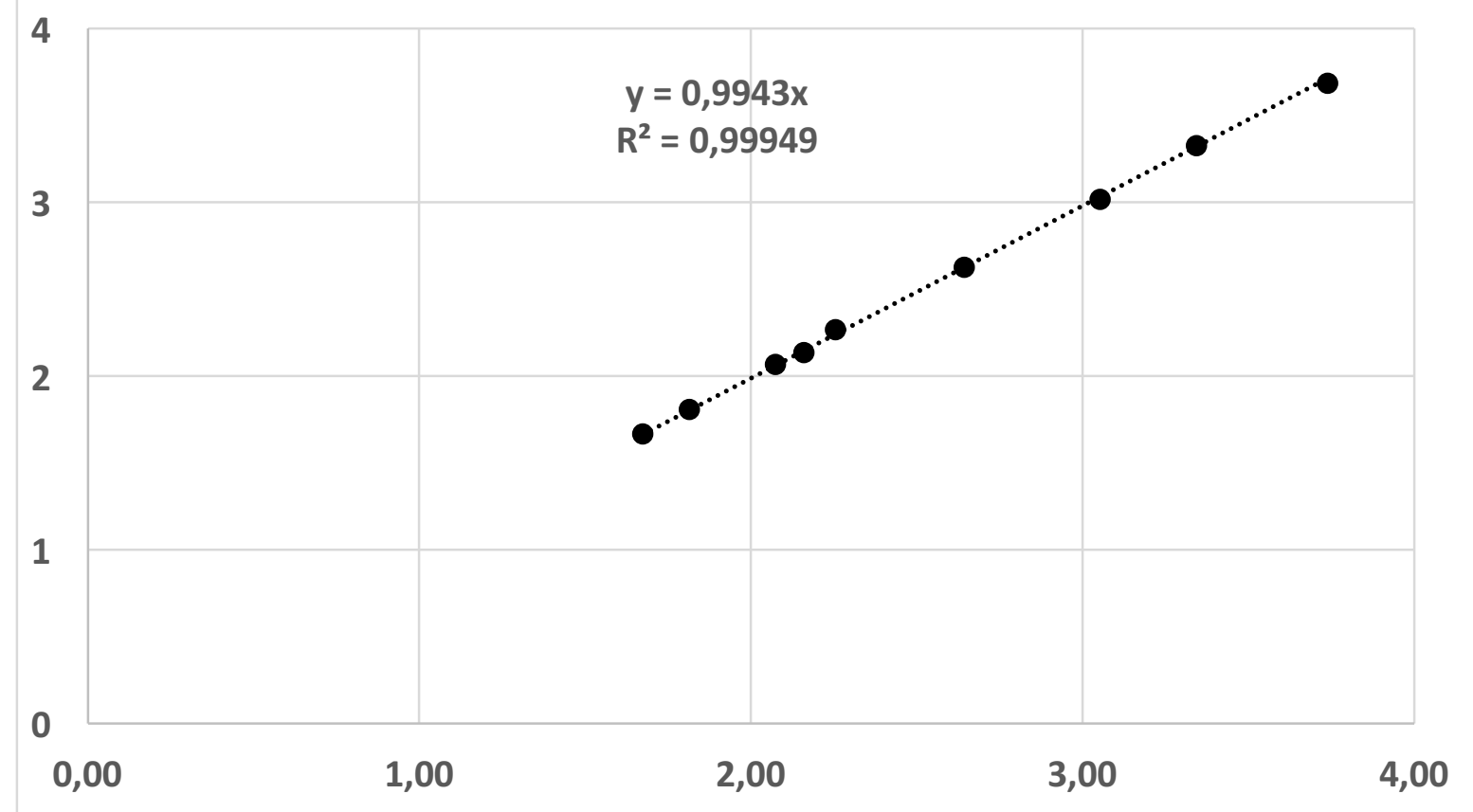


$\mathrm{GeP}_{2} \mathrm{O}_{7} \mathrm{~Pa}-3$
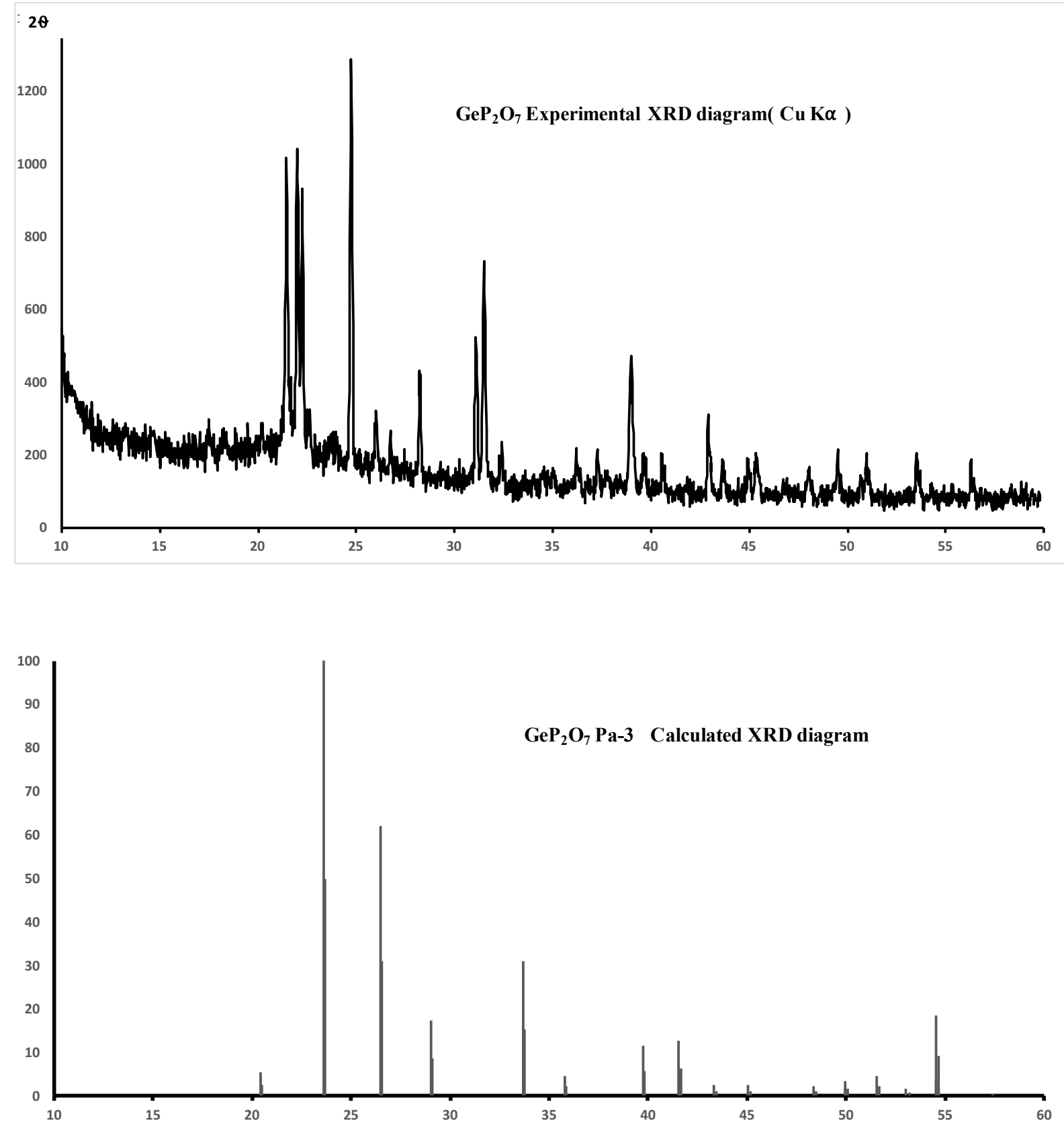
$\mathrm{GeP}_{2} \mathrm{O}_{7}$ Main lines

\begin{tabular}{|c|c|c|c|}
\hline $\operatorname{Exp} d\left(A^{\circ}\right)$ & exp. I & Calc. d $\left(\mathrm{A}^{\circ}\right)$ & Calc. I \\
\hline 4,04 & 81 & 4,34 & 5 \\
\hline 3,99 & 72 & 4,34 & 3 \\
\hline 3,60 & 100 & 3,76 & 100 \\
\hline 3,14 & 33 & 3,07 & 25 \\
\hline 2,88 & 41 & 2,66 & 46 \\
\hline 2,84 & 57 & 2,51 & 5 \\
\hline 2,31 & 36 & 2,27 & 18 \\
\hline 2,11 & 24 & 2,17 & 19 \\
\hline 1,89 & 12 & 2,09 & 4 \\
\hline 2,01 & 15 & 2,01 & 6 \\
\hline 1,84 & 17 & 1,82 & 11 \\
\hline 1,79 & 16 & 1,77 & 3 \\
\hline 1,71 & 16 & 1,73 & 26 \\
\hline 1,63 & 15 & 1,64 & 11 \\
\hline
\end{tabular}

$\mathrm{GeP}_{2} \mathrm{O}_{7}$ expt. vs calc. reticular distances

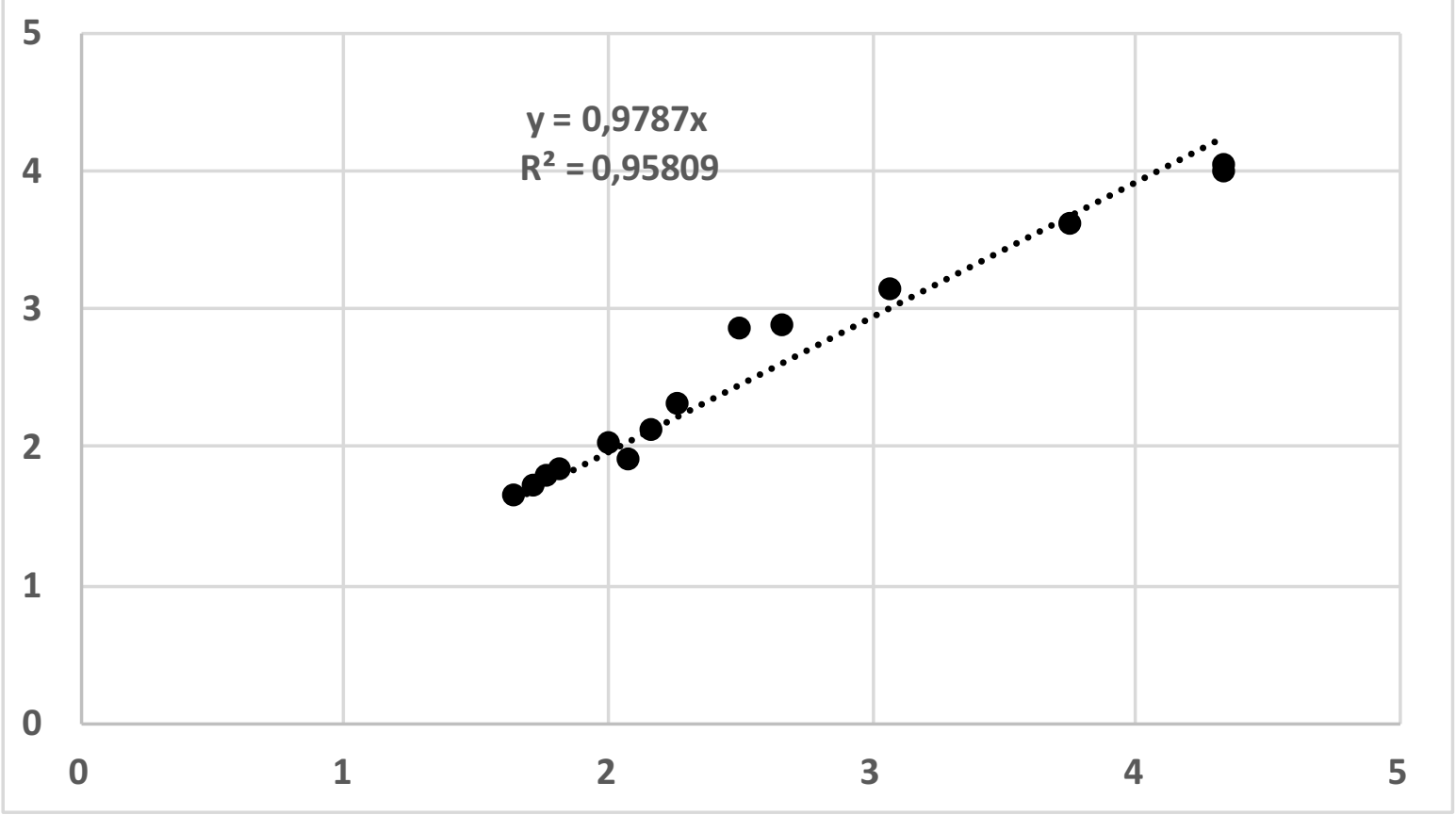


$\mathrm{SnP}_{2} \mathrm{O}_{7} \mathrm{~Pa}-3$
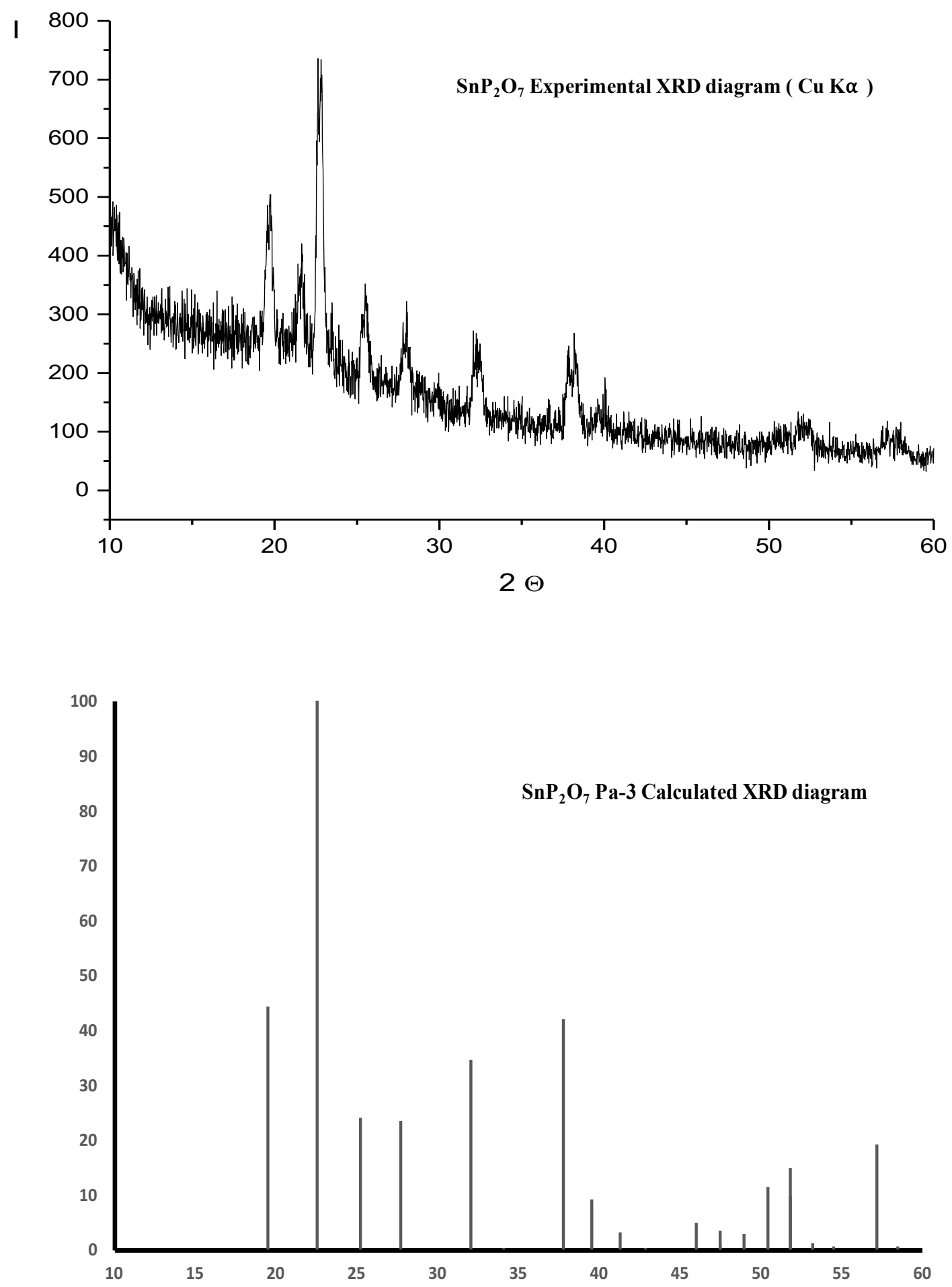
$\mathrm{SnP}_{2} \mathrm{O}_{7}$ Main lines

\begin{tabular}{|c|c|c|c|}
\hline $\operatorname{Exp} d\left(A^{\circ}\right)$ & exp. I & Calc. $d\left(A^{\circ}\right)$ & Calc. I \\
\hline 4,54 & 50 & 4,56 & 44 \\
\hline 3,89 & 100 & 3,95 & 100 \\
\hline 3,48 & 27 & 3,53 & 24 \\
\hline 3,17 & 19 & 3,22 & 23 \\
\hline 2,75 & 25 & 2,79 & 35 \\
\hline 2,36 & 22 & 2,38 & 42 \\
\hline 2,25 & 9 & 2,28 & 8 \\
\hline 1,75 & 6 & 1,76 & 12 \\
\hline
\end{tabular}

$\mathrm{SnP}_{2} \mathrm{O}_{7}$ expt. vs calc. reticular distances

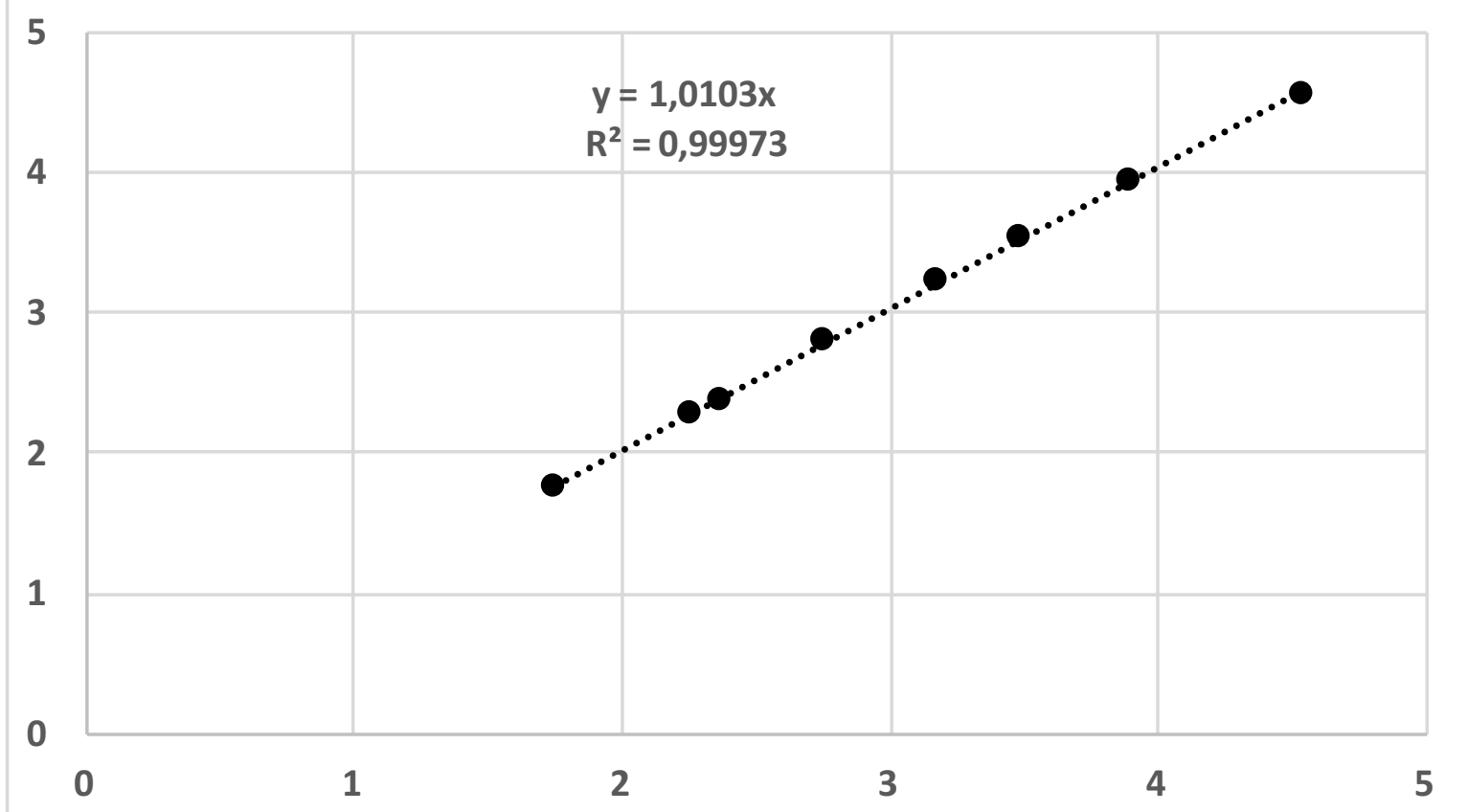


(1) K. Momma and F. Izumi, "VESTA 3 for three-dimensional visualization of crystal, volumetric and morphology data," J. Appl. Crystallogr., 2011, 1272-1276. 


\section{$\underline{\text { BET Areas }}$}

The following table provides the BET surface areas measured on the considered phosphates after calcination at $973 \mathrm{~K}$ :

\begin{tabular}{ccc}
\hline Solid & SG & BET area \\
\hline & & $\mathrm{m}^{2} \cdot \mathrm{g}^{-1}$ \\
\hline $\mathbf{M n}_{2} \mathbf{P}_{2} \mathbf{O}_{7}$ & $\mathrm{C} 2 / \mathrm{m}$ & 6 \\
$\mathbf{C r P O}_{4}$ & $\mathrm{Cmcm}$ & 65 \\
$\mathbf{C O}_{3}\left(\mathbf{P O}_{4}\right)_{2}$ & $\mathrm{P}-1$ & 91 \\
$\mathbf{N i}_{3}\left(\mathbf{P O}_{4}\right)_{2}$ & $\mathrm{P} 1$ & 29 \\
$\mathbf{F e P O}_{4}$ & $\mathrm{P} 3121$ & 17 \\
$\mathbf{M g}_{3}\left(\mathbf{P O}_{4}\right)_{2}$ & $\mathrm{P} 2-1 / \mathrm{c}$ & 46 \\
$\mathbf{A I P O}_{4}$ & $\mathrm{P} 3221$ & 15 \\
$\mathbf{B P O}_{4}$ & $\mathrm{I}-4$ & 12 \\
$\mathbf{T i P}_{2} \mathbf{O}_{7}$ & $\mathrm{~Pa}-3$ & 27 \\
$\mathbf{S i P}_{2} \mathbf{O}_{7}$ & $\mathrm{~Pa}-3$ & 35 \\
$\mathbf{G e P}_{2} \mathbf{O}_{7}$ & $\mathrm{~Pa}-3$ & 42 \\
$\mathbf{S n P}_{2} \mathbf{O}_{7}$ & $\mathrm{~Pa}-3$ & 76 \\
\hline
\end{tabular}




\section{IR Spectra of catalysts}

In the following spectra, the absorbance is plotted as function of wavenumber. Spectrum 1 corresponds to the freshly prepared catalysts, and spectrum 2 to the same material after calcination at $1073 \mathrm{~K}$.

All catalyst present bands in the $3400-3800 \mathrm{~cm}^{-1}$ range of wavenumbers, specific of $\mathrm{n}(\mathrm{OH})$ vibration, and revealing the occurrence of surface hydroxyls groups.

The bands in the vicinity of $3660 \mathrm{~cm}^{-1}$ have been assigned in ref [41] of main text to the $\mathrm{OH}$ stretching of free surface $\mathrm{POH}$ groups.

\section{$\mathrm{Ni}_{3}\left(\mathrm{PO}_{4}\right)_{2}$}

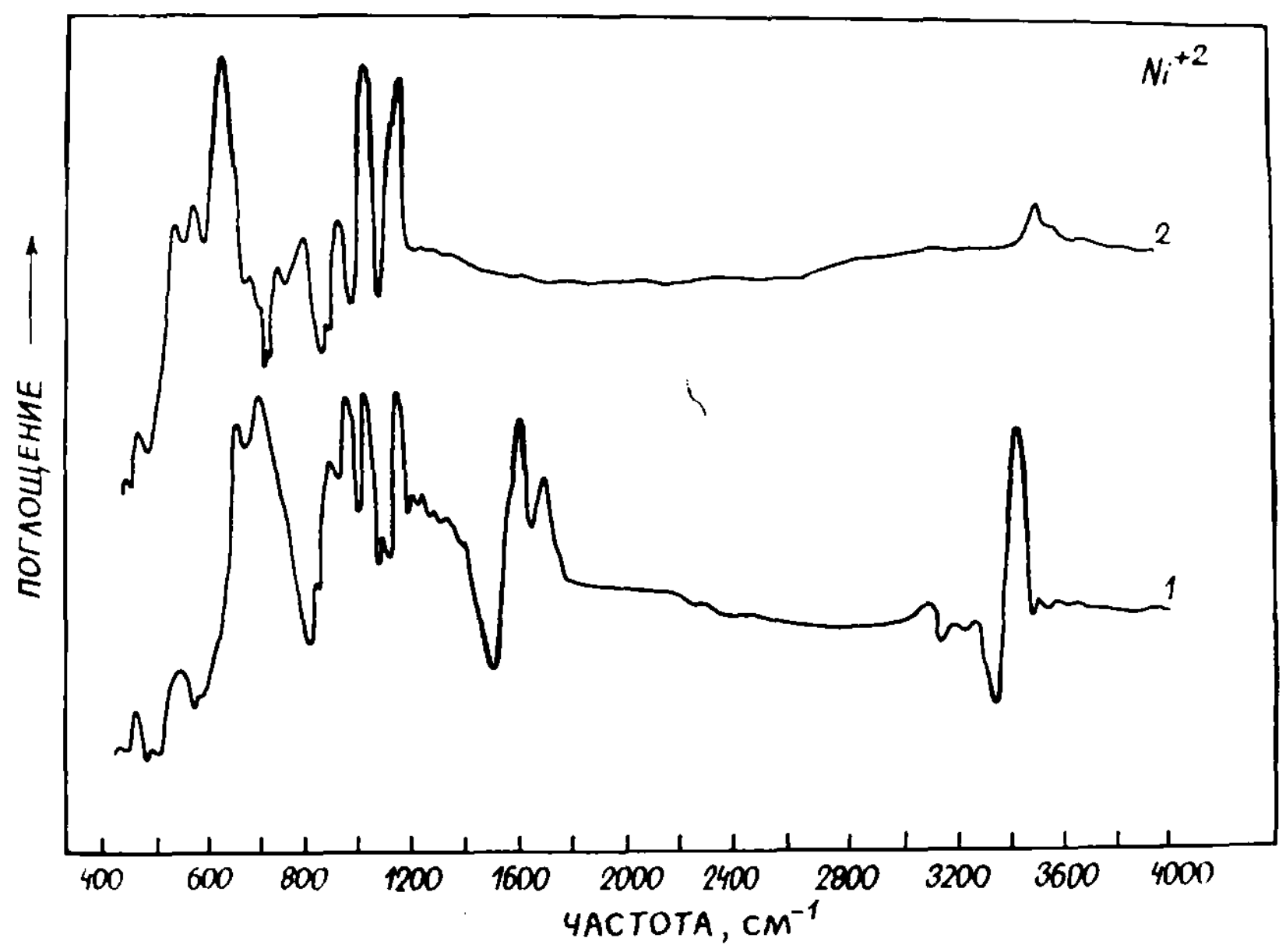




\section{$\mathrm{Co}_{3}\left(\mathrm{PO}_{4}\right)_{2}$}

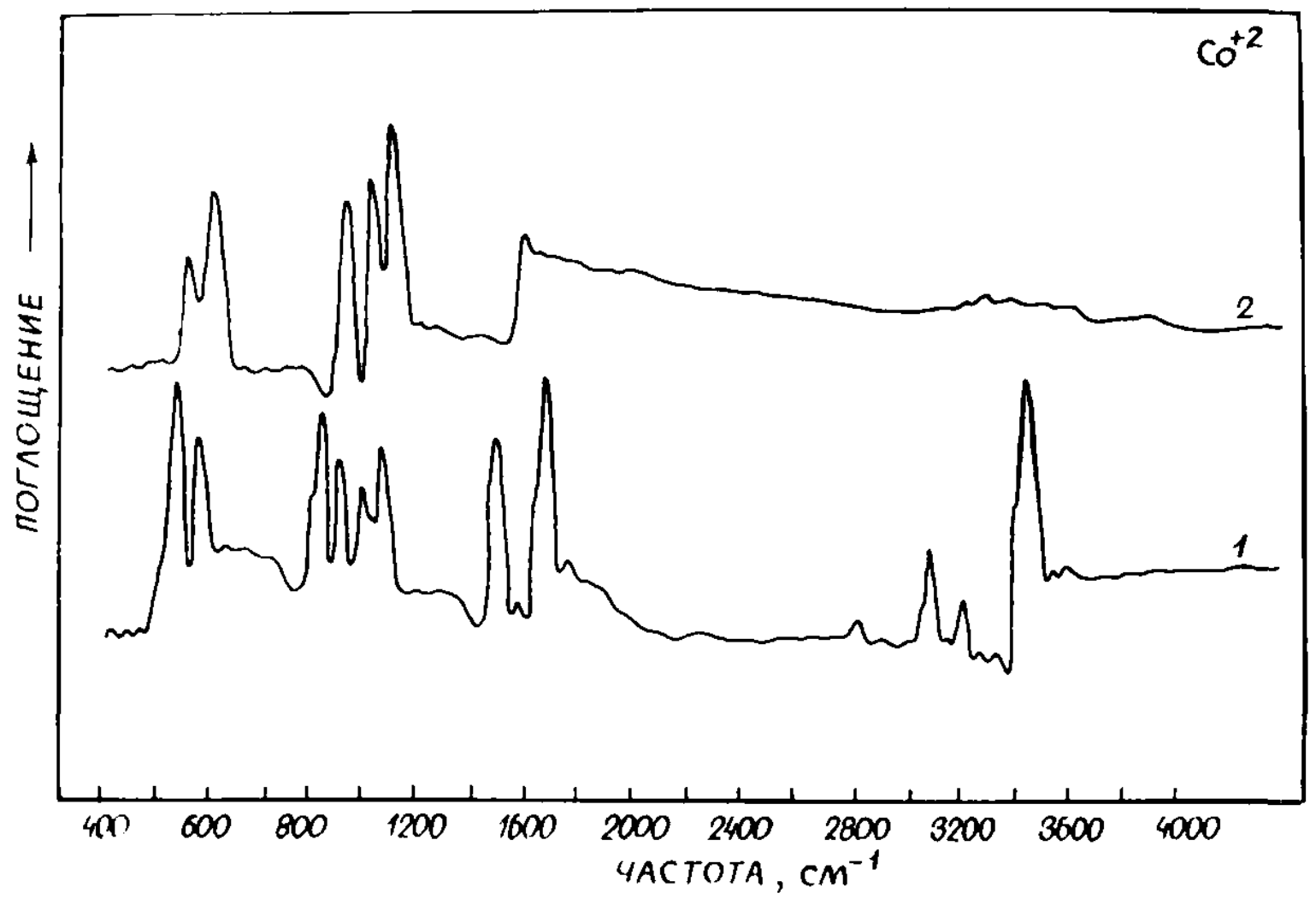


$\mathrm{CrPO}_{4}$

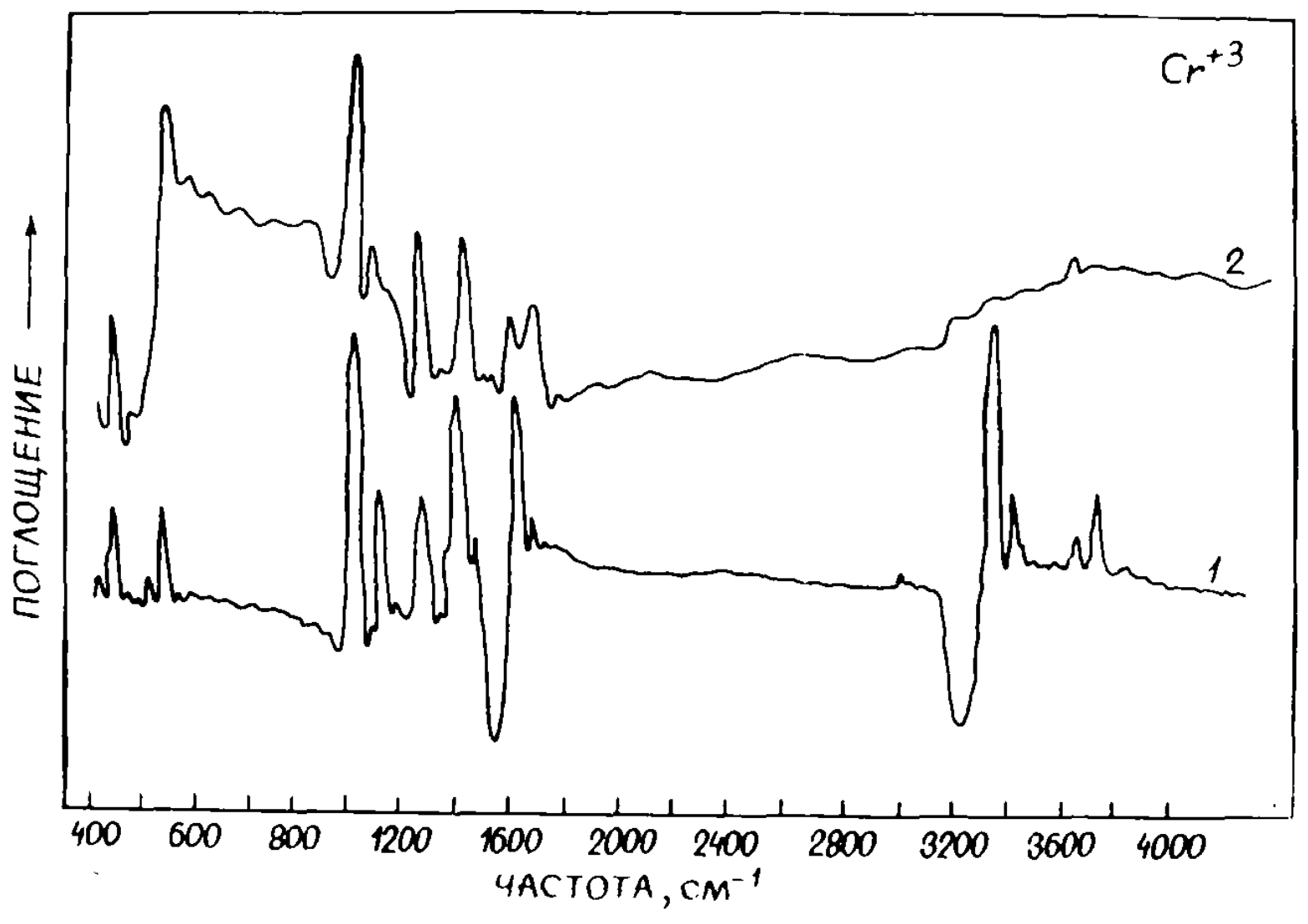


$\mathrm{FePO}_{4}$

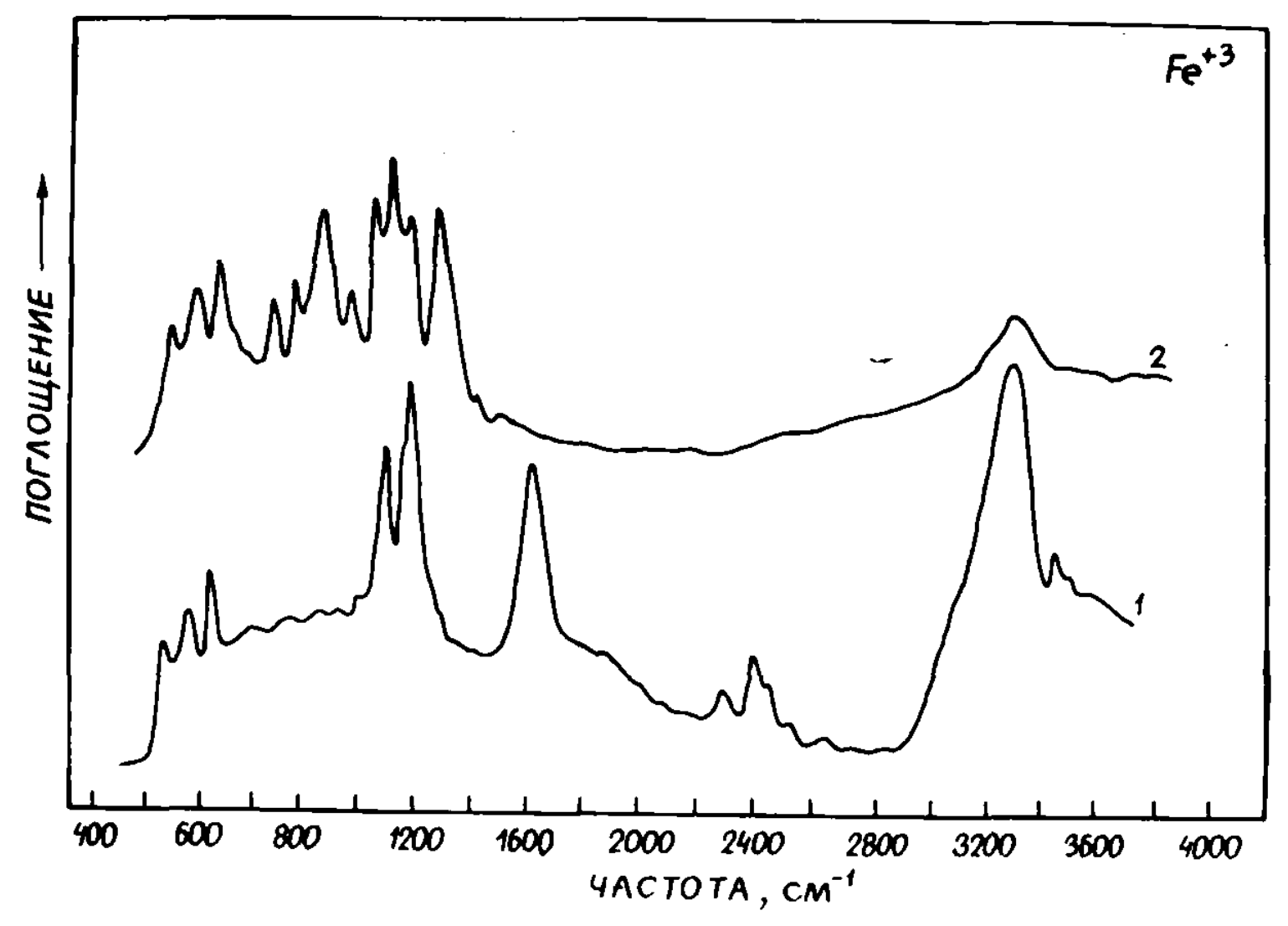


$\mathrm{AlPO}_{4}$

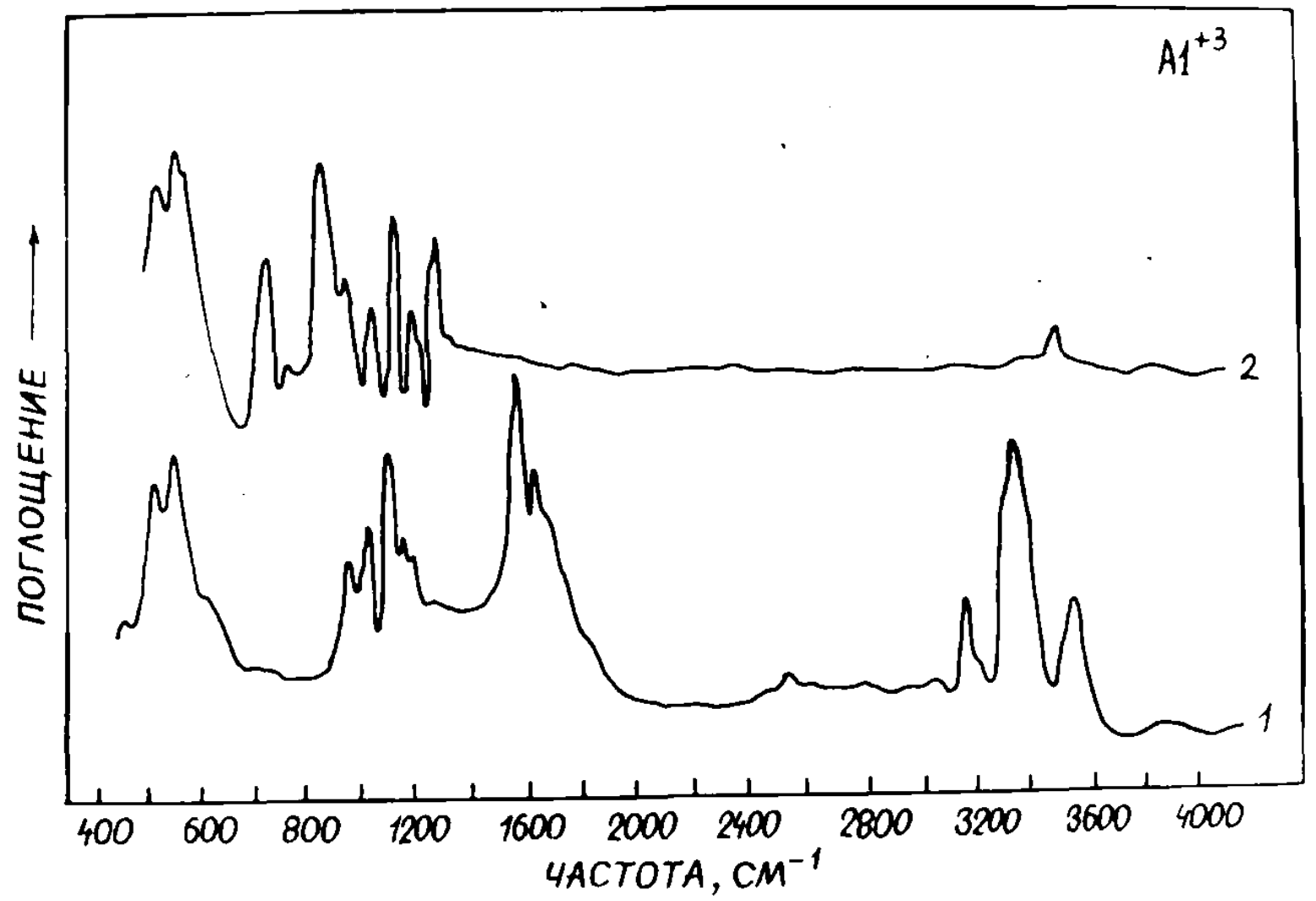




\section{$\mathrm{BPO}_{4}$}

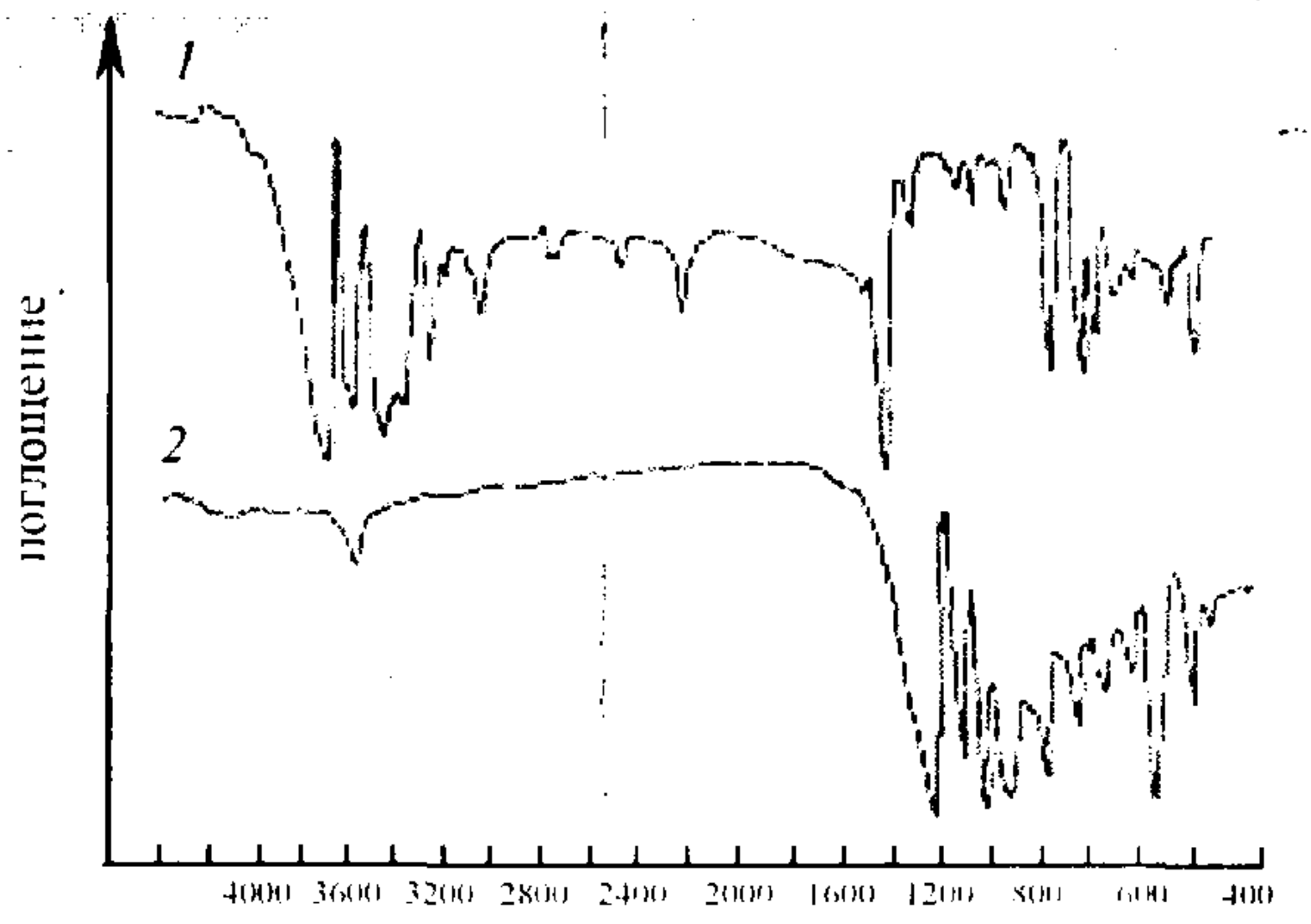




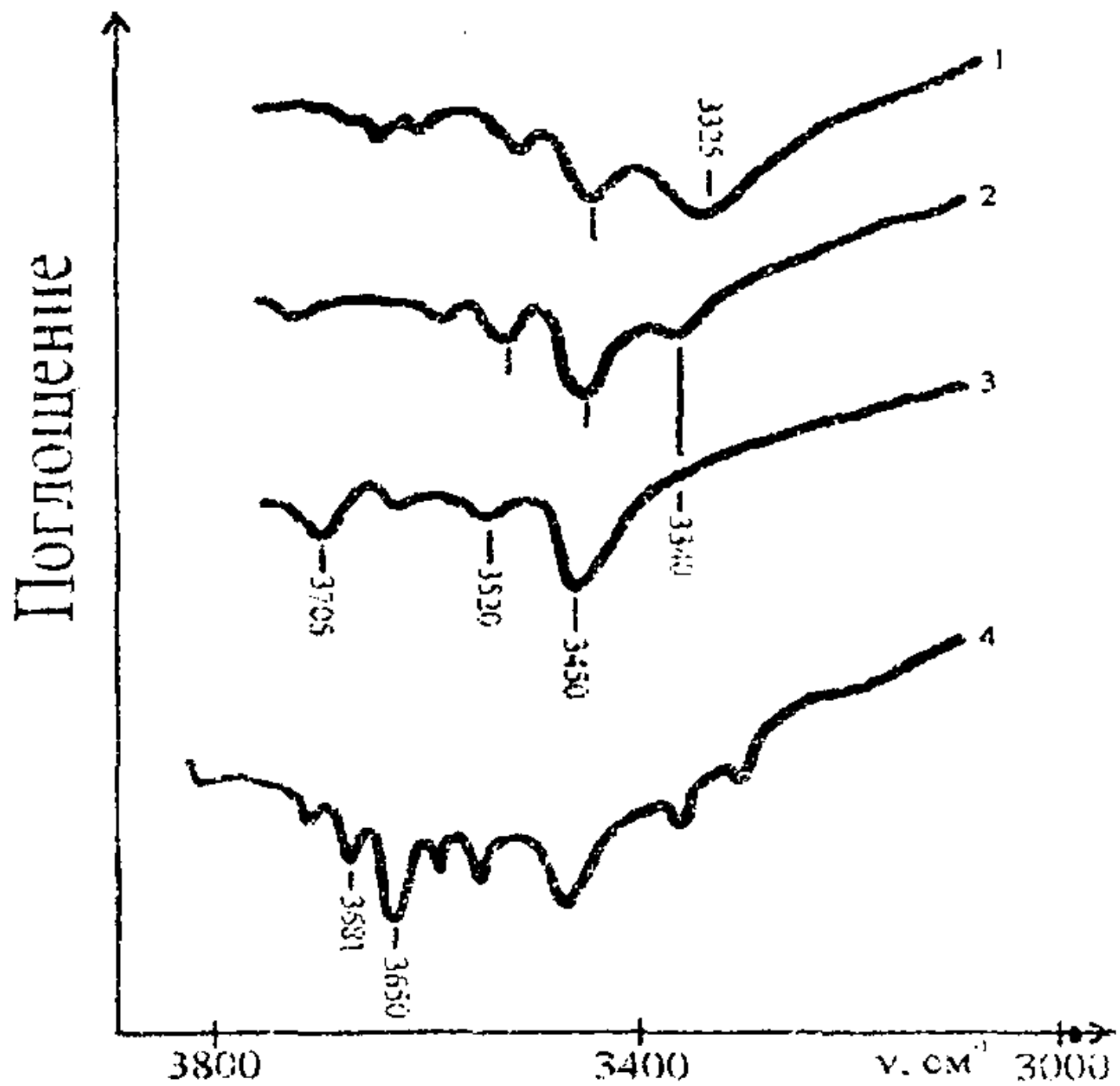

Infrared spectra of $\mathrm{BPO}_{4}$ sample in the domain of surface $\mathrm{OH}$ vibrations : 1- processed in vacuo 4 hours at $900 \mathrm{~K} ; 2$ - after ammonia adsorption at $300 \mathrm{~K} ; 3$ - Evacuated at $423 \mathrm{~K}, 30$ minutes; 4 - Evacuated at $673 \mathrm{~K}, 30$ minutes. 


\section{SI-2 - Bench-scale catalyst testing equipment}

All catalyst were compared in a specially designed flow circulation reactor with reaction mixture quenching (2) as schematically presented below:

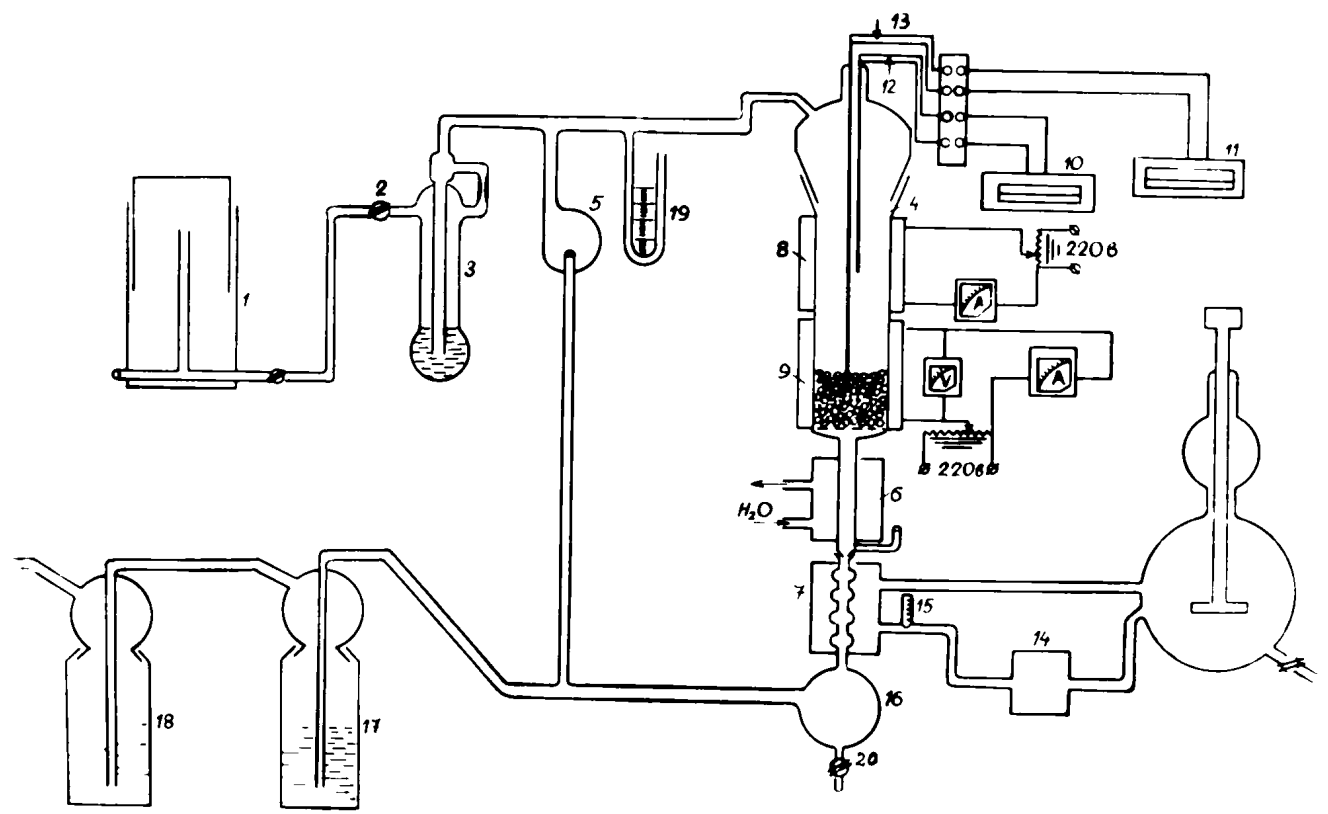

1: Reaction mixture tank (methane+oxygen)

5: Recycle pump

9: Catalyst pellets inside the reactor

6: First stage cooler (room temperature tap water)

7: Second stage cooler for condensation of formaldehyde and water produced by the reaction (circulating fluid, water at $5-10^{\circ} \mathrm{C}$ ).

15, 16 : Condensate collector (aqueous formaldehyde solution)

17, 18 : Condensate scrubbers

The feed rate of reaction mixture is set between 3 and $15 \mathrm{Nl}^{-\mathrm{hr}^{-1}}$, while the recycle flow-rate is maintained at $150 \mathrm{Nl} \cdot \mathrm{hr}^{-1}$ so as to ensure the condition of equivalence with a perfectly stirred differential reactor.

(2) Gomonai, V.I., Doctoral (Chem.) Dissertation, Uzhgorod State Univ., 1990. 


\section{SI-3 Supplementary Tables}

Table SI-3-1: Bader charges in electronic units for DFT optimized reference structures of phosphate bulk catalysts. $Q_{M}$ : averaged Bader charge on M atoms; $Q_{M F}$ : formal charge of $\mathrm{M}$ ion; $Q_{P}$ : averaged Bader charge on $\mathrm{P}$ atoms; $Q_{O a}$ : averaged Bader charge on Oa atoms; averaged $Q_{o b}$ Bader charge on $\mathrm{Ob}$ atoms. Formal charges for $\mathrm{P}$ and $\mathrm{O}$ are +5 and -2 respectively.

\begin{tabular}{lclccc}
\hline Solid & $Q_{M}$ & $Q_{M F}$ & $Q_{P}$ & $Q_{O a}$ & $Q_{O b}$ \\
\hline $\mathrm{Mn}_{2} \mathrm{P}_{2} \mathrm{O}_{7}$ & 1.533 & 2 & 3.687 & -1.478 & -1.568 \\
$\mathrm{CrPO}_{4}$ & 1.815 & 3 & 3.652 & -1.368 & \\
$\mathrm{Co}_{3}\left(\mathrm{PO}_{4}\right)_{2} 2_{2}$ & 1.312 & 2 & 3.656 & -1.402 & \\
$\mathrm{Ni}_{3}\left(\mathrm{PO}_{4}\right)_{2}$ & 1.236 & 2 & 3.616 & -1.368 & \\
$\mathrm{FePO}_{4}$ & 1.703 & 3 & 3.703 & -1.351 & \\
$\mathrm{Mg}_{3}\left(\mathrm{PO}_{4}\right)_{2}$ & 1.697 & 2 & 3.694 & -1.558 & \\
$\mathrm{AlPO}_{4}$ & 2.492 & 3 & 3.756 & -1.562 & \\
$\mathrm{BPO}_{4}$ & 2.380 & 3 & 3.756 & -1.534 & \\
$\mathrm{TiP}_{2} \mathrm{O}_{7}$ & 2.380 & 4 & 3.751 & -1.391 & -1.538 \\
$\mathrm{SiP}_{2} \mathrm{O}_{7}$ & 3.262 & 4 & 3.772 & -1.543 & -1.548 \\
$\mathrm{GeP}_{2} \mathrm{O}_{7}$ & 2.640 & 4 & 3.776 & -1.438 & -1.564 \\
$\mathrm{SnP}_{2} \mathrm{O}_{7}$ & 2.692 & 4 & 3.756 & -1.441 & -1.556 \\
\hline
\end{tabular}


Table SI-3-2: Experimental specific total acidities $H^{0}$ in $\mu$ mol. $\mathrm{m}^{-2}$, catalytic oxidation rates $w$ in $10^{9} \mathrm{~mol} \cdot \mathrm{m}^{-2} \cdot \mathrm{s}^{-1}$ and selectivities in moles $\%$ of oxidation products for phosphate catalysts at $873 \mathrm{~K}$, atmospheric pressure and molar ratio $\mathrm{O}_{2} / \mathrm{CH}_{4}=0.5$. Acidities and selectivities in formaldehyde are correlated.

\begin{tabular}{llllll}
\hline Solid & $\mathrm{H}^{0}$ & $\mathrm{w}$ & $\% \mathrm{CH}_{2} \mathrm{O}$ & $\% \mathrm{CO}$ & $\% \mathrm{CO}_{2}$ \\
\hline $\mathrm{Mn}_{2} \mathrm{P}_{2} \mathrm{O}_{7}$ & 0.09 & 185 & 1 & 15 & 84 \\
$\mathrm{CrPO}_{4}$ & 0.35 & 76.3 & 3 & 19 & 78 \\
$\mathrm{Co}_{3}\left(\mathrm{PO}_{4}\right)_{2}$ & 0.83 & 35.6 & 6 & 23 & 71 \\
$\mathrm{Ni}_{3}\left(\mathrm{PO}_{4}\right)_{2}$ & 1.30 & 25.4 & 10 & 26 & 64 \\
$\mathrm{FePO}_{4}$ & 2.10 & 16.4 & 15 & 33 & 52 \\
$\mathrm{Mg}_{3}\left(\mathrm{PO}_{4}\right)_{2}$ & 3.30 & 11.8 & 24 & 36 & 40 \\
$\mathrm{AlPO}_{4}$ & 5.00 & 8.76 & 38 & 35 & 27 \\
$\mathrm{BPO}_{4}$ & 6.90 & 6.28 & 51 & 32 & 17 \\
$\mathrm{TiP}_{2} \mathrm{O}_{7}$ & 10.6 & 4.85 & 79 & 22 & 9 \\
$\mathrm{SiP}_{2} \mathrm{O}_{7}$ & 13.6 & 3.55 & 83 & 12 & 5 \\
$\mathrm{GeP}_{2} \mathrm{O}_{7}$ & 15.2 & 2.94 & 86 & 11 & 3 \\
$\mathrm{SnP}_{2} \mathrm{O}_{7}$ & 16.5 & 2.45 & 96 & 3 & 1 \\
\hline
\end{tabular}


Table SI-3-3: Comparison of experimental and simulated catalytic oxidation rates $w$ in $10^{9}$ mol. $\mathrm{m}^{-2} \cdot \mathrm{s}^{-1}$ and selectivities in moles $\%$ of oxidation products for phosphate catalysts at $873 \mathrm{~K}$, atmospheric pressure and molar ratio $\mathrm{O}_{2} / \mathrm{CH}_{4}=0.5$. Descriptors $E_{\text {Moa }}$ (computed by DFT, see Table 2) and $H^{0}$ (experimentally measured, see Table 4) are inputs in the kinetic model.

\begin{tabular}{lllll}
\hline Solid & $\mathrm{w}_{\exp }$ & $\mathrm{w}_{\text {sim }}$ & $\% \mathrm{CH}_{2} \mathrm{O}$ & $\% \mathrm{CH}_{2}$ Osim \\
\hline $\mathrm{Mn}_{2} \mathrm{P}_{2} \mathrm{O}_{7}$ & 185 & 185.0 & 1 & 4.1 \\
$\mathrm{CrPO}_{4}$ & 76.3 & 94.4 & 3 & 4.8 \\
$\mathrm{Co}_{3}\left(\mathrm{PO}_{4}\right)_{2}$ & 35.6 & 61.8 & 6 & 7.4 \\
$\mathrm{Ni}_{3}\left(\mathrm{PO}_{4}\right)_{2}$ & 25.4 & 25.3 & 10 & 11.3 \\
$\mathrm{FePO}_{4}$ & 16.4 & 25.6 & 15 & 13.8 \\
$\mathrm{Mg}_{3}\left(\mathrm{PO}_{4}\right)_{2}$ & 11.8 & 11.6 & 24 & 23.7 \\
$\mathrm{AlPO}_{4}$ & 8.76 & 8.41 & 38 & 37.1 \\
$\mathrm{BPO}_{4}$ & 6.28 & 6.18 & 51 & 56.6 \\
$\mathrm{TiP}_{2} \mathrm{O}_{7}$ & 4.85 & 8.99 & 79 & 77.5 \\
$\mathrm{SiP}_{2} \mathrm{O}_{7}$ & 3.55 & 14.6 & 83 & 86.8 \\
$\mathrm{GeP}_{2} \mathrm{O}_{7}$ & 2.94 & 53,4 & 86 & 87.7 \\
$\mathrm{SnP}_{2} \mathrm{O}_{7}$ & 2.45 & 62,4 & 96 & 90.7 \\
\hline
\end{tabular}

\begin{tabular}{lllll}
\hline Solid & $\% \mathrm{CO}$ & $\% \mathrm{COsim}$ & $\% \mathrm{CO}_{2}$ & $\% \mathrm{CO}_{2}$ sim \\
\hline $\mathrm{Mn}_{2} \mathrm{P}_{2} \mathrm{O}_{7}$ & 15 & 16.8 & 84 & 79.1 \\
$\mathrm{CrPO}_{4}$ & 19 & 21.5 & 78 & 71.4 \\
$\mathrm{Co}_{3}\left(\mathrm{PO}_{4}\right)_{2}$ & 23 & 21.1 & 71 & 71.5 \\
$\mathrm{Ni}_{3}\left(\mathrm{PO}_{4}\right)_{2}$ & 26 & 23.7 & 64 & 65.0 \\
$\mathrm{FePO}_{4}$ & 33 & 33.9 & 52 & 52.3 \\
$\mathrm{Mg}_{3}\left(\mathrm{PO}_{4}\right)_{2}$ & 36 & 36.5 & 40 & 39.8 \\
$\mathrm{AlPO}_{4}$ & 35 & 34.9 & 27 & 28.0 \\
$\mathrm{BPO}_{4}$ & 32 & 27.3 & 17 & 16.1 \\
$\mathrm{TiP}_{2} \mathrm{O}_{7}$ & 22 & 11.4 & 9 & 11.1 \\
$\mathrm{SiP}_{2} \mathrm{O}_{7}$ & 12 & 5.9 & 5 & 7.7 \\
$\mathrm{GeP}_{2} \mathrm{O}_{7}$ & 11 & 3.2 & 3 & 9.1 \\
$\mathrm{SnP}_{2} \mathrm{O}_{7}$ & 3 & 2.3 & 1 & 7,0 \\
\hline
\end{tabular}




\section{SI-4 Kinetic Model}

As presented in the main text, we assume that methane oxidation can be decomposed in the following elementary steps for each phosphate catalyst:

\begin{tabular}{|c|c|}
\hline $\begin{array}{l}\text { Step } \\
\text { № }\end{array}$ & Reaction equation \\
\hline 1 & $\mathrm{O}_{2}(\mathrm{~g})+2 \mathrm{Z} \Leftrightarrow 2 \mathrm{ZO}$ \\
\hline 2 & $\mathrm{CH}_{4}(\mathrm{~g})+\mathrm{ZO} \Leftrightarrow \mathrm{ZOHCH}_{3}$ \\
\hline 3 & $\mathrm{ZOHCH}_{3}+\mathrm{ZO} \Leftrightarrow \mathrm{ZOHCH}_{2}+\mathrm{ZOH}$ \\
\hline 4 & $\mathrm{ZOHCH}_{2}+\mathrm{ZO} \Leftrightarrow \mathrm{ZOHCH}_{2} \mathrm{O}+\mathrm{Z}$ \\
\hline 5 & $\mathrm{ZOHCH}_{2} \mathrm{O} \Leftrightarrow \mathrm{CH}_{2} \mathrm{O}(\mathrm{g})+\mathrm{ZOH}$ \\
\hline 6 & $\mathrm{ZOHCH}_{2} \mathrm{O}+\mathrm{ZO} \Leftrightarrow \mathrm{ZHCOOH}+\mathrm{ZOH}$ \\
\hline 7 & $\mathrm{ZHCOOH} \Leftrightarrow \mathrm{CO}(\mathrm{g})+\mathrm{H}_{2} \mathrm{O}(\mathrm{g})+\mathrm{Z}$ \\
\hline 8 & $\mathrm{ZHCOOH}+\mathrm{ZO} \Leftrightarrow \mathrm{CO}_{2}(\mathrm{~g})+\mathrm{H}_{2} \mathrm{O}(\mathrm{g})+2 \mathrm{Z}$ \\
\hline 9 & $2 \mathrm{ZOH} \Leftrightarrow \mathrm{H}_{2} \mathrm{O}(\mathrm{g})+\mathrm{ZO}+\mathrm{Z}$ \\
\hline
\end{tabular}

In these equations, $\mathrm{Z}$ represents a Lewis acidic cationic sites, with $\mathrm{Z}=\mathrm{P}$ or $\mathrm{Z}=\mathrm{M}$. $\mathrm{ZO}$ is a $\mathrm{Z}$ surface site covered by an oxygen adatom.

$\mathrm{ZOHCH}_{3}$ represents the surface species formed by the carbidic insertion of gaseous methane into a surface ZO bond, following a radicalar activation, forward step 2. See figure SI-5-1 in next section for a molecular model of this intermediate.

$\mathrm{ZOCH}_{2}$ is produced in forward step 3 by oxidative dehydrogenation of $\mathrm{ZOHCH}_{3}$, transferring one $\mathrm{H}$ atom to a vicinal ZO. See figure SI-5-2 in next section for a molecular model of this intermediate.

$\mathrm{ZOHCH}_{2} \mathrm{O}$ is produced in forward step 4 by oxidative transfer of an $\mathrm{O}$ atom from a vicinal $\mathrm{ZO}$ to $\mathrm{ZOCH}_{2}$. See figure SI-5-3 in next section for a molecular model of this intermediate, which can also be described as a chemisorbed formaldehyde on a Z-OH surface group. This species will either desorb (forward step 5), or be oxidized by a vicinal ZO into a chemisorbed 
formic acid species ZHCOOH (forward step 6). See figure SI-5-4 in next section for a molecular model of this last intermediate.

ZHCOOH either decomposes into $\mathrm{CO}$ and $\mathrm{H}_{2} \mathrm{O}$ which desorb to gas phase (forward step 7) leaving a free $\mathrm{Z}$ site, or is further oxidized by a vicinal $\mathrm{ZO}$ into $\mathrm{CO}_{2}$ and $\mathrm{H}_{2} \mathrm{O}$ which desorb to gas phase (forward step 8).

Step 9 represents the associative desorption of water from two vicinal $\mathrm{ZOH}$ sites.

In what follows, we will distinguish steps 1, 2 and 9 involving reversible exchanges with the gas phase from steps 3, 4, 6, which describe the successive oxidation steps of a chemisorbed methane molecule at the surface, and from steps 5, 7 and 8 the desorption to gas phase of the final products formaldehyde, $\mathrm{CO}, \mathrm{CO}_{2}$ and $\mathrm{H}_{2} \mathrm{O}$. Since the experiments involve a differential reactor with continuous removal of products from the gas phase recycled at high flow-rate at fixed composition, we will consider steps $3,4,6,5,7$ and 8 as very far from equilibrium, i.e. negligible rates of the reverse reactions.

Steps 1,2 and 9 contribute to determine surface coverages by $\mathrm{O}, \mathrm{OH}$ and $\mathrm{CH}_{4}$ (and its products of oxidation in adsorbed state) as $\mathrm{ZO}, \mathrm{ZOH}$ and $\mathrm{ZOHCH} 3$ sites competing for free $\mathrm{Z}$ sites according to a Langmuir-Hinshelwood scheme. The chemisorption of $\mathrm{CH}_{4}$ on $\mathrm{ZO}$ can be considered as well as following the Eley-Rideal mechanism, however it also possible to consider it formally as the chemisorption on a $\mathrm{Z}$ site of methanol produced from $\mathrm{CH}_{4}$ in the gas phase.

With $\left[\mathrm{Z}^{\circ}\right]$ the total concentration of surface sites, the balance of surface sites in equilibrium with the gas phase may be written:

$$
\left[Z^{0}\right]=[Z]+[\mathrm{ZO}]+[\mathrm{ZOHCH} 3]+[\mathrm{ZOH}] \quad \text { eq. SI-4_1 }
$$

Denoting by $\mathrm{Ki}$ the equilibrium constant for step $\mathrm{i},[\mathrm{ZX}]$ the concentrations of surface intermediates $\mathrm{ZX}$, and $\mathrm{P}_{\mathrm{y}}$ the partial pressures of gaseous species $\mathrm{y}$, one gets: 


$$
\left(\frac{[Z O]}{[Z]}\right)^{2}=P_{O_{2}} K_{1}
$$

$\frac{[\mathrm{ZOHCH} 3]}{[\mathrm{ZO}]}=\mathrm{P}_{\mathrm{CH}_{4}} \mathrm{~K}_{2}$

eq. SI-4_3

$$
\frac{[\mathrm{ZOH}]^{2}}{[\mathrm{Z}][\mathrm{ZO}]}=\frac{P_{\mathrm{H}_{2} \mathrm{O}}}{K_{9}}
$$

Substituting eqs SI-4_2 to SI-4_4 into eq. SI-4_1, and dividing by $\left[Z^{\circ}\right]$ :

$$
1=\left(\frac{[Z]}{\left[Z^{0}\right]}+\frac{[Z]}{\left[Z^{0}\right]}\left(P_{O_{2}} K_{1}\right)^{1 / 2}+\frac{[Z O]}{\left[Z^{0}\right]} P_{C H_{4}} K_{2}+\left(\frac{[Z O]}{\left[Z^{0}\right]} \frac{[Z]}{\left[Z^{0}\right]} \frac{P_{H_{2} O}}{K_{9}}\right)^{1 / 2}\right) \quad \text { eq. SI-4 } 5
$$

Eliminating further $[\mathrm{ZO}]$ :

$$
1=\frac{[Z]}{\left[Z^{0}\right]}\left(1+\left(P_{O_{2}} K_{1}\right)^{1 / 2}\left(1+P_{C H_{4}} K_{2}+\left(P_{O_{2}} K_{1} \frac{P_{H_{2} O}}{K_{9}}\right)^{1 / 2}\right)\right)
$$

Assuming $K_{1} \sim K_{9}$ and since the recycle gas flow is dried $P_{O_{2}} \gg P_{H_{2} O}$ we end up with tha approximation:

$$
1 \approx \frac{[Z]}{\left[Z^{0}\right]}\left(1+\left(P_{O_{2}} K_{1}\right)^{1 / 2}\left(1+P_{C H_{4}} K_{2}\right)\right)
$$

Introducing fractional coverages $\theta_{Z}, \theta_{Z O}, \theta_{Z O H C H 3}, \theta_{Z O H}$ for $\frac{[Z]}{\left[Z^{0}\right]}, \frac{[Z O]}{\left[Z^{0}\right]}, \frac{[Z O H C H 3]}{\left[Z^{0}\right]}, \frac{[Z O H]}{\left[Z^{0}\right]}$, respectively, we get :

$$
\begin{aligned}
& \theta_{Z}=\left(1+\left(P_{O_{2}} K_{1}\right)^{1 / 2}\left(1+P_{C_{H}} K_{2}\right)\right)^{-1}=D^{-1} \quad \text { eq. SI-4_7 } \\
& \theta_{Z O}=\theta_{Z}\left(P_{O_{2}} K_{1}\right)^{1 / 2} \\
& \text { eq. SI-4_8 } \\
& \theta_{\text {ZонСH } 3}=\theta_{Z} \theta_{\text {ZO }} P_{C_{4}} K_{2} \\
& \text { eq. SI-4_9 } \\
& \theta_{Z O H}=\left(\theta_{Z} \theta_{Z O} \frac{P_{H_{2} O}}{K_{9}}\right)^{1 / 2} \\
& \text { eq. SI-4_10 }
\end{aligned}
$$


Next, we further assume: i) that forward step 2, the entrance channel for carbonaceous species to the adsorbed state at the catalyst surface is the overall limiting step; ii) that the comparatively very fast reaction rates for forward steps 3 to 8 are of first order with respect to the respective reacting species. It follows that fractional coverages by other carbonaceous species than ZOHCH3 remain always small fractions of $\theta_{\text {ZонСН3 }}$ which can be considered as a bundled coverage by carbon in the completion for available surface sites. Denoting $k_{i}$ the rate constant for step $i$, and since the rates of consecutive reverse steps 3, 4 and 6 are considered negligible before the corresponding forward rates, we obtain from simple material balances:

$$
\begin{array}{ll}
\theta_{Z O H C H 2}=\frac{k_{2}}{k_{4}} \theta_{Z O H C H 3} & \text { eq. SI-4_11 } \\
\theta_{Z O H C H 2 O}=\frac{k_{2} \theta_{Z O} \theta_{Z O H C H 3}}{\left(k_{5}+k_{6} \theta_{Z O}\right)} & \text { eq. SI-4_12 } \\
\theta_{Z H C O O H}=\frac{k_{2} k_{6} \theta_{Z O}{ }^{2} \theta_{Z O H C H 3}}{\left(k_{5}+k_{6} \theta_{Z O}\right)\left(k_{7}+k_{8} \theta_{Z O}\right)} & \text { eq. SI-4_13 }
\end{array}
$$

And therefore the rates of production of the final gaseous products of methane oxidation $\mathrm{CH}_{2} \mathrm{O}, \mathrm{CO}$ and $\mathrm{CO}_{2}$ :

$$
\begin{aligned}
& w_{\mathrm{CH}_{2} \mathrm{O}}=k_{5} \theta_{\mathrm{ZOHCH} 2 \mathrm{O}}=\frac{k_{5} k_{2} \theta_{Z O} \theta_{Z O H C H 3}}{\left(k_{5}+k_{6} \theta_{Z O}\right)} \quad \text { eq. SI-4_14 } \\
& w_{C O}=k_{7} \theta_{Z H C O O H}=\frac{k_{7} k_{2} k_{6} \theta_{Z O}{ }^{2} \theta_{Z O H C H 3}}{\left(k_{5}+k_{6} \theta_{Z O}\right)\left(k_{7}+k_{8} \theta_{Z O}\right)} \quad \text { eq. SI-4_15 } \\
& w_{\mathrm{CO}_{2}}=k_{8} \theta_{Z O} \theta_{Z \mathrm{ZCOOH}}=\frac{k_{2} k_{6} k_{8} \theta_{Z O}{ }^{3} \theta_{Z O H C H}}{\left(k_{5}+k_{6} \theta_{Z O}\right)\left(k_{7}+k_{8} \theta_{Z O}\right)} \quad \text { eq. SI-4_16 }
\end{aligned}
$$

While the total rate of methane oxidation is:

$$
w_{\mathrm{CH}_{4}}=k_{2} \theta_{\mathrm{ZOHCH3} 3} \quad \text { eq. SI-4_17 }
$$


The selectivity towards formation of a given product is determined by the ratio of its formation to the overall rate of reaction. Dividing equations SI-4_14 to SI-4_16 by equation SI4_17 we obtain the adequate fractional selectivities (summing up to 1):

$$
\begin{array}{ll}
S_{C H_{2} O}=\frac{k_{5}}{\left(k_{5}+k_{6} \theta_{Z O}\right)} & \text { eq. SI-4_18 } \\
S_{C O}=\frac{k_{7} k_{6} \theta_{Z O}}{\left(k_{5}+k_{6} \theta_{Z O}\right)\left(k_{7}+k_{8} \theta_{Z O}\right)} & \text { eq. SI-4_19 } \\
S_{\mathrm{CO}_{2}}=\frac{k_{6} k_{8} \theta_{Z O}{ }^{2}}{\left(k_{5}+k_{6} \theta_{Z O}\right)\left(k_{7}+k_{8} \theta_{Z O}\right)} & \text { eq. SI-4_20 }
\end{array}
$$

Equilibrium adsorption constants from gas phase $K_{i, j}$ for components $i=1,2$ and 9, (i.e. $\mathrm{O}_{2}$, $\mathrm{CH}_{4}$ and $\mathrm{H}_{2} \mathrm{O}$ respectively) and may be expressed as functions of standard pressures $P_{i}^{0}$ and standard free enthalpies of adsorption $\Delta G_{i, j}^{0}(T)$, where subscript $j$ accounts for the specificity of a given catalytic surface:

$$
K_{i, j}=\frac{1}{P_{i}^{0}} \exp \left(\frac{-\Delta G_{i, j}^{0}(T)}{R T}\right)
$$

Rate constants $k_{l, j}$, where subscript $l=2,5,6,7,8$ relates to the forward step number, and subscript $j$ to the catalyst as above, can be expressed according to Eyring:

$$
k_{l, j}=\frac{k_{B} T}{h} \exp \left(\frac{-\Delta G_{l, j}^{ \pm}(T)}{R T}\right)
$$

Where $k_{B}$ and $h$ are the Boltzmann and Planck constants respectively, and $\Delta G_{l, j}^{ \pm}(T)$ is the free energy of activation of $\operatorname{step} l$ for catalyst $j$.

In order to test the ability of this kinetic model to predict the patterns of activity and selectivities obtained from our methane oxidation experiments catalyzed by the set of 12 solid phosphates described in the present report, the next step was to introduce quantitative dependencies of free energies $\Delta G_{i, j}^{0}(T)$ and $\Delta G_{l, j}^{ \pm}(T)$ with respect to numerical descriptors of 
the catalysts. For the latter, the natural choice was bond energies $E_{M O, j}$ and $E_{P O a, j}$ computed by DFT, and experimental total acidities $H_{j}^{0}$ as presented and tabulated in the main text.

Decomposing free energies of adsorption and activation into their entropic $\Delta S_{i, j}^{0} \Delta S_{l, j}^{ \pm}$, and enthalpic $\Delta H_{i, j}^{0}, \Delta H_{l, j}^{ \pm}$components assumed temperature independent, we postulate linear continuous relationships between enthalpies and bond energies:

$$
\begin{array}{ll}
\Delta H_{i}^{0}=E_{i}^{0}-\beta_{i} E_{X O} & \text { eq. SI-4_23 } \\
\Delta H_{l}^{ \pm}=E_{l}^{ \pm}-\alpha_{l} E_{X O} & \text { eq. SI-4_24 }
\end{array}
$$

Where $E_{X O}$ is the bond energy, and in our case $\mathrm{X}=\mathrm{M}$ or $\mathrm{X}=\mathrm{P}$, since we consider $\mathrm{M}$ and $\mathrm{P}$ cations at the surface as contributing potential sites. Energies $E_{i}^{0}, E_{l}^{ \pm}$and adimensional coefficients $\beta_{i}, \alpha_{l}$ are parameters to be determined in the fitting protocol described below. Equations SI-4_23 are usually referred to as compensation relationships, and equations SI-4_24 as Brönsted-Evans-Polanyi (BEP) relationships.

The selectivity in formaldehyde is, according to this model, crucially determined by the competition between forward steps 5 and 6. Forward step 5 is the desorption of $\mathrm{CH}_{2} \mathrm{O}$ from the $\mathrm{Z}$ center of a $\mathrm{ZOH}$ site, as pictured below by Fig. SI-5-3, therefore breaking a Z-C bond. $\mathrm{CH}_{2} \mathrm{O}$ is a very polar molecule, and in the adsorbed state its carbonyl group will undergo an electrophilic attack of the terminal oxygen by any vicinal acidic proton (e.g. $\left.\mathrm{H}^{\delta+} \ldots . \mathrm{O}^{\delta-}=\mathrm{P}\right)$ and a nucleophilic attack of the carbon by the conjugated base (e.g. $\left.\mathrm{O}^{-}=\mathrm{P}\right)$, thus weakening the Z$\mathrm{CH}_{2} \mathrm{O}$ bond. Therefore, the more acidic the catalyst, the easier the desorption of formaldehyde and this explains why the total acidity $\mathrm{H}^{0}$ can be taken as a proximal descriptor of $\mathrm{Z}-\mathrm{CH}_{2} \mathrm{O}$ bonds weaknesses. By analogy with BEP relationships like equations SI-4_24, we introduce for forward step 5:

$$
\Delta H_{5}^{ \pm}=E_{5}^{ \pm}-\alpha_{5} H^{0}
$$

Where $\alpha_{5}$ is positive and has the appropriate dimension $\mathrm{kJ} \cdot \mathrm{m}^{2} \cdot \mu \mathrm{mol}^{-2}$. 
Combining equations S-4_ 7 to S-4_25, we note that the oxidation rate $w_{\mathrm{CH}_{4}}$ and selectivities in the three gaseous carbonaceous products are completely determined by parameters $\Delta S_{i, j}^{0}$, $\Delta S_{l, j}^{ \pm}, E_{i}^{0}, E_{l}^{ \pm}, \beta_{i}, \alpha_{l}$, for $i=1,2$ and $l=2,5,6,7,8$ as long as catalysts can be described by $E_{X O}$, for $X=P, M$, and $H^{0}$. We further assume:

$$
\begin{array}{ll}
\Delta S_{i, j}^{0}=\Delta S_{i}^{0} & \text { eq. SI-4_26 } \\
\Delta S_{l, j}^{ \pm}=\Delta S^{ \pm} & \text {eq. SI-4_27 }
\end{array}
$$

and in order to express the expected increasing affinity of $\mathrm{O}_{2}$ for $\mathrm{Z}$ sites and decreased affinity of $\mathrm{CH}_{4}$ for $\mathrm{ZO}$ sites as $E_{X O}$ increases, we set $\beta_{1}=-1$ and $\beta_{2}=1$.

Therefore 15 parameters remain to be determined through a fitting procedure: $\Delta S_{1}^{0}, \Delta S_{2}^{0}$, $E_{1}^{0}, E_{2}^{0}, \Delta S^{ \pm}, E_{l}^{ \pm}$and $\alpha_{l}$ for $l=2,5,6,7,8$.

Since we consider $\mathrm{X}=\mathrm{M}$ and $\mathrm{X}=\mathrm{P}$ separately, we sum up predicted rates for both kinds of sites and add moreover a catalyst independent thermal rate:

$$
w_{C_{4}}=W_{C H_{4}}^{M}+W_{C H_{4}}^{P}+W_{C H_{4}}^{T h}=k_{2}^{M} \theta_{M O H C H 3}+k_{2}^{P} \theta_{P O H C H 3}+W_{C H_{4}}^{T h} \quad \text { eq. SI-4_28 }
$$

where the superscripts $M$ and $P$ refer to the choice of descriptors $E_{M O}$ or $E_{P O}$ in equations SI4_23 and SI-4_24. The thermal rate, a $16^{\text {th }}$ free parameter, sets a lower limit to the rate in absence of catalyst, and imparts more physical realism by allowing a smooth convergence of the predicted residual rate for vanishing or very high values of the descriptors $E_{M O}$ or $E_{P O}$. Accordingly, predicted selectivities become:

$$
S_{A}=\frac{w_{C H_{4}}^{M}}{W_{C H_{4}}} S_{A}^{M}+\frac{w_{C H_{4}}^{P}}{W_{C H_{4}}} S_{A}^{P}
$$

For $\mathrm{A}=\mathrm{CH}_{2} \mathrm{O}, \mathrm{CO}, \mathrm{CO}_{2}$

We have adopted a two steps fitting procedure. In the first step an objective function is defined as the root mean square deviation (rmsd) of predicted from experimental Neperian logarithms 
of the rates of oxidation $w_{\mathrm{CH}_{4}}$. This first function is minimized with respect to the eight first parameters $\Delta S_{1}^{0}, \Delta S_{2}^{0}, E_{1}^{0}, E_{2}^{0}, \Delta S^{ \pm}, E_{l}^{ \pm}$and $\alpha_{l}$ for $l=2$, and $W_{C H_{4}}^{T h}$, using 8 experimental rates of oxidation corresponding to $\mathrm{Mn}_{2} \mathrm{P}_{2} \mathrm{O}_{7}$ and the 7 orthophosphates catalysts (see Table SI-3-3) and constraining $E_{2}^{ \pm}$to remain positive in the range of $E_{X O}$ values spanned by these catalysts. The four remaining pyrophosphates are excluded from this first training set since they appear obviously out of the regular volcano trend observed, when plotting experimental $w_{C_{4}}$ versus $E_{X O}$. We obtained for this step a relative rmsd of $6.3 \%$.

In the second step, a second objective function is built as the root mean square deviation of predicted from experimental selectivities, and minimized with respect to the 8 remaining parameters $E_{l}^{ \pm}$and $\alpha_{l}$ for $l=5,6,7,8$ using all 24 independent experimental selectivities available (see Table S-3-3), constraining $E_{l}^{ \pm}$for $l=5,6,7,8$ to remain positive in the range of $E_{X O}$ values spanned by these catalysts. We obtained for this step a relative rmsd of $1.8 \%$.

Rate constants given by equation SI-4_17 are converted from theoretical units of molecule.site ${ }^{-1} \cdot \mathrm{s}^{-1}$ into experimental units of $10^{9} \mathrm{~mol} \cdot \mathrm{m}^{-2} \cdot \mathrm{s}^{-1}$ using an average site density of $1,25.10^{19} \mathrm{~m}^{-2}$ estimated according to the volumic density of $\mathrm{P}$ atoms reported in Table 1 of main text.

Best fitted parameters are listed in the following Table SI-4-1: 
Table SI-4-1: Best fitted parameters of the kinetic model. Other inputs are operating conditions, average site density for phosphate catalysts $1.2510^{19}$ site.m $^{-2}$; $\mathrm{T}=873 \mathrm{~K},\left[\mathrm{CH}_{4}\right]=$ $10^{-2}$ mol..$^{-1} ;\left[\mathrm{O}_{2}\right]=5.10^{-3}$ mol. $1^{-1}$ and Boltzmann and Planck fundamental constants $k_{B}$ and $h$

$\begin{array}{cll}\Delta S_{1}^{0} & 73 \cdot 5 & \mathrm{~J} \cdot \mathrm{mol}^{-1} \cdot \mathrm{K}^{-1} \\ \Delta S_{2}^{0} & 201.04 & \mathrm{~J} \cdot \mathrm{mol}^{-1} \cdot \mathrm{K}^{-1} \\ \Delta S^{ \pm} & -56.78 & \mathrm{~J} \cdot \mathrm{mol}^{-1} \cdot \mathrm{K}^{-1} \\ E_{1}^{0} & 0.00 & \mathrm{~kJ} \cdot \mathrm{mol}^{-1} \\ E_{2}^{0} & 29.96 & \mathrm{~kJ} \cdot \mathrm{mol}^{-1} \\ E_{2}^{ \pm} & 179.12 & \mathrm{~kJ} \cdot \mathrm{mol}^{-1} \\ \alpha_{2} & -0.16 & - \\ E_{5}^{ \pm} & 4.29 & \mathrm{~kJ} \cdot \mathrm{mol}^{-1} \\ \alpha_{5} & 0.32 & \mathrm{~kJ} \cdot \mathrm{m}^{2} \cdot \mu \mathrm{mol}^{-2} \\ E_{6}^{ \pm} & 15.62 & \mathrm{~kJ} \cdot \mathrm{mol}^{-1} \\ \alpha_{6} & -0.04 & - \\ E_{7}^{ \pm} & 52.21 & \mathrm{~kJ} \cdot \mathrm{mol}^{-1} \\ \alpha_{7} & -0.29 & - \\ E_{8}^{ \pm} & 28.98 & \mathrm{~kJ} \cdot \mathrm{mol}^{-1} \\ \alpha_{8} & -0.36 & - \\ W_{C H_{4}}^{T h} & 2.00 & 10^{9} \cdot \mathrm{mol}^{-\mathrm{m}^{-2}} \cdot \mathrm{s}^{-1}\end{array}$




\section{SI-5 Molecular models of key surface intermediates along the catalytic pathways}

The atomistic models presented in this section were built with the MAPS platform from SCIENOMICS (http://www.scienomics.com) provided to HT and LRS according to their participation to the Scienomics Group of Scientific Excellence (SGSE). The configurations shown were not optimized.

Figure SI-5-1: atomistic model of $\mathrm{ZOHCH} 3$ surface species produced from step 2, in the case of a tri-periodic 2 layers slab of $\mathrm{SnP}_{2} \mathrm{O}_{7}$ exposing two (200) surfaces (the $\mathrm{z}$ axis is parallel to the original 200 vector of the $\mathrm{SnP}_{2} \mathrm{O}_{7} \mathrm{~Pa}-3$ cubic unit-cell). The "bottom" surface is fully covered by $\equiv \mathrm{P}-\mathrm{OH}$ and $\equiv \mathrm{M}-\mathrm{OH}$ hydroxyl groups. The "top" surface shows arrays of HO-Sn$\mathrm{CH}_{3}$ surface species (noted $\equiv \mathrm{M}\left(\mathrm{CH}_{3}\right)-\mathrm{OH}$ ), $\mathrm{PO}$ species (i.e. $\mathrm{ZO}$ with $\mathrm{Z}=\mathrm{P}$, noted $\equiv \mathrm{P}=\mathrm{O}$ ) and coordinatively unsaturated surface $S n$ cations (i.e. $Z$ with $Z=S n$, noted $\equiv M$ ). Sn centers in blue, $\mathrm{P}$ in magenta, $\mathrm{O}$ in red, Carbon in grey, Hydrogen in white. Perspective view.

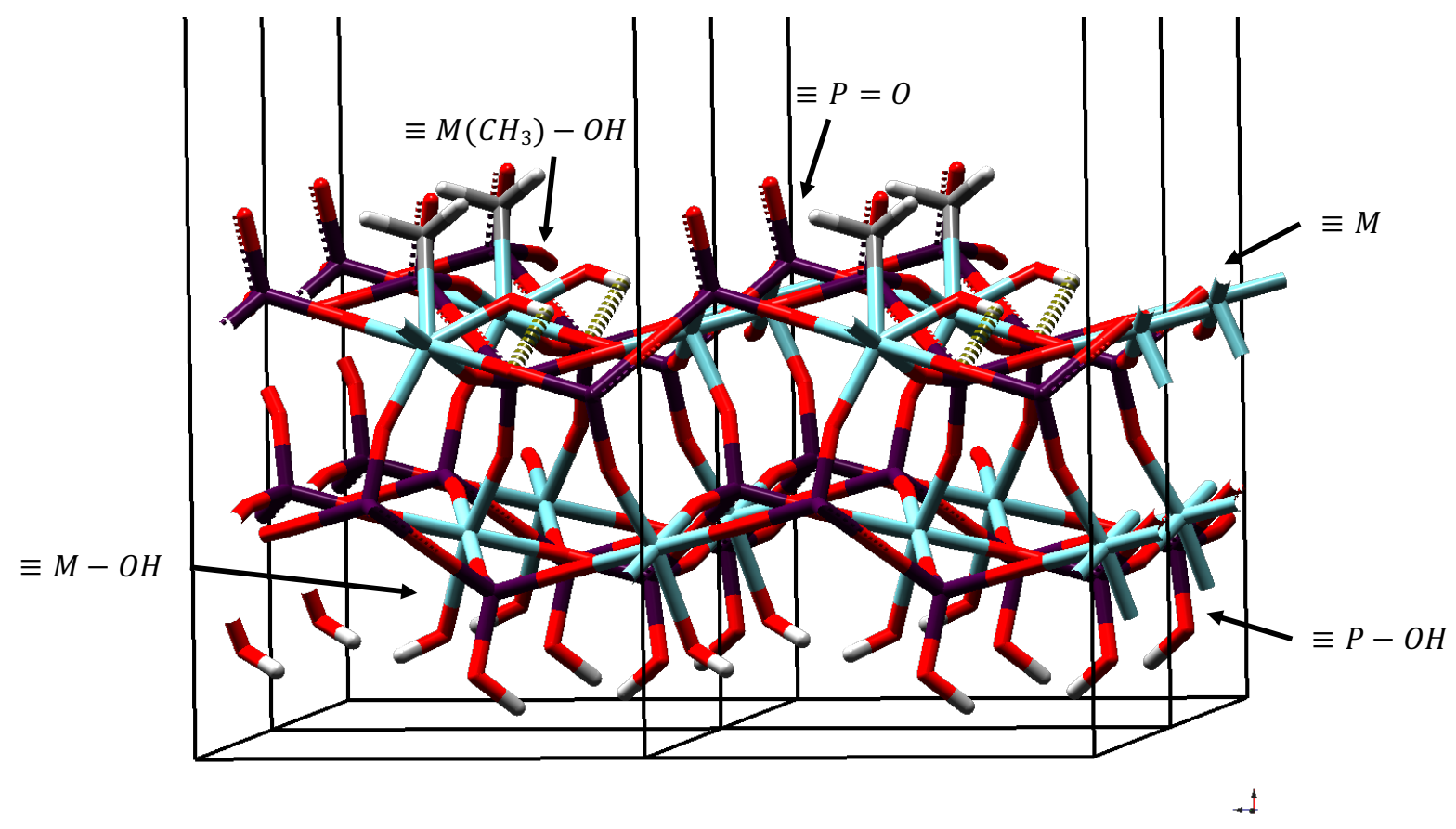


Figure SI-5-2: atomistic model of $\mathrm{ZOHCH} 2$ surface species produced from step 3, in the case of a tri-periodic 2 layers slab of $\mathrm{SnP}_{2} \mathrm{O}_{7}$ exposing two (200) surfaces (the $\mathrm{z}$ axis is parallel to the original 200 vector of the $\mathrm{SnP}_{2} \mathrm{O}_{7} \mathrm{~Pa}-3$ cubic unit-cell). The "bottom" surface is fully covered by $\equiv \mathrm{P}-\mathrm{OH}$ and $\equiv \mathrm{M}-\mathrm{OH}$ hydroxyl groups. The "top" surface shows arrays of HO-Sn$\mathrm{CH}_{2}$ surface species (noted $\equiv \mathrm{M}\left(\mathrm{CH}_{2}\right)-\mathrm{OH}$ ), $\mathrm{P}-\mathrm{OH}$ species (i.e. $\mathrm{ZOH}$ with $\mathrm{Z}=\mathrm{P}$, noted $\equiv \mathrm{P}-\mathrm{OH}$ ) and $\mathrm{Sn}-\mathrm{OH}$ species (i.e. $\mathrm{ZOH}$ with $\mathrm{Z}=\mathrm{Sn}$, noted $\equiv \mathrm{M}-\mathrm{OH}$ ). Sn centers in blue, $\mathrm{P}$ in magenta, $\mathrm{O}$ in red, Carbon in grey, Hydrogen in white. Perspective view.

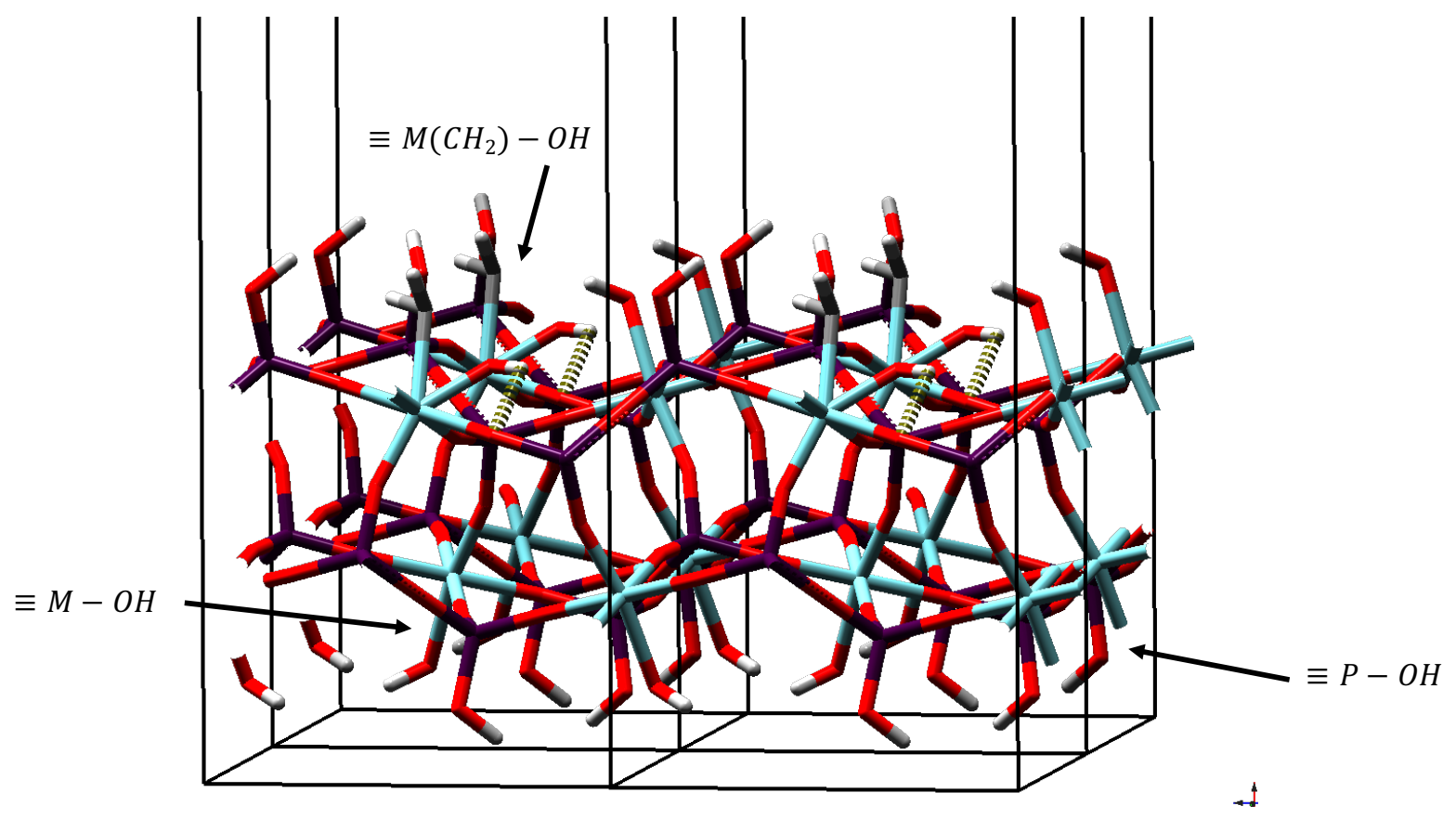


Figure SI-5-3: atomistic model of $\mathrm{ZOHCH} 2 \mathrm{O}$ surface species produced from step 6 in the case of a tri-periodic 2 layers slab of $\mathrm{SnP}_{2} \mathrm{O}_{7}$ exposing two (200) surfaces (the $\mathrm{z}$ axis is parallel to the original 200 vector of the $\mathrm{SnP}_{2} \mathrm{O}_{7} \mathrm{~Pa}-3$ cubic unit-cell). The "bottom" surface is fully covered by $\equiv \mathrm{P}-\mathrm{OH}$ and $\equiv \mathrm{M}-\mathrm{OH}$ hydroxyl groups. The "top" surface shows arrays of HO-Sn$\mathrm{CH}_{2} \mathrm{O}$ surface species (noted $\equiv \mathrm{M}\left(\mathrm{O}=\mathrm{CH}_{2}\right)-\mathrm{OH}$ ), $\mathrm{POH}$ species (i.e. $\mathrm{ZOH}$ with $\mathrm{Z}=\mathrm{P}$, noted $\equiv \mathrm{P}$ $\mathrm{OH}$ ) and coordinatively unsaturated surface $S n$ cations (i.e. $Z$ with $Z=S n$, noted $\equiv M$ ). Sn centers in blue, $\mathrm{P}$ in magenta, $\mathrm{O}$ in red, Carbon in grey, Hydrogen in white. Perspective view.

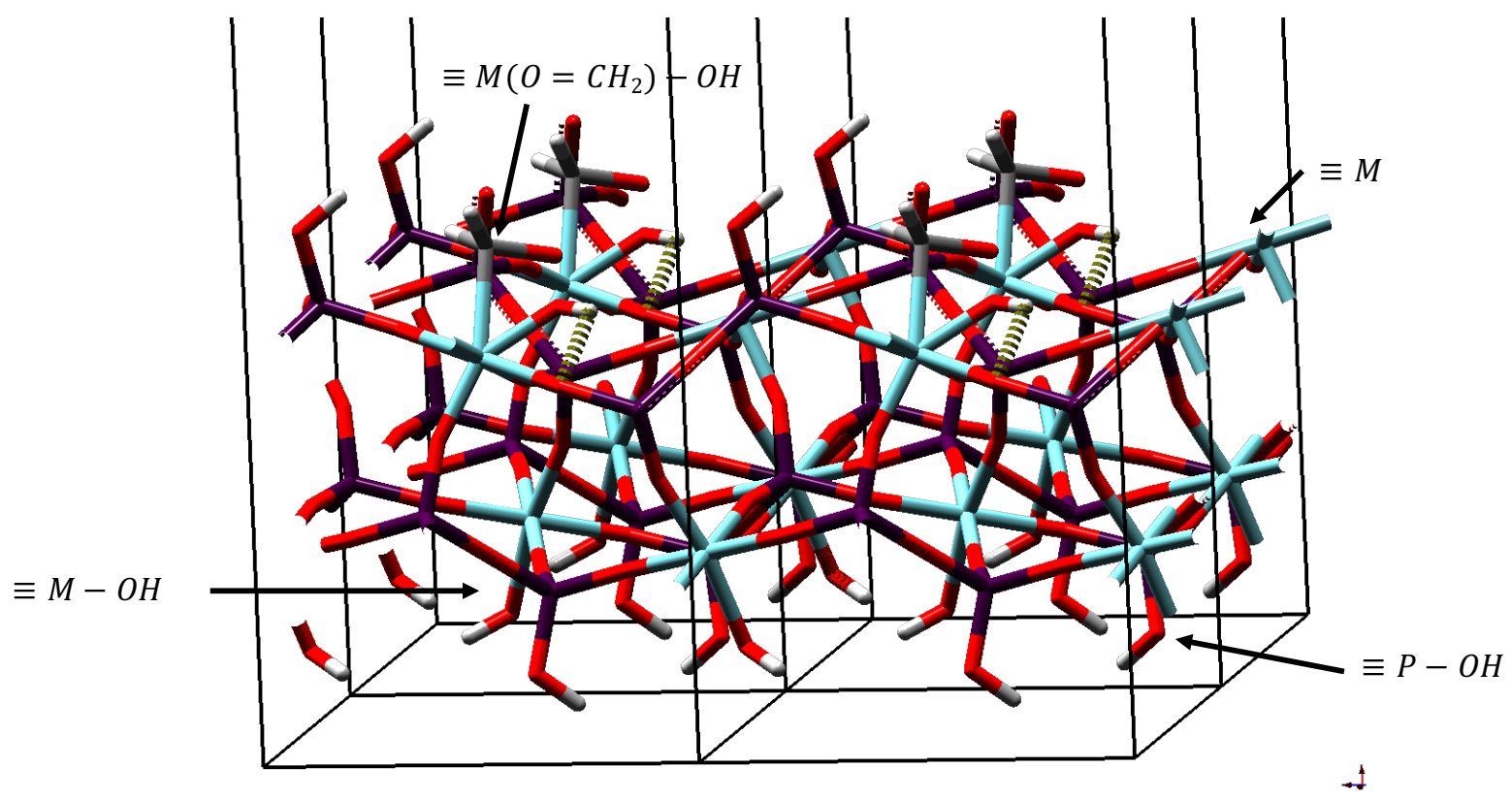


Figure SI-5-4: atomistic model of $\mathrm{ZHCOOH}$ surface species produced from step 6 in the case of a tri-periodic 2 layers slab of $\mathrm{SnP}_{2} \mathrm{O}_{7}$ exposing two (200) surfaces (the $\mathrm{z}$ axis is parallel to the original 200 vector of the $\mathrm{SnP}_{2} \mathrm{O}_{7} \mathrm{~Pa}-3$ cubic unit-cell). The "bottom" surface is fully covered by $\equiv \mathrm{P}-\mathrm{OH}$ and $\equiv \mathrm{M}-\mathrm{OH}$ hydroxyl groups. The "top" surface shows arrays of Sn$\mathrm{HCOOH}$ surface species (noted $\equiv \mathrm{M}(\mathrm{HCOOH}), \mathrm{POH}$ species (i.e. $\mathrm{ZOH}$ with $\mathrm{Z}=\mathrm{P}$, noted $\equiv \mathrm{P}-\mathrm{OH}$ ) and coordinatively unsaturated surface $S n$ cations (i.e. $Z$ with $Z=S n$, noted $\equiv M$ ). Sn centers in blue, $\mathrm{P}$ in magenta, $\mathrm{O}$ in red, Carbon in grey, Hydrogen in white. Perspective view.

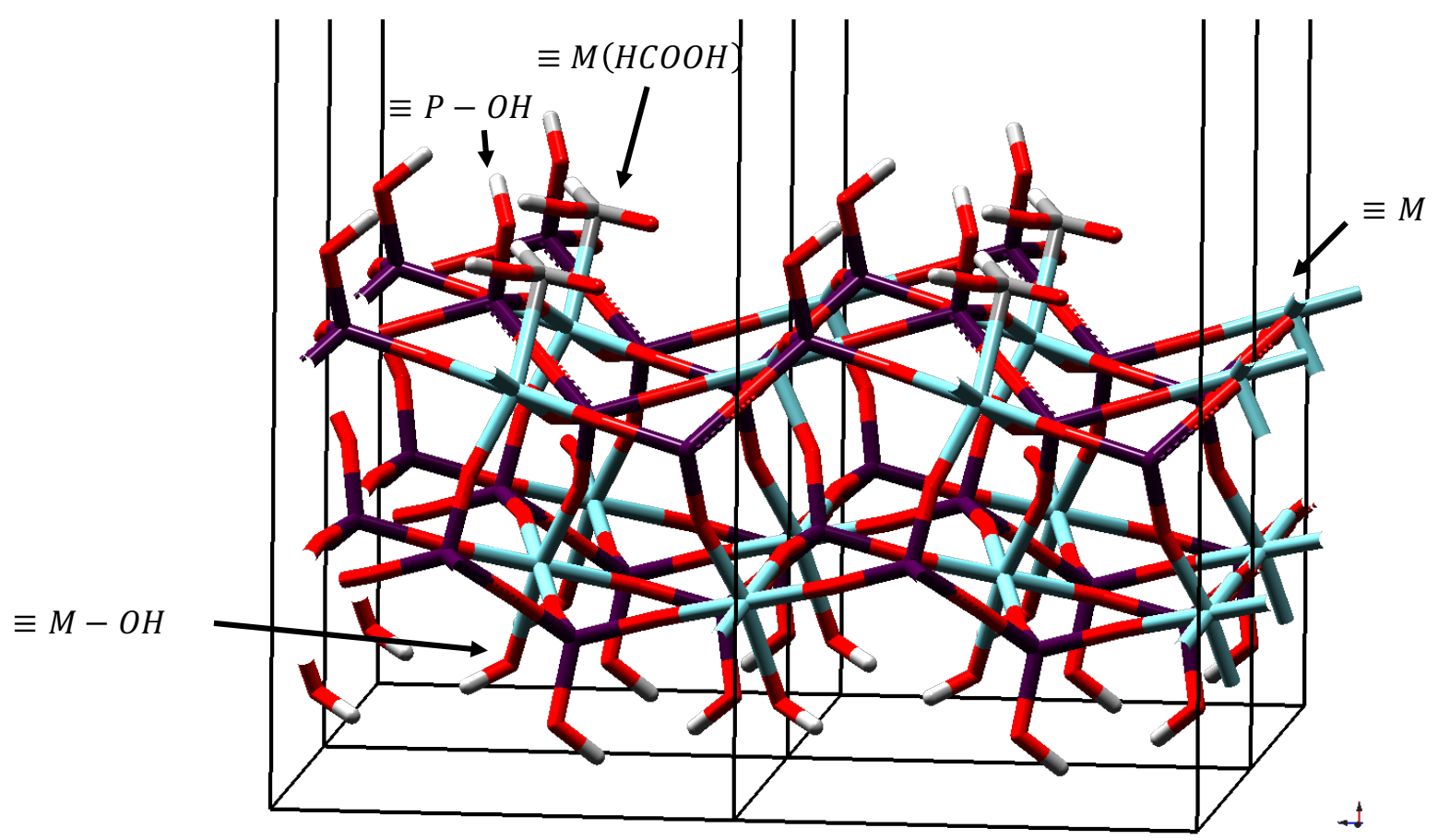

